\title{
An Online Gratitude Intervention for Young Adults with Advanced Cancer
}

\author{
Katharine Emily Adelstein \\ Charlottesville, Virginia
}

BA, Hamilton College, 2003

MSN, Yale University, 2008

A Dissertation presented to the Graduate Faculty of the University of Virginia in Candidacy for the Degree of

Doctor of Philosophy

Department of Nursing

University of Virginia

August, 2016

Jessica Keim-Malpass, PhD, RN

Chair of Committee

Susan Bauer-Wu PhD, RN, FAAN

Lee Ritterband, $\mathrm{PhD}$

Jeanne Erickson, PhD, RN, AOCN

Julie Haizlip, MD, MA 


\begin{abstract}
Background: Confrontation of mortality in young adults (YAs) with advanced cancer often leads to significant feelings of grief over the loss of opportunity to achieve lifetime goals and milestones as well as other cancer-related losses. Literature on the palliative care needs of YAs with advanced cancer suggests that an intervention targeting well-being may provide significant benefit to this patient population. Promotion of positive emotions may be helpful in enhancing well-being in YAs with advanced cancer by helping them focus on the pleasures that life still has to offer. Gratitude, one such positive emotion, is characterized by the affirmation of goodness in life. Gratitude interventions have been shown to improve well-being in patients experiencing traumatic life events and to be negatively correlated with anxiety and depression. It can be cultivated in a short time frame and lends itself well to a self-directed journaling intervention. Because of their known comfort with and usage of the Internet to seek information and build community, an Internet-delivered gratitude intervention may best meet the needs of YAs with advanced cancer.
\end{abstract}

Objective: The purpose of this study is to determine the feasibility and acceptability of an online gratitude intervention for YAs with advanced cancer and to evaluate its preliminary effects on gratitude, mindful observation, positive and negative affect and emotional experience, and psychological well-being, when compared with a waitlist-control group.

Design and Methods: This study was a randomized, prospective, waitlist-controlled feasibility study informed by the Broaden and Build Theory of Positive Emotion. Participants were recruited through social networking sites (Facebook and Twitter) and other online forums. Participants gave consent and completed pre-intervention measures online. Those in the experimental group kept a daily, online gratitude journal for 21 days. Automated daily emails 
were sent to remind participants to journal. All participants completed follow-up measures after 21 days and again 30 days later.

Results: Overall 26 potential participants expressed interest in the study, and 19 participants were enrolled using exclusively online recruitment methods. Geographic diversity was excellent, but the sample lacked racial and gender diversity. Attrition was 15.8\%. Average number of journal entries was 14 , with an average word count of 186 . Post-intervention, the experimental group saw significant improvement in gratitude $(p=0.043)$, mindful observation $(p=0.012)$, negative emotion $(p=0.042)$, negative affect $(p=0.007)$, self-acceptance $(p=0.011)$, and personal growth (0.035). Large overall effect sizes were seen for gratitude, mindful observation, negative emotion, and negative affect. The control group saw significant improvement in positive relations with other $(\mathrm{p}=0.041)$. At the 30-day follow-up overall effect sizes remained large for gratitude, mindful observation, negative emotion, and negative affect. A large effect size was also seen at 30-days for personal growth.

Conclusion: The results of the MyGratefulSelf study provide support for the ongoing exploration of the Internet as a way to reach young adults with cancer and engage them in them in clinical and behavioral research studies. The Internet may be and effective resource for engagement of young adults if used as a tool for social networking and community engagement rather than a virtual bulletin board. Additionally, the MyGratefulSelf study adds to the current literature of the efficacy of gratitude interventions by demonstrating a significant impact on wellbeing in a highly distressed clinical population, however the results are limited in generalizability dues to the small sample size. Future, fully powered studies should expand on the MyGratefulSelf system to promote better engagement and enhance its positive effects. 


\section{TABLE OF CONTENTS}

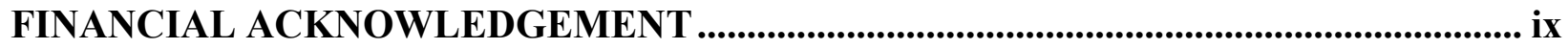

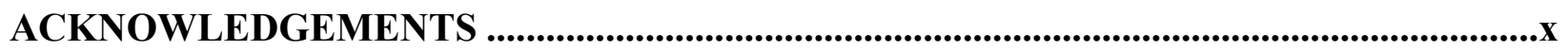

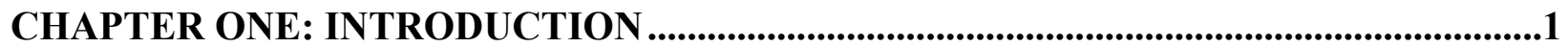

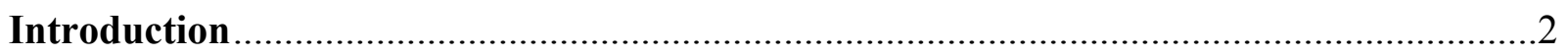

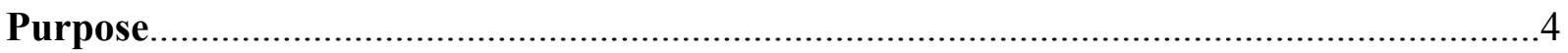

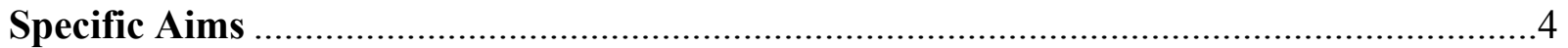

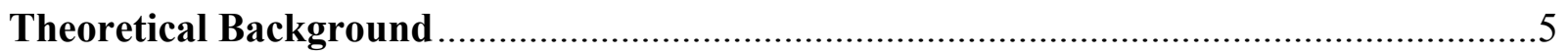

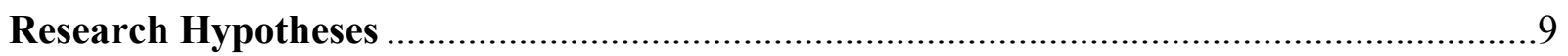

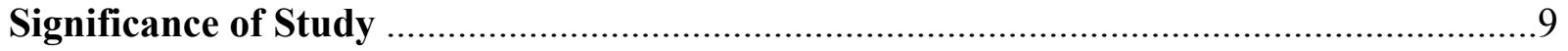

CHAPTER TWO: REVIEW OF THE LITERATURE.........................................................11

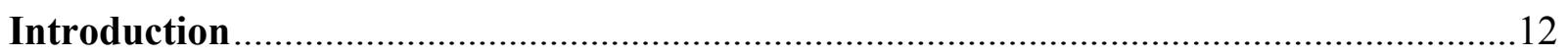

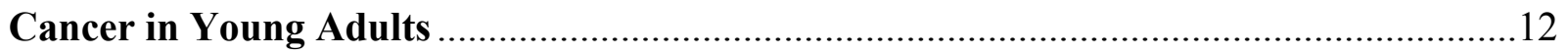

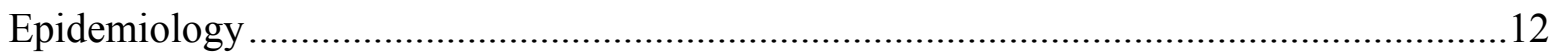

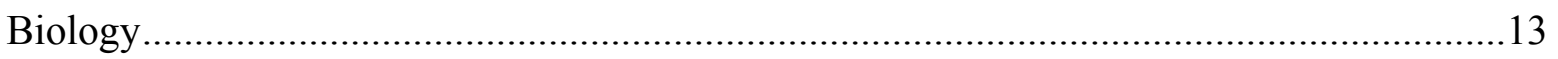

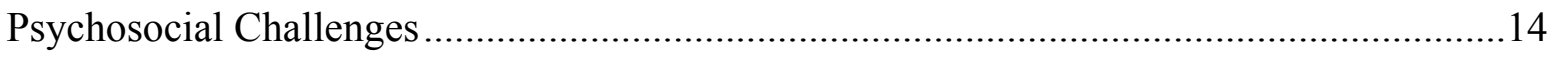

Unique Challenges with Advanced Cancer .................................................................. 16

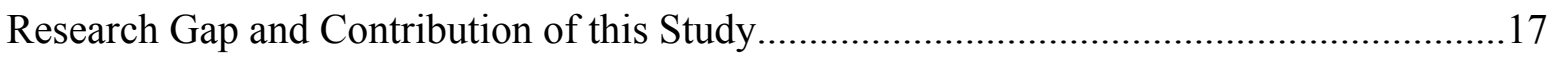

Gratitude as a Psychological Intervention to Promote Well-being .................................. 18

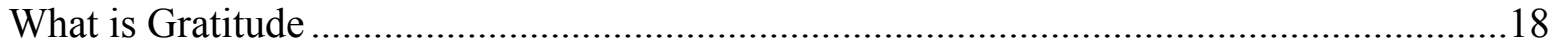

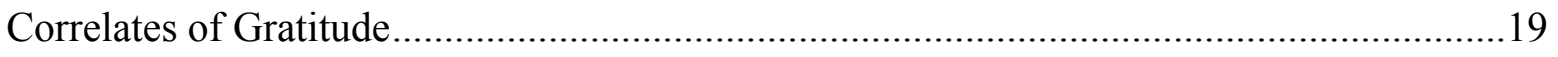

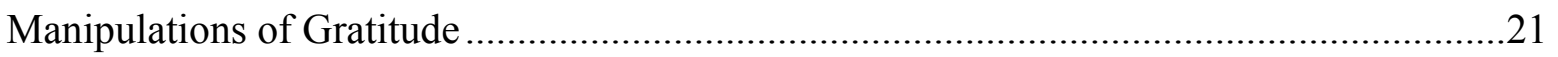

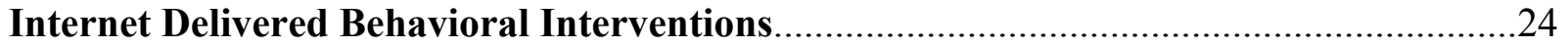

Current Internet Usage by Young Adults with Cancer .................................................24

Using the Internet to Recruit Young Adults for Research Studies ...................................25

Successful Internet-Based Behavioral Interventions ................................................25

Framework for Designing Internet-Based Behavioral Interventions................................26

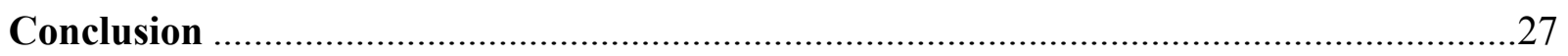

CHAPTER THREE: METHODS .............................................................................................29

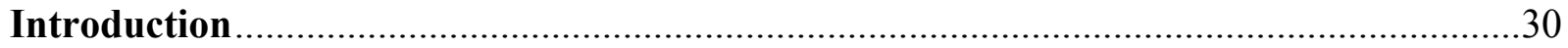




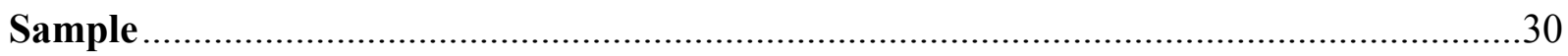

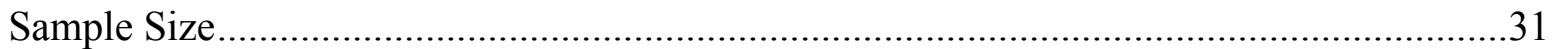

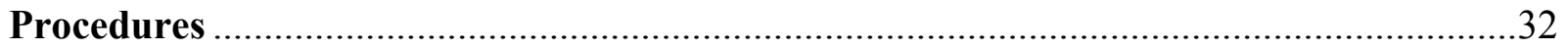

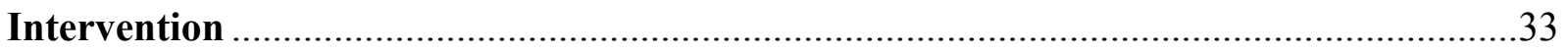

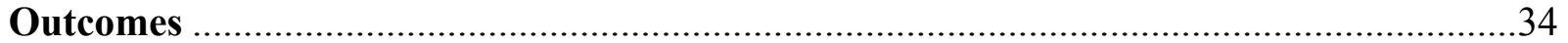

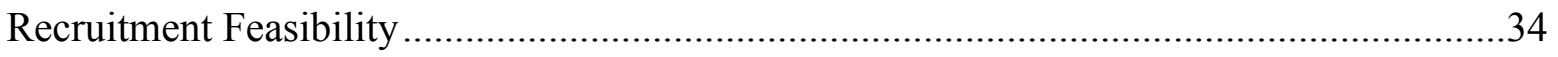

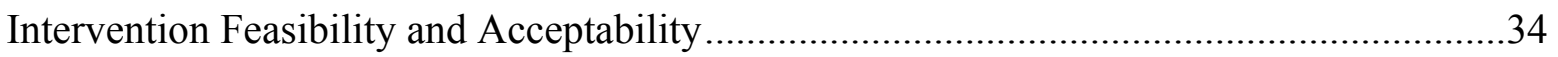

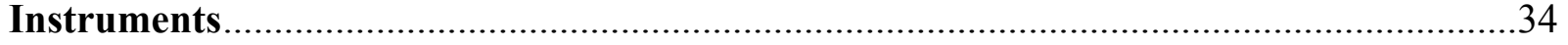

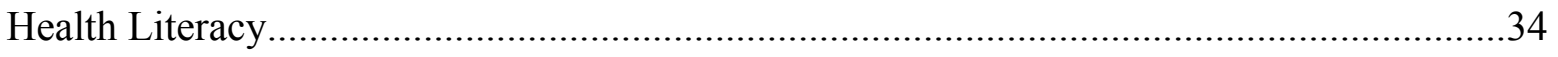

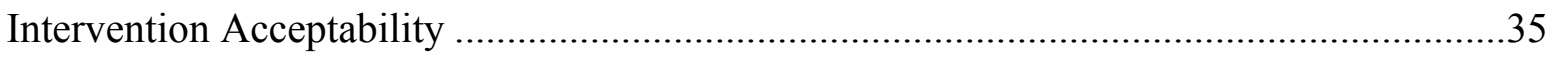

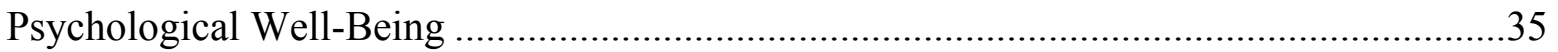

Emotional Experience .....................................................................................................

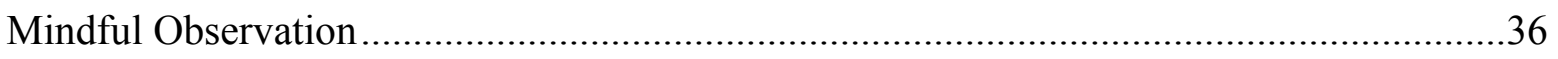

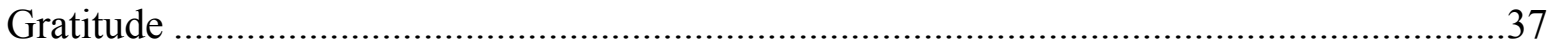

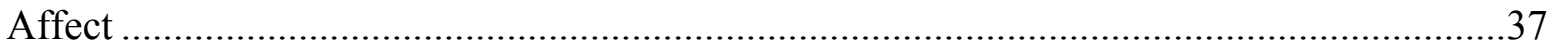

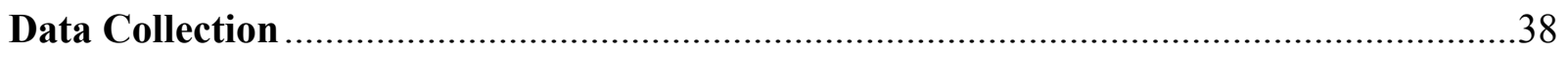

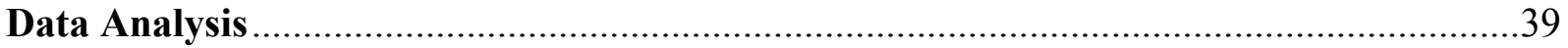

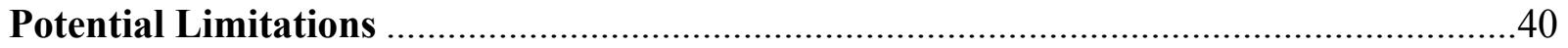

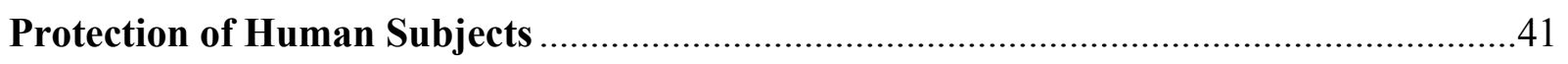

Privacy and Confidentiality ........................................................................................

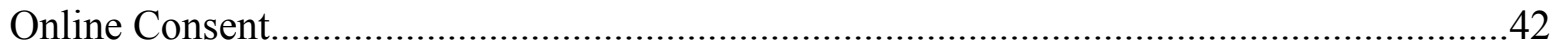

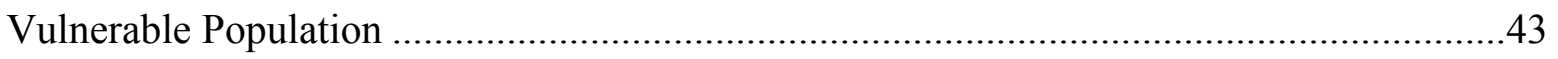

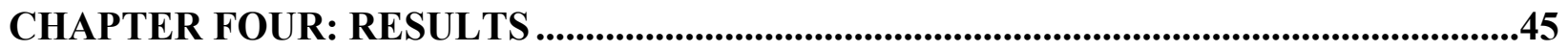

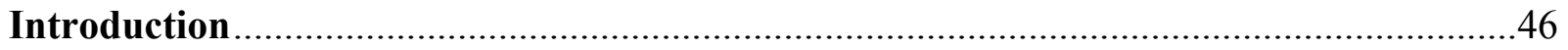

Intervention Development: MyGratefulSelf System Description.......................................46

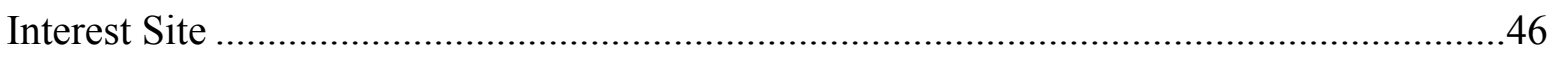

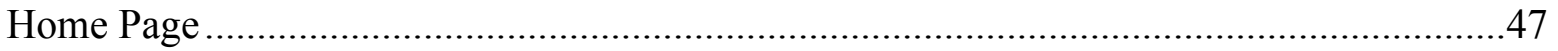

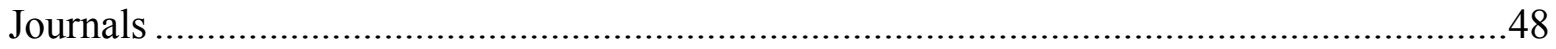

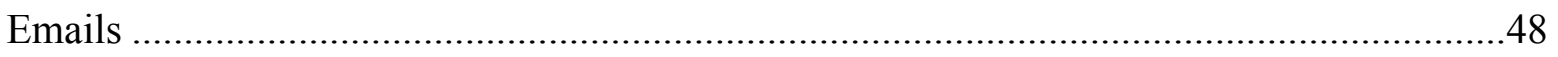

Participant Recruitment ............................................................................................ 49

Recruitment Strategy: Changes Over Time ………………………………………...........49 


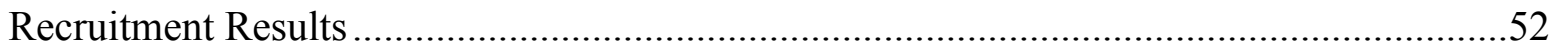

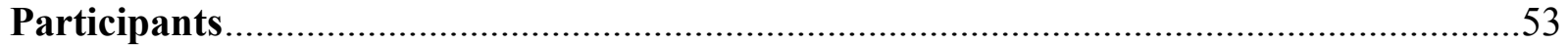

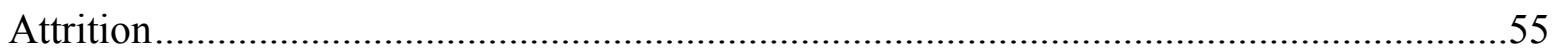

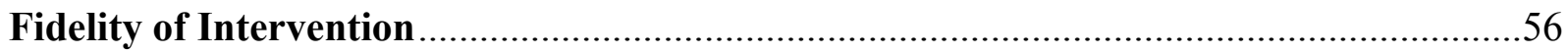

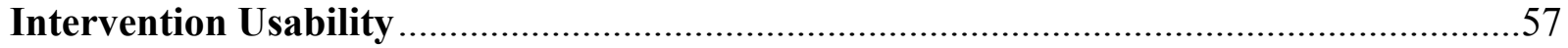

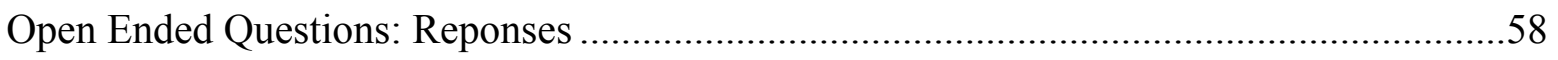

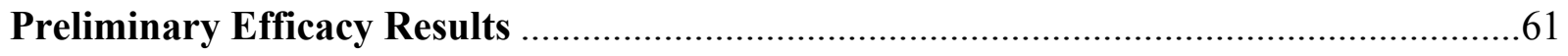

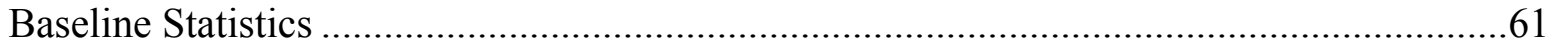

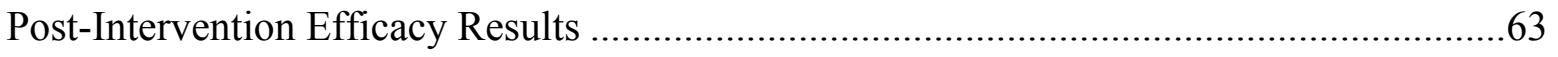

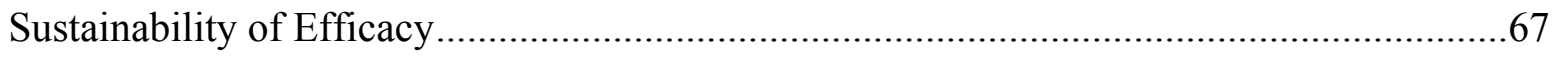

CHAPTER FIVE: DISCUSSION

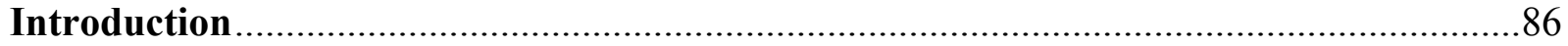

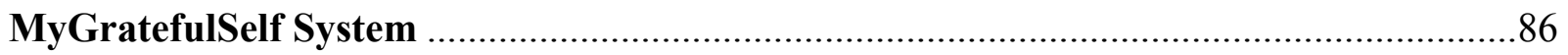

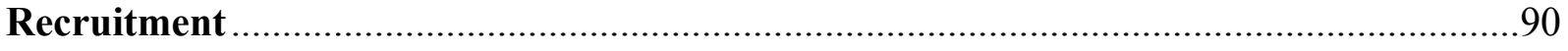

Sample

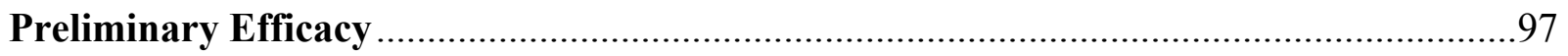

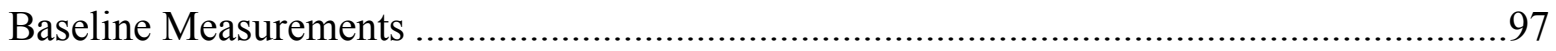

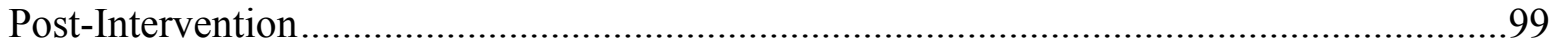

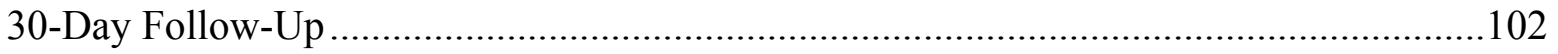

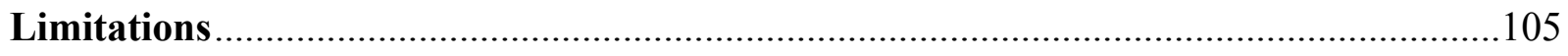

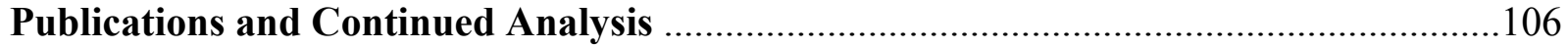

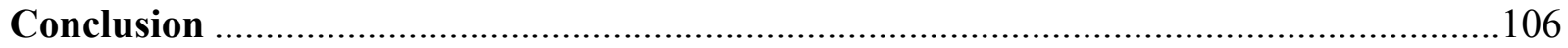

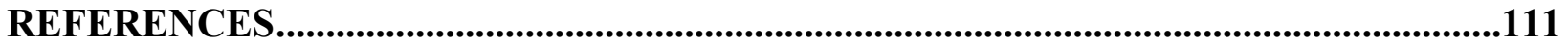

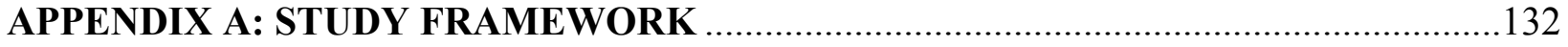

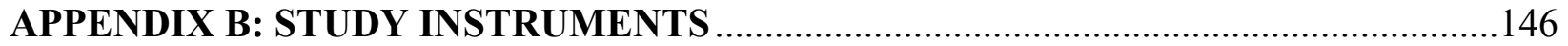

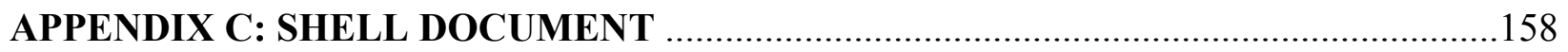

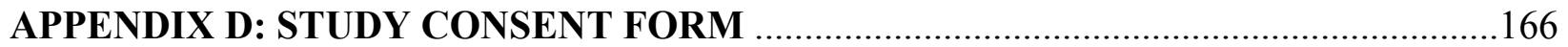

APPENDIX E: INTEREST SITE WEBLOW AND SHELL DOCUMENT .....................169

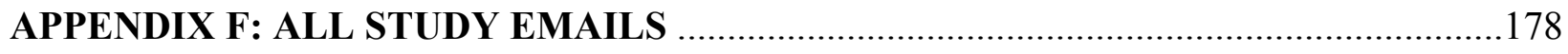

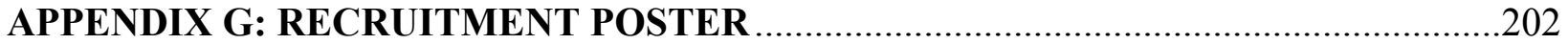




\section{TABLES AND FIGURES}

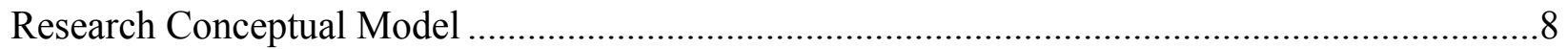

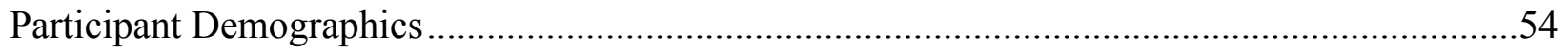

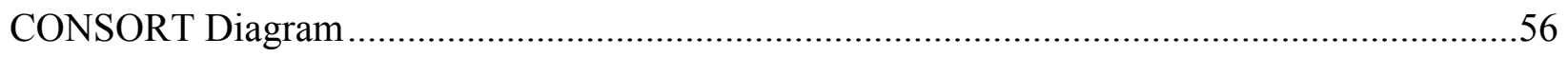

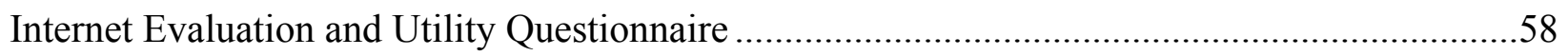

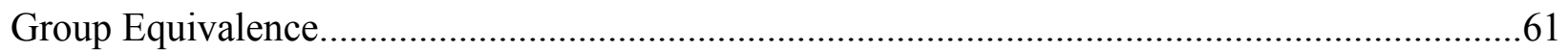

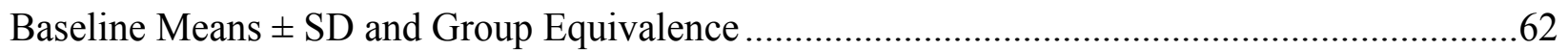

Experimental Group Outcome Measure Pre- v. Post-Intervention .............................................64

Control Group Outcome Measures Pre- v. Post-Intervention..................................................64

Experimental and Control Group Outcome Pre- v. Post-Intervention........................................65

All Post-Intervention Outcomes with Effect Sizes by Treatment Condition ...............................66

Experimental and Control Group Outcomes Pre- v. 30-day Follow-up ....................................69

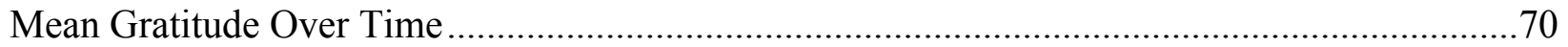

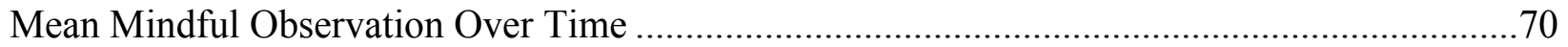

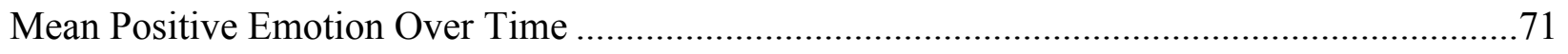

Mean Negative Emotion Over Time ............................................................................... 71

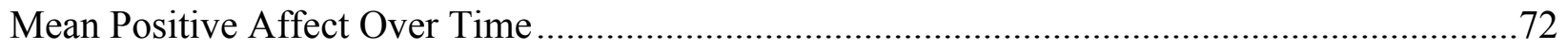

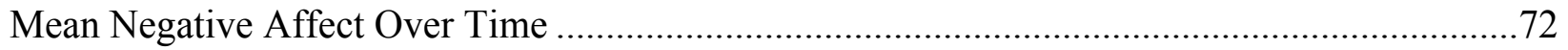

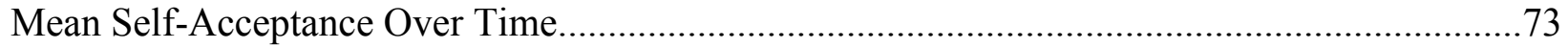

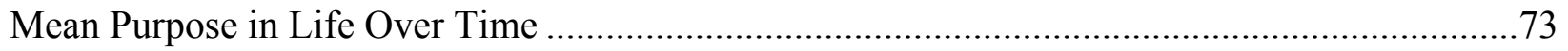

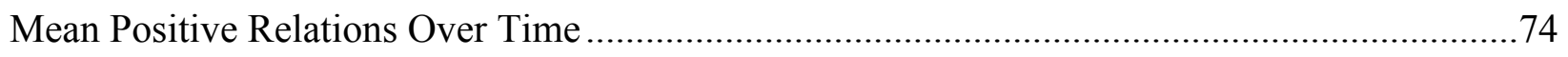

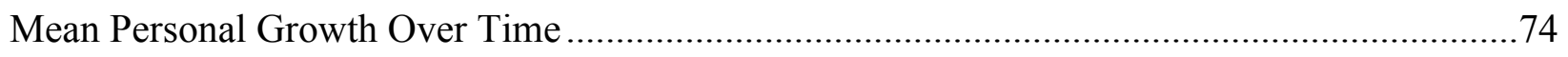

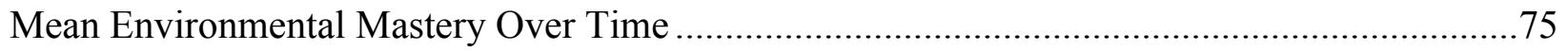

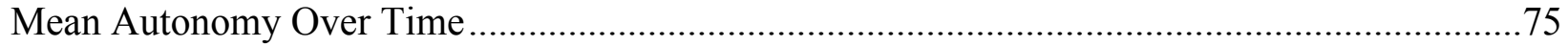

All 30-Day Follow-Up Outcome Measure Effect Sizes by Treatment Condition.......................76

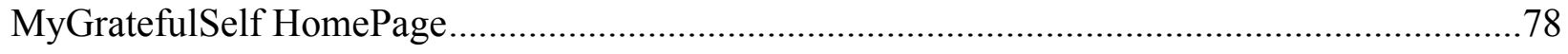

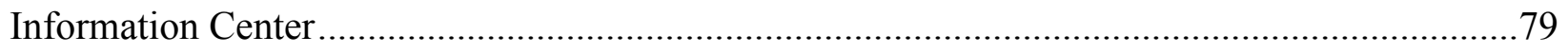

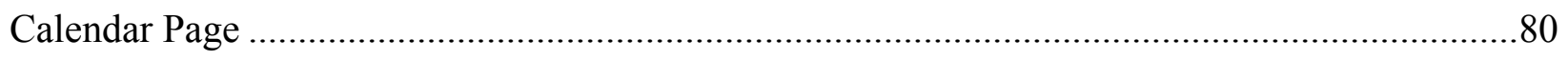

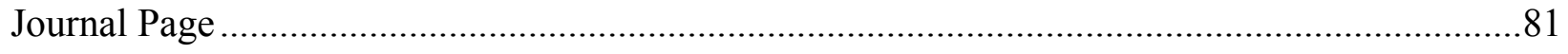

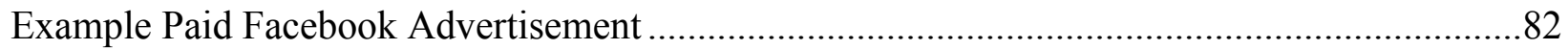

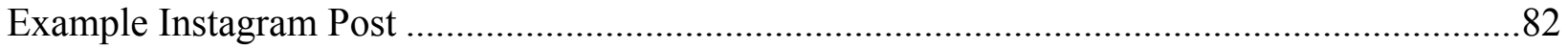




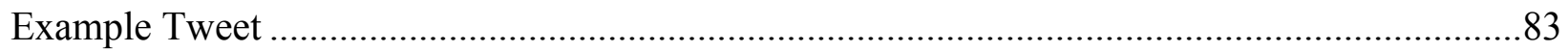

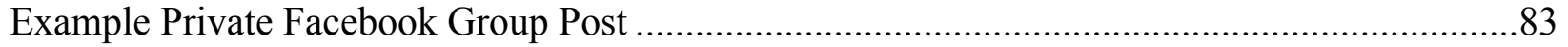

Example General MyGratefulSelf Facebook Wall Post ..........................................................84

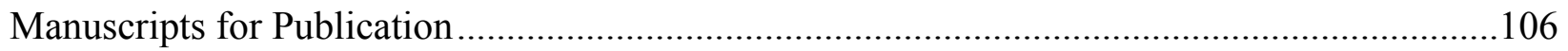




\section{FINANCIAL ACKNOWLEDGEMENTS}

This dissertation study was supported by a Doctoral Degree Scholarship in Cancer Nursing (Award \#: 127262-DSCN-15-092-01-SCN) from the American Cancer Society. 


\section{IN GRATITUDE}

The saying goes, "It takes a village to raise a child." My experience over the past four years has taught me that this rings true for doctoral dissertations as well. I want to thank every member of my village, whether or not I have been able to individually mention you here.

First I would like to thank my dissertation committee Jessica Keim-Malpass, Susan Bauer-Wu, Lee Ritterband, Jeanne Erickson, and Julie Haizlip. I never could have completed this work without your wisdom, guidance, commitment, and belief in me. I want to thank you for all the time you spent talking me through difficult intellectual and practical problems, reading (and re-reading) my work, answering so many questions, and particularly for the gentle nudges (and sometime great pushes) right out of my comfort zone. I feel proud of my work, and I have all of you to thank for that.

I owe a huge thanks to the members of the Behavioral Health and Technology Lab. Thank you to Karen Ingersoll, Kirsten MacDonnell, and Christina Frederick for welcoming me into your space and showing such support and interest in my work. It made the hours I spent at the BHT such a pleasure. A special thank you to Gabe Heath and Steve Johnson for making my imaginary website into a real website and thank you for always being so kind when I asked question after question about computers. And to Holly Lord, who stepped in at the last minute to help me make sense of my data and figure out how to tell its story, thank you so much. I could not have finished this without you!

I want to thank Professor Ann Gill Taylor and Jewel Holmberg for laying the very best foundation possible for this work. Without your mentorship I wouldn't have known how to begin much less how to finish. I also want to thank Professors Christine Kennedy and Linda Bullock for knowing what was best for me when I could not see that for myself. 
To Gina DeGennaro. Renee Breeden, and the students of the Clinical Nurse Leader program, thank you for allowing me to experience the unexpected joy of teaching new nurses. Your hard work, determination, and compassion inspires me to work harder and to be better. Thank you for being my anchor and reminding me that I am, first and foremost, a nurse.

Tyler Fleming, you have been by my side from the very beginning of this journey. Thank you for sticking with me through the ups and downs of the past years. Thank you for reminding me that all my tumultuous emotions are normal. And thank you for loving me so well. I could not have asked for a better psych sister!

To my family: Mom, Dad, Rachie, Viv, Sherwin, Joyce, Louise and crew. Without you, I never would have had the courage to take the first step. You have truly given me roots and wings. You have sacrificed so much for me to have this opportunity and this achievement is as much yours as it is mine. Thank you, I love you.

And lastly, a special thank you to my participants who took such time and energy to participate in this study. I promise to take what I have learned from you and continue to work to improve the lives of young people struggling with advanced cancer. \#ayascm \#Lifer 
Running Head: GRATITUDE

An Online Gratitude Intervention for Young Adults with Advanced Cancer

Chapter 1

Introduction 


\section{Introduction}

Confrontation of mortality is a common experience among young adults with cancer at any stage (Barling, Stevens, \& Davies, 2014a; Cohen-Gogo et al., 2011; KeimMalpass \& Steeves, 2012; Shaha \& Bauer-Wu, 2009). Young adults are in the midst of developmental tasks that broadly include establishing an identity separate from their families of origin and starting their own families (D'Agostino, Penney, \& Zebrack, 2011; Morgan, Davies, Palmer, \& Plaster, 2010; Zebrack \& Isaacson, 2012a; Zebrack, 2011). Many young adults with cancer feel a sense of urgency to complete life milestones, such as education and childbearing, and some are compelled to rearrange their life priorities with the realization that life is fragile (Keim-Malpass \& Steeves, 2012; Shaha \& Bauer$\mathrm{Wu}, 2009)$. For those with advanced cancer, however, the urgency to achieve life milestones and an experience as much of life as possible, may be replaced by grief over cancer-related losses including missed opportunities to achieve life goals and a return to the dependence associated with adolescence (Trevino, Maciejewski, Fasciano, \& Prigerson, 2011). Grief related to such losses is associated with higher levels of perceived life disruption and a diminished sense of well-being in young adults with advanced cancer (Trevino et al., 2011; Trevino et al., 2012; Zebrack \& Isaacson, 2012a). A growing body of literature on the palliative care needs of young adults with advanced cancer suggests that an intervention to promote well-being in the face of significant cancer-related losses and challenges may provide meaningful benefit in this population (D'Agostino et al., 2011; Trevino et al., 2011; Trevino et al., 2012; Zebrack \& Isaacson, 2012a; Zebrack et al., 2014), though no specific interventions have been studied. 
In considering a useful intervention, the promotion of positive emotions may be helpful in enhancing well-being in young adults with advanced cancer by building resilience and allowing them to achieve a sense of peaceful well-being, even in the face of disease-related challenges and premature mortality (Duckworth, Steen, \& Seligman, 2005; Fredrickson, 2004a; Fredrickson \& Joiner, 2002; Prigerson \& Maciejewski, 2008). Gratitude is a positive emotion characterized by the acknowledgment that one has received a valuable benefit from a source other than him or herself (Emmons \& Stern, 2013). The feeling of gratitude is created in two steps, (1) when an individual identifies goodness or positive things in his or her life and (2) when the individual recognizes that the source of those good things lies, at least partially, outside of the self (Emmons \& Stern, 2013). Gratitude is considered both an emotional state and a personality trait and is highly correlated with psychological well-being above and beyond other positive emotions or personality traits (Wood, Joseph, \& Maltby, 2009). Gratitude is also correlated with personal growth, positive relationships, purpose in life, and selfacceptance (Wood et al., 2009), and can be cultivated in a relatively short timeframe even in those who have low baseline levels of gratitude and those who have a medical diagnosis (Kerr, O'Donovan, \& Pepping, 2014). Gratitude interventions have been shown to improve both physical and mental health in patients experiencing traumatic life events (Emmons \& Stern, 2013) and to be negatively correlated with anxiety, depression and hostility in an adult cancer population (Ruini \& Vescovelli, 2013). Young adults with advanced cancer may benefit from an intervention based in gratitude that directs attention to the pleasures that can still be experienced even when struggling with a life-threatening 
illness, thereby reducing focus on the illness-related losses. To date, however, no such interventions have been studied in this population.

The Internet is an important, well-utilized resource for young adults with advanced cancer to exchange information, share their experiences, gain emotional support from other young adults in similar situations, cope with troubling emotions, and explore their identities as young adults with cancer (Keim-Malpass et al., 2013; KeimMalpass \& Steeves, 2012; Love et al., 2012). Most young adults have access to the Internet and are comfortable using the Internet for a variety of social and pleasurable activities, so it may be a developmentally appropriate and accessible way to reach this population and invite them to participate in research. Online research studies provide an excellent forum to both recruit young adult participants and to deliver behavioral interventions that may help promote well-being in this distressed population (D'Agostino et al., 2011; Zebrack et al., 2014).

\section{Purpose of Study}

The purpose of this study is to develop and evaluate the feasibility and preliminary efficacy of an Internet-delivered gratitude intervention designed to promote well-being in a sample of young adults between the ages of 20-39 living with advanced cancer.

\section{Specific Aims}

1. The primary aim of this study is to describe the feasibility (participant recruitment and retention) and acceptability of an online gratitude intervention designed 
specifically for young adults with advanced cancer.

2. The secondary aim is to assess the preliminary effect of participating in an online gratitude intervention on psychological well-being and emotional experience of young adults with advanced cancer.

\section{Theoretical Background}

A positive emotion is defined as a multi-component response tendency that begins with an individual assessment of the personal meaning of an event (Fredrickson, 2004a). Positive emotions are typically associated with a positive cognitive appraisal or meaning assessment of an event. Examples of positive emotions include joy, interest, contentment, gratitude, and love (Fredrickson, 2004a).

The Broaden and Build Theory of Positive Emotions is so named because it suggests that positive emotions broaden an individual's momentary thought-action repertoire and in so doing, serve to build his or her long-term personal resources and resilience (Fredrickson, 2004a). This is in contrast to negative emotions, which narrow an individual's thought-action repertoire, leading to quick and decisive action that carries immediate, often life-preserving, benefit. For example, the negative emotion fear, calls to mind the urge to escape; anger, the urge to attack; and disgust, the urge to expel (Fredrickson, 2004a). By contrast joy, a positive emotion, promotes a broader range of actions. It creates the urge to play, to be creative, and to stretch limits, all of which can result, not only in physical behaviors, but in intellectual and artistic behaviors as well. The thought-action tendencies set into motion by positive emotions (including the urge to play, explore, and savor) are the ways in which positive emotions help to expand habitual modes of thinking and acting (Fredrickson, 2004a). These broadened patterns of thought 
and action carry short-term benefits such as pleasure, but they also carry long-term benefits by making us more flexible, more social, more knowledgeable, more creative, and more resilient.

In addition to these long-term psychological benefits, Fredrickson suggests that positive emotions may be able to "undo" some of the lingering effects of negative emotions (Fredrickson, 2004a). She posits that positive emotions are, in some ways, incompatible with negative emotions in discrete moments. By increasing the momentary range of thoughts, interpretations, and subsequent actions in any given situation, a positive emotion may, in fact, loosen the hold that a negative emotion has on a person's mind and body by undoing the preparation for specific action (Fredrickson, 2004a). Fredrickson illustrates this potential by citing several studies that demonstrate that negative emotions raise heart rate and blood pressure, and when positive emotions are elicited, participants' heart rate and blood pressure return to normal much faster than when neutral feelings are elicited (Fredrickson, 2004a). While the precise cognitive and physiologic mechanisms of this effect are unknown, phenomenologically, it appears that positive emotions may be able to help people place negative events in their lives in a broader context of positive emotions, which may lessen the impact (or stress) of the negative event (Fredrickson, 2004a).

The promotion of positive emotion may help individuals in stressful circumstances make a daily effort to find positive meaning in everyday events, thus building personal resources and psychological resilience (Fredrickson, 2004a). Research into the effects of positive emotion suggest that it can improve subjective quality of life (Cho \& Oh, 2011) and reduce treatment-related side effects and physiological markers of 
stress, including salivary cortisol levels in patients with cancer (Lawson et al., 2012).

Fredrickson's model suggests that positive emotions may stimulate positive meaningmaking, but as suggested by the very name, the effects of positive emotions span a broad range. Using Fredrickson's model, those studying the effects of positive emotion can measure one or more aspects of meaning, but can also measure other outcomes associated with positive emotions such as overall subjective or psychological well-being.

Gratitude, one such positive emotion, has been shown to have particularly positive effects on well-being and resilience. Fredrickson suggests that over time, actions inspired by gratitude build and strengthen social bonds, which are personal resources, and that people who regularly feel grateful are more likely to feel loved and cared for by others (Fredrickson, 2004b). One of the key personal resources built by gratitude is mindful observation of our own lives (Fredrickson, Cohn, Coffey, Pek, \& Finkel, 2008). Fredrickson and her team suggest that because the regular practice of gratitude requires attention to everyday pleasures in addition to acknowledgement of the greater gifts in life, practitioners develop increased mindful observation that can promote well-being synergistically with the experience of feeling grateful (Fredrickson et al., 2008). She also suggests that gratitude may edge out negative emotions like envy, resentment, anger or regret through the "undoing" properties of positive emotions (Fredrickson, 2004b).

Research on the effects of gratitude suggests that it promotes positive affect, improvement in overall life appraisals, and positive health behaviors in young adults (Emmons \& McCullough, 2003a). Gratitude has also been shown to positively impact subjective well-being (Emmons \& McCullough, 2003a) and promote post-traumatic growth, positive relationships, and relaxation in clinical populations with life-limiting 
illnesses (Ruini \& Vescovelli, 2013). Gratitude can also be cultivated in a short timeframe, about 21 days, through short, daily writing exercises, even under stressful conditions (Emmons \& McCullough, 2003b; Emmons \& Stern, 2013). These results indicate that gratitude practice in a sample of young adults with advanced cancer, may be helpful in promoting overall well-being and resilience in the face of difficult and stressful

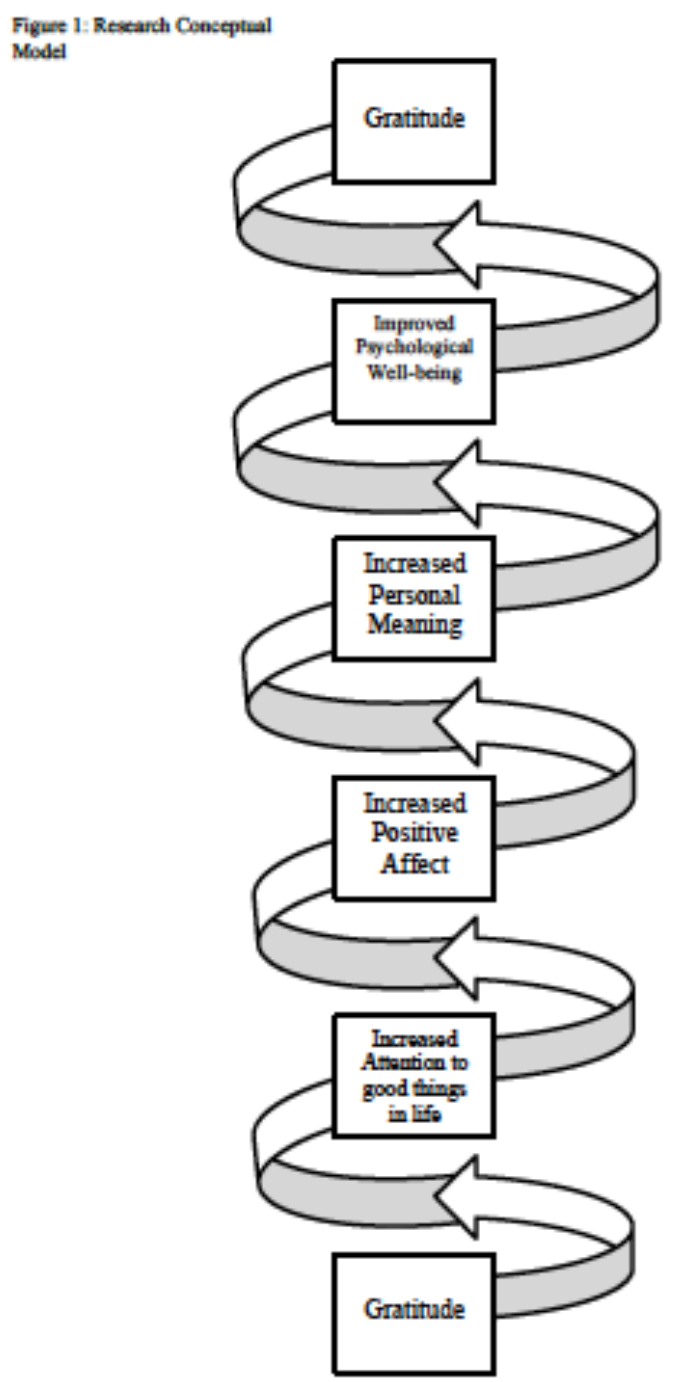
circumstances. Using Fredrickson's model, outcome measures for a study cultivating gratitude in young adults with advanced cancer, would be related to overall psychological well-being, positive affect, mindful observation, and emotional experience. Figure 1 represents a conceptual model of the upward spiral of positive outcomes set in motion by gratitude.

For young adults with advanced cancer, who may be near the end of life, promotion of positive emotions through a gratitude intervention may result in improvement in well-being and positive affect, increased awareness of everyday pleasures, improved relations with those around them, and feelings of appreciation of life. These personal resources could have a great effect on their coping and adjustment to the to the stresses of 
living with advanced cancer, especially at a young age, and may help them find personal meaning in their lives and in their illness.

\section{Research Hypotheses}

Based on the introduction and theoretical background, the following three hypotheses will be tested in this study:

1. The use of social media and social networking sites for participant recruitment will yield the target sample size of young adults with advanced cancer within 4 months.

2. Young adults between the ages of 20-39 with advanced cancer will consent to an Internet-delivered psychological intervention and at least $70 \%$ of recruited participants will complete the full (100\%) or partial (14-20 days) intervention protocol.

3. Participants in the intervention group will demonstrate improvement on measures of gratitude, mindful observation, positive and negative emotion, positive and negative affect, and psychological well-being after the 21-day intervention period compared to those in the wait-list control group.

\section{Significance of Study}

The results of the proposed pilot study have great implications for promoting well-being in young adults with advanced cancer. While there is a growing body of literature on the needs and experiences of young adults with cancer, the large majority of this research focuses on survivorship, while very little has been done to investigate the 
well-being of those with advanced or chronic cancers who are actively facing their own mortality. As a group with unique physical and psychosocial needs that have been largely unmet (Bleyer \& Barr, 2009; D'Agostino et al., 2011; Zebrack, 2011; Zebrack et al., 2014), this study will provide evidence for the feasibility of an easily accessible and developmentally appropriate intervention to help promote well-being in young adults with advanced cancer.

Additionally, there are many challenges in recruitment of young adults with cancer into clinical research studies (Burke, Albritton, \& Marina, 2007; Cantrell et al., 2012; Ferrari, Montello, Budd, \& Bleyer, 2008). The novel use of the Internet to both recruit participants and deliver the intervention has implications for future use for participant recruitment in studies with young adults, especially for those patients who live in rural or underserved areas and may have limited access to major medical centers, or for those who are too ill to travel long distances to participate in trials.

Lastly, there is a known stigma surrounding mental health in oncology care (Leykin et al., 2012; Zebrack \& Isaacson, 2012a). The Internet-based delivery of this psychosocial intervention may fill an important gap in providing quality cancer care because it allows for private and individual access to mental health care, sidestepping the issue of stigma around accessing such care. Overall, this study has the potential to introduce and provide evidence for a method of recruitment and intervention delivery that could impact the practice of Adolescent and Young Adult Oncology, and behavioral research in that area, significantly. 
An Online Gratitude Intervention for Young Adults with Advanced Cancer

Chapter 2

Review of the Literature 


\section{Introduction}

The following review of the literature focuses on three distinct concepts important to this study: (1) Cancer in young adults, (2) gratitude as a psychological intervention to improve well-being, and (3) the use of the Internet to recruit participants and deliver behavioral interventions. For this literature review PubMed, PsychINFO, and CINHAL were queried as well as the reference lists of particularly pertinent articles.

\section{Cancer in Young Adults}

\section{Epidemiology}

The National Cancer Institute estimates that 69,212 adolescents and young adults between the ages of 15-39 were diagnosed with cancer in 2011. That is approximately six times the number of cases diagnosed in children under the age of 15 (A snapshot of adolescent and young adult cancers, 2013). In the last 15 years the adolescent and young adult population has become an important field of study in cancer research. However, despite the fact that cancer is 4.4 times more likely to develop in those aged 20-39 than in those younger than 20 years old, less research has been focused on the distinct needs of the young adult population (Bleyer \& Barr, 2009). Cancer is the leading cause of diseaserelated death in young adults between the ages of 20-39, surpassing heart disease in females and HIV, diabetes mellitus, chronic liver disease, cerebrovascular disease, and congenital anomalies in both sexes (A snapshot of adolescent and young adult cancers, 2013; Bleyer \& Barr, 2009).

Additionally the gains in survival seen in many pediatric cancers have not been reflected the survival rates of young adults with cancer. The 5-year survival rates for 
some cancers commonly diagnosed in the young adult population, including thyroid and testicular cancer, exceed $80 \%$. However 5-year survival rates for diseases such as acute myeloid leukemia and ovarian carcinoma are only between $20-50 \%$, and malignant melanoma, colorectal carcinoma and lung carcinoma have 5-year survival rates below $20 \%$ within the young adult population (Bleyer, 2011).

\section{Biology}

There is some evidence that the biology of malignant disease in young adults differs from children and older adults, in spectrum of cancers, symptoms experienced by the patient, and character of the diseases (Bleyer et al., 2008). This provides one possible reason for the lag in survival gains seen in young adults when compared to children and older adults. Many cancers in young adults that may initially appear to be in the same histological grouping as those appearing in other age demographics, are, in fact, not biologically equivalent (Bleyer et al., 2008). This may be related to the complex etiology of cancers in young adults. Cancers in children are often linked to pre-natal and congenital factors, while cancers in older adults are linked to environmental exposures and DNA changes (Bleyer et al., 2008). In young adults, however, malignant disease may arise from pre-natal/congenital factors, environmental exposure, and DNA damage. Because it typically takes longer than 20-30 years for environmental exposures to manifest as cancer, a working hypothesis is that cancer in young adults may be linked to a predisposing genotype in addition to a carcinogenic exposure (Bleyer et al., 2008; Bleyer \& Barr, 2009) causing changes in the character of the disease and making it harder to treat. 


\section{Psychosocial Challenges for Young Adults with Cancer}

Because of their developmental stage, young adults with cancer face numerous challenges that are distinct from those experienced by their younger or older counterparts. Young adults between the ages of 20-39 are typically engaged in activities that include moving away from their parents' home and establishing an identity distinct from their families of origin, pursuing higher education or technical training, laying the foundation for their careers, establishing financial independence, forming a sexual identity, exploring intimate relationships, and starting families of their own (D'Agostino et al., 2011; Zebrack \& Isaacson, 2012a; Zebrack et al., 2014). A diagnosis of cancer often drives young adults back into a situation of dependence on their parents for both financial and psychological support and can disrupt personal, educational, and professional development (D'Agostino \& Edelstein, 2013; D'Agostino et al., 2011; Zebrack, 2011).

A 2012 study by Zebrack \& Isaacson, explored, in depth, the psychosocial challenges facing adolescents and young adults with cancer. The authors broke down the psychosocial stressors of cancer in adolescence and early adulthood into five categories including (1) information issues (e.g. poor communication with providers), (2) practical issues (e.g. finances, access to care, and physical disability), (3) emotional issues (e.g. effects of cancer and cancer treatment on self-esteem, body image and sexuality), (4) interpersonal issues (e.g. forced dependence on parents and other family members and isolation from peers), and (5) existential issues (e.g. confrontation of mortality and crises of previously held faith) (Zebrack \& Isaacson, 2012a). This study also briefly reviewed interventions to address many of the stressors identified, including peer support interventions to reduce isolation, skill-based interventions (problem-solving and CBT) to 
improve coping, and technology-based interventions to present pertinent information and promote social engagement (Zebrack \& Isaacson, 2012a).

Lastly, Zebrack \& Isaacson suggest some institutional and policy changes that may help the adolescent and young adult oncology population, including a broad suggestion to implement polices in clinics and communities to reduce stigmas related to seeking mental health care, which has been identified as a barrier to integrating psychosocial care into routine oncology care (Holland, Kelly, \& Weinberger, 2010). They also suggest that a national or state policy of comprehensive health insurance for adolescents and young adults will help alleviate some of the practical and financial concerns faced by this population (Zebrack \& Isaacson, 2012).

This is an important study because it covers a broad spectrum of psychosocial stressors affecting adolescents and young adults with cancer and provides an overview of the interventions that already exist to address some of these stressors. A weakness of this study, along with many others, is that it groups adolescents aged 15-19 with young adults aged 20-39 under the banner of adolescent and young adult (AYA) oncology. However, social, emotional, and financial issues vary widely among patients ages 15-39, as younger adolescents may still be living as dependents with their families of origin and young adults may be financially independent and in the process of starting families of the own (Bleyer \& Barr, 2009). With such a wide age range included in this, and several other studies examining the challenges facing adolescents and young adults with cancer (D'Agostino et al., 2011; Kazak et al., 2010; Morgan et al., 2010) it is difficult to distinguish which psychosocial stressors are most distressing for each age group, and 
which interventions would be developmentally appropriate, practical, and helpful for adolescents or young adults facing cancer.

Additionally, while this paper identified existential and spiritual concerns as an important psychosocial stressor in the adolescent and young adult oncology population, Zebrack \& Isaacson do not mention any intervention studies that specifically target these issues and offer no recommendations for addressing these concerns in the adolescent and young adult population. This is a weakness of many studies looking at the psychosocial care of adolescents and young adults with cancer (Barling, Stevens, \& Davies, 2014b; Smith et al., 2013; Wein, Pery, \& Zer, 2010; Zebrack et al., 2014). In fact, much of the research on the psychosocial and spiritual needs of adolescents and young adults with cancer focuses on survivorship, while end-of-life issues have not been examined as extensively.

\section{Unique Challenges for Young Adults with Advanced Cancer}

Confrontation of mortality is a common experience among young adults with cancer at any stage (Barling et al., 2014a; Cohen-Gogo et al., 2011; Keim-Malpass \& Steeves, 2012; Shaha \& Bauer-Wu, 2009). The understanding that time may be limited, brings about a sense of urgency to complete life milestones and experience as much as possible (Keim-Malpass \& Steeves, 2012; Shaha \& Bauer-Wu, 2009). Young adults with advanced cancer may have limited time or resources to achieve life goals, and this, in combination with other disease-related losses (e.g., physical functioning, alopecia, job disability) puts them at particularly high risk for psychological and spiritual distress including high levels of illness-related grief, anxiety, and depression (Trevino et al., 
2011). The coping styles of young adults with advanced cancer tend to mirror those of older adults. And, similarly to their older counterparts, negative coping, such as avoidance, is associated with more psychological distress (Trevino et al., 2012). Of particular interest, a negative expression style of coping or "venting" has been found to be associated with higher levels of life-disrupting grief in young adults with advanced cancer (Trevino et al., 2012). However, when compared to older adults, YAs have been shown to be relatively inexperienced when it comes to coping with health-related issues which leads to increased cancer-related distress when compared to older adults (Burgoyne, Bingen, Leuck, Dasgupta, Ryan, \& Hoffmann, 2015). Because of this inexperience and increased distress level, YAs require additional support in coping with advanced illness (Ishibashi, Okamura, Ueda, Sunami, Kobayashi, \& Ogawa, 2015; Kwak et al., 2013). Several studies suggest that young adults with advanced cancer would greatly benefit from interventions that help enhance well-being despite illness-related losses with a focus on reducing negative expression and promoting adaptive coping strategies, such as acceptance, though such interventions have not been widely explored in the young adult population (Trevino et al., 2011; Trevino et al., 2012).

\section{Research Gap and Contribution of this Study}

While there is an expanding body of literature exploring the experiences of young adults with cancer, interventions that will improve their quality-of-life during and after treatment, and their unique survivorship needs, there is very little literature addressing concerns related to incurable or chronic cancers, or issues at end-of-life (Barr, Ferrari, Ries, Whelan, \& Bleyer, 2016). Given the 5-year survival rates for many cancers 
common in young adults, it is evident that incurable cancer, advanced cancer, and end-oflife is an area that needs to be explored in this age group. There is a great deal of evidence suggesting that psychosocial and spiritual issues are of paramount importance at the end of life and there is a growing body of literature exploring interventions to promote psychological and spiritual well-being for older adults at the end of life (Alaka et al., 2006; Block, 2006; Breitbart, Gibson, Poppito, \& Berg, 2004; Lobb, Clayton, \& Price, 2006; Prince-Paul, 2008). However, because of the unique psychosocial and spiritual stressors and challenges facing young adults, more research is needed to learn about specific interventions to promote well-being in those between ages of 20-39 with incurable or advanced cancer, who may be nearing the end of life. This study seeks to fill this gap in the literature by examining an intervention for young adults with advanced cancer that addresses the feelings of loss and grief experienced by this population and promotes well-being.

\section{Gratitude as a Psychological Intervention to Promote Well-Being}

\section{What is Gratitude?}

Gratitude can be broadly defined as a positive emotion characterized by the acknowledgement of good things in life such as the presence of cherished others (Lambert, Graham, \& Fincham, 2009), or the recognition and appreciation of gifts from others or from a non-human source such as luck, chance, or a conception of the divine (Emmons, 2010; Emmons \& Stern, 2013; McCullough, Emmons, \& Tsang, 2002). Gratitude is considered to be both a trait, meaning that depending on an individual's disposition, levels of gratitude can be assumed to be relatively stable across time, and a 
state, meaning that depending on circumstances individuals may feel more or less grateful at any given time (Krejtz, 2014; McCullough et al., 2002). A grateful disposition is thought to be dependent on the individual's attributional breadth, meaning that grateful people are more able to recognize the many people and circumstances that contribute to their positive outcomes and experiences and less grateful people may not recognize the contributions of others to their happiness as readily (McCullough et al., 2002).

\section{Correlates of Gratitude}

Gratitude has been widely studied over the past 15 years and has been shown to be highly associated with physical and mental health including an enhanced sense of psychological well-being (Wood, Froh, \& Geraghty, 2010). A 2009 study established that gratitude is uniquely important to psychological well-being as defined by the six domains delineated by Ryff \& Keyes (1995). This study found that gratitude was related to a meaningful life as opposed to simply a pleasant life and that it was highly correlated with personal growth, positive relationships, purpose in life, and self-acceptance, all of which are identified domains of psychological well-being (Ryff \& Keyes, 1995; Wood et al., 2009). In fact, gratitude has been shown to have a significant positive impact on psychological well-being even after controlling for the five major personality traits associated with optimism and subjective well-being (McCullough et al., 2002; Wood et al., 2009). Other positive psychological correlates of gratitude include increased positive affect, greater sense of spirituality, increased pro-social behavior, and decreased materialism, envy, and hostility (Froh, Sefick, \& Emmons, 2008; McCullough et al., 2002). Similarly, gratitude is associated with increases in social functioning and other 
positive emotions including warmth, altruism, gregariousness, and trust (Wood, Maltby, Gillett, Linley, \& Joseph, 2008; Wood et al., 2009)

Gratitude can have positive effects on physical health as well. A 2011 study found that gratitude practice decreased worry and promoted sleep in a population of college students (Digdon \& Koble, 2011). A similar study found that thinking grateful thoughts before falling asleep was associated with higher subjective sleep quality and improved physical functioning the following day (Wood et al., 2009).

Gratitude also appears to provide a buffer against the effects of negative events or experiences. A 2006 study found that Vietnam War veterans with higher levels of dispositional, or trait, gratitude were less likely to experience symptoms of PTSD and that regardless of PTSD status daily gratitude practice was associated with higher levels of self-esteem and subjective well-being (Kashdan, Uswatte, \& Julian, 2006). Another recent study examined correlations of gratitude with post-traumatic growth, psychological well-being, and distress in a sample of 67 patients with breast cancer ranging in age from 35-84 (Ruini \& Vescovelli, 2013). The authors found that gratitude was significantly positively correlated with post-traumatic growth, positive relations, relaxation, and contentment, though no correlation with overall psychological well-being was found. Gratitude was negatively correlated with anxiety, depression, hostility, and irritability in this population as well (Ruini \& Vescovelli, 2013).

It is also important to recognize that the relationship between gratitude and other positive emotions or affective states, reflect the effects of gratitude but that gratitude itself is a distinct emotional state, separate from affect or other positive emotions (Krejtz, 2014). Gratitude has been shown to be correlated with positive affective states (pleasure) 
and may promote other positive emotional experiences (joy), but it is distinct from these experiences. While there is little consensus in the literature regarding the exact relationship, particularly the distinction, between emotion and affect, it is widely recognized that affect and emotion, while related to one another, are not the same. Affect can be described as the subjective experience of emotion with no cognitive value judgment as to the positive or negative meaning of the experience (Ekkekakis, 2012). Affect tends to be described in terms of states of arousal and intensity over time. Examples of core affective states include tension and relaxation, or energy and tiredness, each of which can have positive or negative emotional associations (Ekkekakis, 2012). The term emotion refers to the affective state coupled with a cognitive appraisal of the meaning of the "feeling," whether it is positive or negative (Ekkekakis, 2012). For example, an individual may feel a high level of arousal or energy (affect) but may attribute the meaning of the arousal to fear (negative emotion) or inspiration (positive emotion). Although gratitude is correlated with and related to positive affect, it is distinct from the affective states it stimulates (Emmons \& McCullough, 2003b; Weiner, 1985).

Also, while gratitude may be related to declared religiosity, it tends to be broader and does exist independent of any religious beliefs (Emmons \& Kneezel, 2005; Tsang, Schulwitz, \& Carlisle, 2012). The pro-social effects of gratitude are also distinct from a sense of indebtedness or reciprocity. These feelings tend to be associated with more negative emotions, while gratitude is associated with a positive emotional experience (Watkins, Scheer, Ovnicek, \& Kolts, 2006).

\section{Manipulations of Gratitude}


In 2003, Emmons \& McCullough investigated the effects of grateful thinking (using a weekly grateful writing exercise) on psychological well-being in the daily lives of young adults. They found that those in the gratitude condition showed higher scores in positive affect, adaptive coping behaviors, health behaviors such as physical exercise, and overall life appraisals, when compared to those writing about hassles of daily life and those writing about neutral life events (Emmons \& McCullough, 2003b).

These same investigators also looked at the effects of gratitude practice for adults whose well-being was compromised by health challenges. Emmons \& McCullough (2003) used a randomized, controlled experimental design to investigate the effects of daily gratitude practice on 66 adults, ages 22-77, with congenital and adult onset neuromuscular diseases. They found that gratitude practice improved subjective reports of well-being, health-related behaviors, and daily affect in the treatment group, when compared to the control group, and could determine that these improvements were a direct result of the daily gratitude exercises. They also determined that daily gratitude practice was more effective that weekly practice in this population (Emmons \& McCullough, 2003a).

As one of the first studies to investigate the effects of gratitude on well-being, an important weakness of these studies is related to the intervention dose. The investigators conducted the experiment three times, twice using weekly gratitude writing exercises for one month, and once using daily writing exercises for 21 days. While they found a greater improvement in well-being with daily writing, there is no empirical reason or evidence for the length of the intervention (Emmons \& McCullough, 2003), and no further investigation as to whether a shorter number of days of daily writing would have 
produced the same results, or whether a longer number of days of daily writing would have produced even more dramatic effects. There is also no exploration of the effects of writing three times weekly, or every other day. With many studies investigating the effects of gratitude on well-being in various populations, following this model for gratitude practice (daily writing for 21 days), this is a major limitation in gratitude research overall.

Since 2003, several studies have examined the effects of daily gratitude practice on various clinical populations. One study looked at the effect of daily gratitude practice, when compared to kindness practice and neutral writing practice, on psychological wellbeing in a sample of 48 adults aged 19-67, who were awaiting psychological treatment for a variety of conditions (Kerr et al., 2014). These researchers determined that gratitude, but not kindness, could be cultivated in a short intervention timeframe (21 days) and that both gratitude and kindness interventions built a sense of connectedness, enhanced satisfaction with daily life, increased optimism and reduced anxiety when compared to placebo. However, in the timeframe allotted neither gratitude nor kindness had significant effects on measures of psychological well-being or meaning in life (Kerr et al., 2014). A 2010 study found that maintaining a gratitude diary (gratitude lists) for 3 weeks reduced body dissatisfaction in a sample of patients with clinically significant body-image disruption (Geraghty, Wood, \& Hyland, 2010).

Different methods of gratitude practice have also been studied. A 2012 study found that writing letters of gratitude, instead of keeping a journal or diary, increased happiness and life satisfaction and decreased depressive symptoms in the experimental group when compared to the control group (Toepfer, Cichy, \& Peters, 2012). Another 
recent study found that an online gratitude intervention increased eudemonic well-being (feeling like life is meaningful, rather than simply pleasurable(Hui, Glitza, Chisholm, Yennu, \& Bruera, 2013)) and decreased stress in a sample of 88 healthy, communitydwelling older adults when compared to controls, and no difference was found between the electronic gratitude journal and a paper version (Killen \& Macaskill, 2014).

The above studies begin to build the case that gratitude practice may be an effective intervention in young adults with advanced cancer to improve overall psychological well-being, as well as to reduce anxiety and depression, increase optimism and a sense of connectedness, promote adaptive coping and positive affect, and improve overall life appraisals. These may be important improvements in quality of life for a population, such as young adults with advanced cancer, facing difficult circumstances and many stressors.

\section{Internet Delivered Behavioral Interventions}

\section{Current Internet Usage by Young Adults with Cancer}

Young adults with cancer have been shown to use the Internet a great deal for information gathering, sharing experiences, and building social communities (KeimMalpass et al., 2013; Keim-Malpass \& Steeves, 2012; Love et al., 2012; Treadgold \& Kuperberg, 2010). One study found that YAs with cancer spent an average of 2.3 hours per day online with a large portion of that time spent looking at cancer-related websites that provide information about services for young adults with cancer and especially those that help build community among young adults with cancer, who often feel very isolated by their experiences (Schiffman, Csongradi, \& Suzuki, 2008). Given the comfort young 
adults already have with the Internet, it follows that the Internet would be an ageappropriate and accessible method to recruit participants for research studies and to deliver interventions in this population (Zebrack \& Isaacson, 2012b).

\section{Using the Internet to Recruit Young Adults for Research Studies}

Young adults with cancer have traditionally been difficult to recruit for clinical research trials. The reasons for this vary and include parental concern for their adult children (Hendricks-Ferguson et al., 2013), lifestyle characteristics such as the frequency of interface with the healthcare environment (Cantrell et al., 2012), access to providers who are likely to refer patients to clinical trials (Burke et al., 2007), and research protocols that tend to exclude YAs on the basis of age (Fern \& Whelan, 2010). With the emergence of young adults as a distinct population with unique disease biology and psychosocial needs, more interest has developed in increasing their participation in clinical research and designing research projects addressing the specific needs of the young adult oncology population (Bleyer \& Barr, 2009; D'Agostino et al., 2011; Zebrack, Mathews-Bradshaw, \& Siegel, 2010). With the comfort level and current Internet usage of young adults with cancer, some research suggests that using online recruitment via social media may yield increased participation rates from young adults (Cantrell et al., 2012; Gorman et al., 2014). Reasons for this include breaking barriers of access and information sharing, and providing an age-targeted advertisement space (Cantrell et al., 2012). 


\section{Successful Internet-Based Behavioral Interventions}

Internet interventions for behavioral change and mental health have been gaining in popularity in recent years. There are a host of studies that demonstrate that Internet based interventions can improve mental health outcomes in particular (Ritterband et al., 2003). A 2001 randomized controlled trial found that an Internet-delivered intervention targeting posttraumatic stress and pathological grief in young adults yielded clinically significant improvement in $80 \%$ of the participants in the experimental group (Lange, van de Ven, Schrieken, \& Emmelkamp, 2001). Another study showed that an Internet delivered intervention improved body image in 60 women at risk for eating disorders when compared to a control group (Winzelberg et al., 2000). A more recent study found that an Internet-delivered intervention improved coping, self-image, positive affect, and life appreciation, when compared to usual care controls, in a sample of breast cancer survivors (Cleary \& Stanton, 2014).

A 2012 review article on the use of Internet interventions for improving psychological health in cancer patients found that there are very few rigorous studies of such interventions in the oncology population but given the growing body of evidence that Internet interventions are efficacious, acceptable, and accessible in a variety of other clinical populations, future researchers should design and test Internet-delivered interventions for the oncology population (Leykin et al., 2012). This review also suggested that Internet-based interventions may fill an important gap in providing quality cancer care because it allows for private and individual access to mental health, sidestepping the previously identified issue of stigma around mental health care (Leykin et al., 2012). 
Framework for Designing Internet-Based Behavioral Interventions

Internet-based interventions have been shown to produce and maintain behavior change and symptom improvement through nine, non-linear steps. These steps form a scientific framework for developing and implementing Internet interventions and they include the (1) user as influenced by (2) the environment which then affects (3) website use which is influenced by (4) support and (5) website characteristics. Website use then leads to (6) behavioral change and (7) symptom improvement through various (8) mechanisms of change and ultimately sustained through (9) treatment maintenance. Each component of this framework encompasses areas that must be carefully considered in the development of Internet-based interventions and provides intervention developers with a guide to help design user-friendly, tailored, and testable interventions (Ritterband, Thorndike, Cox, Kovatchev, \& Gonder-Frederick, 2009).

With careful attention to each of the important components for the success of Internet interventions, it is possible to develop an online intervention designed specifically for young adults with advanced cancer, and to thoroughly evaluate its feasibility, acceptability and potential efficacy in promoting well-being in this population.

\section{Conclusion}

This review of the literature provides substantial evidence of the following: (1) there is an unmet need for interventions that address the spiritual and existential concerns accompanying the diagnosis of cancer. There is particular need in the young adult population (ages 20-39) especially for those with advanced cancer, for whom 
survivorship issues are of less importance. (2) Promotion of positive emotion, particularly gratitude may improve psychological well-being, increase positive affect and emotional experience, increase awareness of daily pleasures, and improve overall life appraisal. Daily practice in the form of journaling is an effective way to cultivate gratitude and this can be achieved in a relatively short timeframe, around 21 days. (3) The Internet represents an easily accessible and effective resource for delivering interventions designed to improve mental health and well-being and there is a need for research on these interventions in the oncology population. 
An Online Gratitude Intervention for Young Adults with Advanced Cancer

Chapter 3

Methods 


\section{Introduction}

This pilot study is a prospective, randomized, waitlist-controlled feasibility trial of an online gratitude intervention designed to promote well-being in young adults with advanced cancer. The primary outcome measure for this study is the description of the feasibility of the protocol including the participant recruitment strategy and retention over the course of the 21-day intervention and follow-up period. The secondary outcomes are the mean changes in measures of psychological well-being, mindful observation, gratitude, psychological affect, and emotional experience from baseline to the end of the 21-day intervention, and from baseline to the 30-day follow-up period, in both the intervention and the control groups.

\section{Sample}

Young adults between the ages of 20 and 39 who have advanced cancer are the target population for recruitment. For the purposes of this study, advanced cancer is defined as stage III or IV solid tumors, recurrent or relapsed malignancy, disease that is refractory to treatment, or the presence of multiple malignancies, none of which are in remission. Participants must also score $\geq 2$ on the Eastern Cooperative Oncology Group (ECOG) Performance Status assessment to be eligible. The goal is to recruit a sample of young adults with cancer, for whom cure is unlikely. Eligibility is confirmed over telephone or video call, depending on the capabilities and preferences of the interested candidate.

Inclusion criteria include:

- $\quad$ Age $20-39$ years 
- Diagnosed with advanced cancer, defined as stage III or IV, relapsed, refractory, or recurrent disease $\underline{\text { AND }}$ ECOG Performance Status score $\geq 2$.

- Willingness to participate in a 21-day online writing intervention

- Alert, oriented, and able to give consent

- English language fluency in reading, writing, and speaking

Exclusion criteria include:

- Limited or unreliable access to the internet

- Inability to type on a keyboard

- Current or previous participation in structured or unstructured gratitude practices Recruitment methods include advertisements posted on social networks (primarily

Facebook, Twitter, and Instagram), websites, and forums, frequented by young adults with cancer, as well a flyers posted in the local medical center, and word of mouth. Interested participants indicate initial interest by visiting the study website and completing an Initial Interest Form, which contains preliminary questions to determine eligibility.

Sample Size

Based on a power analysis using NQuery software, a full-scale study would aim to recruit 120 participants, with 60 randomized to the treatment and control conditions respectively, and 32 completers in each arm. However, given that this is a pilot study with a primary aim of feasibility of protocol including recruitment of participants and attrition from intervention, a confidence interval (CI) method was used to determine the target sample size (Hetzog, 2008). This method of determining ideal sample sizes creates 
a CI around mean value of importance to the feasibility aim of the study. For this study, attrition was chosen as the mean value around which to create the CI. Mean attrition in behavioral oncology studies is approximately $30 \%$, related to both average study attrition and attrition due to morbidity and mortality (Hui, Glitza, Chisholm, Yennu, \& Bruera, 2013). Using confidence intervals suggested by Hertzog (2008), with an observed attrition rate of $30 \%$, in a pilot study of 50 participants we can be $90 \%$ confident of the feasibility of protocol within 10 percentage points (Hertzog, 2008). With this in mind, given the novel use of the Internet to recruit participants and the primary aim of describing the feasibility of the recruitment strategy, researchers will recruit participants for a period of 4 months, aiming for 25 participants randomized to each arm, and describe the results.

\section{Procedures}

After completing the Initial Interest Form on the study website, all interested participants are contacted by the PI through email. Those who are immediately deemed ineligible are sent a thank-you email and referred to several resources for young adults with cancer. Those who appear to be eligible are contacted by the PI to set up a time for a video call to establish eligibility, gain consent, and complete the demographic and medical history form designed by the study team. After confirming interest and eligibility, all potential participants indicate consent through an electronic consent form acknowledging that $\mathrm{s} / \mathrm{he}$ is informed regarding the study. In addition participants in both groups complete the self-report medical history and demographic form designed by the 
study team, which is administered orally during the video call. Each participant completes baseline measures of study instruments prior to randomization.

Consenting participants who have completed the baseline measures are randomized, using a random number generator, into the intervention or waitlist control group. Equal numbers of participants are assigned to the two study groups. Participants will be blinded to the randomization, however all participants are given descriptions of the two groups in the consent form and it is therefore likely that study participants are able to deduce which group they are in. Only co-investigators have access to the randomization scheme.

Participants in the intervention group complete follow-up measures at the end of the 21-day intervention, and 30-days post-intervention and participants in the control group compete follow-up measures 21 days after enrollment in the study, and 30-days after the completion of the 21-day follow up measures. A step-by-step description of the study procedures, including the online consent process, is included in Appendix A. Upon completion of the 30-day follow-up measures, all participants will be entered into a lottery to win one of six $\$ 50$ gift certificates to Amazon.com.

\section{Intervention}

The intervention is a daily, online gratitude journal. Participants in the experimental group are instructed to $\log$ in to a secure, password-protected website daily for 21 days (Emmons \& McCullough, 2003a). Once logged in, they will be instructed to write about at least one thing for which they are grateful and why, or at least one thing that elicited pleasure that day and how it did so. The prompt will focus on the experience 
of the emotion rather than the length or completeness of the writing itself. These instructions are consistent with other gratitude interventions that have been successfully studied (Emmons, 2010; Emmons \& McCullough, 2003a; Kerr et al., 2014; Killen \& Macaskill, 2014; Ruini \& Vescovelli, 2013). The full prompt is included in Appendix C. Participants log off once they have completed their daily writing. The online journals are private and only the study team members have access to the contents of the journals.

\section{Outcomes}

Recruitment feasibility: Feasibility of the recruitment strategy will be determined by the length of time it takes to reach the recruitment goal, or the final recruitment tally after the 4-month recruitment timeframe. Recruitment strategy details will be collected through meticulous record keeping of recruitment sites, interest queries, and online "ad clicks." Intervention feasibility and acceptability: Feasibility of the intervention protocol will be described by the number of times each participant logs into the study website (if they are writing daily) and how many of the recruited participants complete the full (100\%) or partial (15-20 days) intervention protocol. Acceptability of the intervention protocol will be measured using the Internet Evaluation and Utility Questionnaire (Ritterband et al., 2008; Thorndike et al., 2008). Included in this measure are two open-ended questions asking the participants to describe the most and least helpful part of the intervention.

\section{Instruments}

Health Literacy: The Set of Brief Screening Questions (SBSQ-D) (Chew, Bradley, \& Boyko, 2004; Sarkar, Schillinger, López, \& Sudore, 2011) is a 3-item, self-report health literacy assessment that was developed as a low participant burden screening measure of 
health literacy for diverse English and non-English-speaking populations. The SBSQ-D has been validated against the Test of Functional Health Literacy in Adults (TOHFLA, the "gold standard" in health literacy assessment among adults), and can distinguish English and Spanish speakers with adequate health literacy from those with inadequate (concordance-index 0.82) and inadequate plus marginal health literacy (concordance index 0.81). It consists of three questions and respondents rate their level of agreement on a scale of 1 (never) to 5 (always) with the exception of the first question which is reverse worded and respondents rate their level of agreement on a scale of 1 (extremely) to 5 (not at all). A lower score indicates a higher level of health literacy and a higher score indicates a lower level of health literacy. The scale takes approximately 2 minutes to complete and has an overall concordance index of 0.82 . For the purposes of this study, the SBSQ-D is used only as a sample descriptor.

Intervention Acceptability: The Internet Evaluation and Utility Questionnaire (Ritterband et al., 2008; Thorndike et al., 2008) was developed to measure participant experience and perceptions of Internet interventions. The measure assesses constructs including ease of use, convenience, engagement, enjoyment, layout, privacy, satisfaction, usefulness, comprehension, credibility, likelihood of returning, mode of delivery, and helpfulness. Participants rate their level of agreement on a 5-point likert scale from 0 (not at all) to 4 (very), with 2 open-ended items requesting participants to identify "most helpful" and "least helpful" parts of the web program. The measure has evidence of internal reliability $($ alpha $=0.69)($ Ritterband et al., 2008). Psychological well-being: The Psychological Well-Being Scales [PWB] (Ryff \& Keyes, 1995) were developed to assess 6 distinct domains of psychological well-being including 
autonomy, environmental mastery, personal growth, positive relations with others, purpose in life, and self-acceptance. Each construct is measured separately, though there is some overlap, and the individual domain scores can be added up to obtain a score representing overall psychological well-being. The original instrument included 120 items (20 per dimension), but shorter version containing 84 items (14 per dimension), 54 items ( 9 per dimension), 42 items ( 7 per dimension), and 18 items ( 3 per dimension) are now widely used. For the present study the 42 -item version will be used because it is the shortest version with the best psychometric properties with evidence for internal consistency (alphas ranging from $0.86-0.93$ ) and test-retest reliability (coefficients ranging from $0.81-0.88$ ) (Abbott, Ploubidis, Huppert, Kuh, \& Croudace, 2010). Subscales will be measured separately to better understand the intricacies of the effects of gratitude on psychological well-being. The 42-item PWB takes approximately 15 minutes to complete. Respondents rate their level of agreement on a 6-point Likert-type scale ranging from 1 (strongly disagree) to 6 (strongly agree). Mean (SD) scores for each subscale in a sample of 4015 healthy adults aged 20-60 are as follows: Autonomy = 37.14(6.96), Environmental Mastery $=38.15(7.41)$, Personal Growth $=38.40(6.93)$, Positive Relations with Others $=40.57(6.96)$, Purpose in Life $=38.40(6.98)$, SelfAcceptance $=38.12(8.20)$ Emotional Experience: The Modified Differential Emotions Scale [mDES] (Fredrickson, Tugade, Waugh, \& Larkin, 2003) is a modified version of the Differential Emotions Scale (Boyle, 1984), which was originally developed to assess 10 discrete emotions. The mDES includes 18 discrete emotions, divided into Positive Emotions and Negative Emotions subscales. The mDES can measure discrete emotions (average scores for each 
item) or, using item analysis, researchers can create separate aggregate subscales for positive and negative emotions (sum of scores of all items in that subscale). The mDES consists of 20 statements that each include three emotionally descriptive words and respondents rate the greatest amount they have experienced these feelings in the past two weeks on a 5-point Likert scale ranging from 0 (not at all) to 4 (extremely). The mDES has evidence of reliability and internal consistency with alphas ranging from $0.82-0.86$ (Cohn, Fredrickson, Brown, \& Mikels, 2009). Mindful Observation: The Five-Facet Mindfulness Questionnaire [FFMQ] (Baer, Smith, Hopkins, Krietemeyer, \& Toney, 2006) was developed as a self-report measure of the five component skills of mindfulness including observing, describing, acting with awareness, non-judging of inner experience, and non-reactivity to inner experience. Each facet can be measured separately and the scores can be summed to generate a total score for mindfulness. The FFMQ consists of 39 items to which respondents rate their level of agreement on a 5-point Likert-type scale ranging from 1 (never or very rarely true) to 5 (very often or always true). The FFMQ has good evidence for internal consistency with alphas for each scale ranging from $0.72-0.92$ ) (Baer et al., 2008). For the purposes of this study, only the Observing facet will be measured, in order to capture the mindful observing of everyday pleasures built by gratitude practice. The normal score for the observation subscale in this age group, in non-meditating sample is 24.32(4.84) (Baer et al., 2008). This scale consists of eight items and takes approximately 2-3 minutes to complete.

Gratitude: The Gratitude Questionnaire-Six Item Form [GQ-6] (Emmons \& McCullough, 2003a) was developed to assess individual differences in the proneness to 
experience gratitude in daily life. The GQ-6 is a six-item self-report scale. Respondents endorse each item on a 7-point Likert-type scale ranging from 1 (strongly disagree) to 7 (strongly agree). The average range (SD) in this age group is 34.13-37.99(7.11-4.41) (Giacalone, Paul, \& Jurkiewicz, 2005, Kashdan et al., 2009). The scale takes approximately 3 minutes to complete. The GQ-6 has strong evidence for reliability with coefficient alphas ranging from $0.76-0.84$ (McCullough et al., 2002).

Affect: The Positive and Negative Affect Schedules - Short Form [PANAS-SF]:

(Watson, Clark, \& Tellegen, 1988) was developed for the purposes of assessing mood states, particularly distinguishing between positive and negative affect. The scales are sensitive to short-term affect (today or within the past few days), medium-term affect (in the last two weeks), and long-term affect (within the last few months or ever). For the purposes of this study, given its timeframe, respondents will complete this scale for the medium-term (in the last two weeks). The PANAS is composed of two 10-item selfreport scales (one measuring positive affect and one measuring negative affect) that take approximately 10 minutes to complete. Respondents rate each item on a 5-point Likerttype scale ranging from 1 (very slightly) to 5 (extremely). The mean score on the positive affect subscale is 33.3(7.2), and the mean score for this age group on the negative affect subscale is 17.4 (6.2) (Watson, Clark, \& Tellegen, 1988). The PANAS has evidence for internal consistency with alphas ranging from $0.87-0.88$ and for testretest reliability with alphas ranging from $0.68-0.71$ (Watson et al., 1988).

Copies of each instrument including the demographic and medical history form created by the PI are included in Appendix B. 


\section{Data Collection}

After consent is obtained, participants receive an email containing a link to the pre-intervention questionnaires from the UVA School of Nursing Survey Program, SurveySelect. Survey Select offers a confidential online survey mechanism that meets IRB privacy requirements. All data is collected confidentially with only a participant ID number connecting identifying information with survey responses. Participants can compete all the questionnaires in one sitting, or their data can be saved and they can partially complete the questionnaires and return at a later time to finish. Participants do not have access to the web program until the pre-intervention questionnaires have been completed. Participants are able to indicate their responses by simply clicking their mouse in the appropriate area. If participants do not complete the questionnaires on the first day they are available, email reminders are sent on days 2 and 3 and phone call reminders on days 4 and 10. Participants have 14 days to complete the pre-intervention questionnaires before they are dropped from the study.

Following completion of the pre-intervention questionnaires, and randomization, those in the experimental group are sent a username and password and are able to log into the study website and begin journaling. After 21-days, they are locked out of the system. At study day 21, all participants receive an email containing a link to the postintervention questionnaires. Those in the experimental group regain access to the study website after completion of the post-intervention questionnaires, and those in the control group gain access after completion of the 30-day follow-up questionnaires which are sent by email to all participants on study day 51 . 


\section{Data Analysis}

For the primary aim of the proposed study, participant recruitment results, adherence to the daily writing exercise, and participant retention will be documented. Additionally, regarding acceptability, participants will have the option to respond in writing to an open-ended question asking for feedback about the usability of web program. For the secondary aim of the proposed study, investigators will compare mean changes in scores on the PWB (all subscales), mDES (positive and negative subscales), FFMQ (observing subscale only), GQ-6, and PANAS (positive and negative subscales) between the intervention and control groups. Data will be analyzed using SPSS v. 22. Treatment group (intervention v. control) will serve as the independent variable, and psychological well-being and emotional experience, as defined by scores of the aforementioned instruments, will serve as the dependent variable.

Group equivalence by age, gender, race, cancer type and baseline scores on the PWB, mDES, FFMQ, GQ-6, and PANAS will be determined using independent $t$-tests for continuous variables and $\chi 2$ for categorical variables. Mean change in scores on the outcome measures, pre-, post-intervention, and 30-day follow-up in both the intervention and control groups will be determined using dependent $t$-tests. Between-group differences in mean change in scores on outcome measures will be determined using independent $t$-tests. All tests will be two-tailed as the investigators are unsure of the impact of the intervention on scores on the outcome measures. Level of significance for all analyses is set at $\leq 0.05$. Data will be analyzed using a "completers" analysis.

\section{Potential Limitations}


Potential limitations of this study relate largely to issues of an online study. We are recruiting from a distance and are not be able to confirm diagnosis through a medical record review and are thus relying on the honesty of potential participants to determine if they meet the eligibility requirements. A second concern, given the nature of the population, is that of potential missing data and participant attrition due to morbidity and mortality. To address this issue, investigators hope to recruit participants to meet the sample size guidelines determined by the power analysis, though given that this is a feasibility pilot study, information regarding attrition and missing data is a key outcome measure. Additionally, given the social nature of the Internet and communities formed by young adults, contamination of the control group is possible. Investigators will ask those in the intervention group to refrain from discussing the intervention with other young adults until the completion of the study. Another limitation is the importance of daily access to a computer and reliable Internet access. While most young adults have access to computers that are connected to the Internet in their homes, public computers are still widely available in such locations as libraries and hospitals. Additionally, this intervention can be completed on mobile computers such as tablets that have a keyboard, as long as they are able to connect to the Internet.

\section{Protection of Human Subjects}

Privacy and Confidentiality: There are several steps researchers on this study will take to provide privacy and confidentiality to their potential research participants, even when recruiting through ads on social media sites. Research team members will not invite potential participants to be their online "friend" thereby restricting access to private 
information on participant profile pages, giving researchers access only to information that participants make publically available on social networks, until informed consent is given (Curtis, 2014). Additionally an online-ad click sends potential participants to a general interest site where they indicate initial consent to send information to the research team over the Internet, thereby preventing the release of any personal information about the person who clicked the ad to the social network site or to the research team without consent (Curtis, 2014). After providing consent to send information over the Internet, including consent to be contacted by the research team, the remainder of interactions take place via phone or Internet calls where risks involved with information exchange are similar to in-person exchanges (Jerome et al., 2000). Additionally with regards to the collection of confidential, HIPAA-protected health information, all assessments are collected after formal informed consent is obtained, through a secure website built by the study team members, that is not housed on the social networking site and that uses current standards of password protection and is stored behind a firewall (Curtis, 2014), thus meeting all the AMA guidelines for protecting the confidential information of patients. All data is de-identified prior to being downloaded off the website.

\section{On-line Consent}

Potential participants will be recruited from all over the United States and Canada through online advertisements. The following is a step-by-step of the online consent process, which has been designed to mimic an in-person consent process to reduce risk to the participants and ensure that true informed consent is obtained. 
1. Interested individuals learn of the study and go to the study interest website for more information. A copy of the consent form (in .pdf format) is available on this website for them to download and read.

2. Interested individuals are prompted to sign an initial consent. Once that is complete, they are sent to our Interest Form, which includes basic information and study's enrollment criteria. The user enters in her information and clicks submit.

3. Based on this preliminary information, we follow up with the individual by phone and/or email to determine if they meet eligibility criteria.

4. During the phone call:

1. Provide a brief overview about the study and open up the conversation to hear more about their cancer diagnosis and prognosis.

2. Confirm information on Interest Application is correct.

3. After confirming eligibility, PI clicks the 'Send Consent Form" button from WASABII and requests Interested Candidate log onto their email.

4. PI asks participant to open email and click on the link to the Interactive Consent Form.

5. PI asks participant to type in their name at the top of the Consent Form.

6. PI reviews the Consent Form in detail and answers any questions they may have.

7. Once they are ready, they check the box indicating that they understand the process and agree to consent.

8. PI makes clear that their signature would not be used for any other purposes and would remain secured on the server.

9. After subject submits Consent Form, it is automatically stamped with date, time, and PI's signature. It then appears in the Consenting Candidates folder in WASABII. A copy of the signed consent form (with Coordinator's signature) is automatically emailed to the participant. The signature image is saved in our secure server database with a time/date stamp, and after subject is assigned to a group, the Consent Form becomes viewable under the Candidate Info tab.

5. The following items will be stored for auditing purposes:

1. An image of the participant's signature

2. Time/date stamp of signature

3. Indication of checkboxes checked

4. Emails sent to the participants

This process eliminates the need for more extensive confirmation of comprehension including on-line quizzing of recall regarding the content of the consent form and third 
party age verification (Curtis, 2014). A copy of the consent form is included in Appendix D.

\section{Vulnerable Population}

While young adults do not typically fall into the category of vulnerable populations, it can be argued that those with advanced cancer, who may be severely ill, or terminal, would merit special ethical consideration. This study seeks to investigate an intervention that may improve well-being and quality of life, but does not, in any way claim to offer disease treatment or potential cure. Therefore the risk/benefit ratio to this potentially vulnerable population is low. Potential risks of this study are related largely to psychological distress. In the event that any participant does experience significant distress related to the study, each participant is provided the number for the helpline at the American Psychosocial Oncology Society. If a participant were to call this number he or she would be connected to a person trained in crisis management ( 24 hour per day) and then would be referred to a clinician who specializes in the psychosocial needs of cancer patients in their area.

To ensure all ethical standards are met, researchers obtained University of Virginia Social and Behavioral Sciences Institutional Review Board approval before proceeding with any study activities. Additionally, all reasonable steps were taken to obtain informed consent, as discussed above, with the PI over the telephone or by Internet call. All participants are made aware of the risks, and informed that they have the right to withdraw from the study at any time. Additionally, the researchers will take great precautions to protect the privacy and confidentiality of the participants, as discussed above. Only the research team members have access to the data collected from 
participants including medical history, demographic data, answers to questionnaires, and the contents of the gratitude journals themselves. This data will be housed in passwordprotected HIPAA approved network folders at the University of Virginia. 
An Online Gratitude Intervention for Young Adults with Advanced Cancer

\section{Chapter 4}

Results 


\section{Introduction}

This chapter reports the results of the MyGratefulSelf study. The chapter begins with a detailed description of the development of the MyGratefulSelf system and a description of each component of the user interface. Then, the results of the study are reported in relation to each specific aim.

\section{Intervention Development: MyGratefulSelf System Description}

The Internet intervention (MyGratefulSelf) was developed using pre-existing infrastructure created at the Behavioral Health and Technology Lab at the University of Virginia. Components of the intervention included an interest site with a signable online consent to send information over the Internet, a home page accessible with a username and password, a journal function, and several automated emails alerting participants to their progress through the intervention.

\section{Interest Site}

When interested candidates clicked the link: www.mygratefulself.org, they were directed to the interest site. On the interest site they were able to learn about the study and the researchers, read the study consent form, and complete an online interest form to express their interest in participating in the study. Prior to completing the online interest form, participants indicated consent to send information over the Internet to the researchers by using their mouse to sign a consent form. Candidates were not able to access the fillable interest form without signing the online consent to send information 
over the Internet. Appendix E includes all the content of the interest site and the participant webflow through the interest site.

\section{Home Page}

The MyGratefulSelf system was created with an emphasis on both usability and appeal, with the ultimate goal of creating an online environment that is engaging, effective, and secure. Once randomized into the experimental group, each participant was issued a username and password that was created by the system and sent to the participant via email. Once logged in, each participant is presented with a personalized "Home Page." (see Figure 2) that provides information based on the participant's progress in the MyGratefulSelf program. For example, a new participant would have a welcome page that directs them immediately to a "How to Use" module, while a participant who has been using the program would see a home page with day counter indicating their progress through the 21-day intervention. The left side of the screen contains the "Information Center" (see Figure 3). The Information Center allows for easy navigation to the journal function and back to home page. The "Alerts" section of the Information Center includes a "Messages" line which shows a random assortment of informational reminders and inspirational messages, and a "Journal" line which shows each user how many journal entries they have completed at the time of log in. In addition, the Information Center has tabbed links to the journal entry function and back to the Home Page.

There are three tabs at the bottom of the home page that participants are able to access at any time. New users are instructed to click the "How to Use" tab which brings 
them to a tutorial containing step-by-step instructions for navigating the program. The "Contact Us" tab provides contact information for the researchers. The "Disclaimer" tab reminds users that the activity provided is for supplemental use only and should not replace or override a physician's or mental health care provider's care.

\section{Journals}

When participants click on the "Journal" tab in the Information Center they are directed to a Calendar page (see Figure 4) that shows the 30 days within which their 21day intervention timeframe lies. There are instructions for how to use the calendar to access the daily journaling space, or to re-read previous journal entries. Participants are able to read but not edit previously submitted entries. Participants are instructed to click on the present day, or the previous day, on the calendar at which time they are directed to the journal page (see Figure 5) which includes the prompt, a writing box, and a "Submit" button. Once participants have reached Day 22 after first login, they see a new Home Page that instructs them that they have completed the intervention and will be able to access their journal again after they have completed the follow-up measures to arrive by email. Appendix $\mathrm{C}$ includes all content and user webflow through the MyGratefulSelf Intervention system and Appendix A includes the MyGratefulSelf study procedures.

\section{Emails}

The MyGratefulSelf study used both automated and manual emails. Automated emails were sent from the MyGratefulSelf system. Initial automated emails included an "Interest Form Received," email which is sent automatically after an interested candidate 
submits an interest form, and "Initial Contact" email that is sent after the PI reviewed the interest form and established initial eligibility, and "Online Consent" and "Online Consent Received" emails which are sent at the time of consent video chat and after the consent form is the signed. The "Online Consent Received" email includes a signed, dated, and stamped copy of the consent form for the participant's records. Intervention automated emails include a "Welcome" email that includes a username and password, two "Disuse Prompts" reminding participants to log in, and "Reminder" emails sent daily during the intervention timeframe. Appendix F includes timing and content of all automated and manual emails sent throughout the entire MyGratefulSelf study.

Specific Aim 1: To describe the feasibility (participant recruitment and retention) and acceptability of an on-line gratitude intervention designed specifically for young adults with advanced cancer.

\section{Participant Recruitment}

\section{Recruitment Strategy: Changes over Time}

After the development and testing of the MyGratefulSelf system, participant recruitment officially opened on 10/19/15. In August of 2015, prior to the official opening of recruitment, researchers built profiles on Facebook, Twitter, and Instagram and began to engage in the social networks. These profiles used the study logo as a profile picture and represented only the study, not the personal engagement of the researchers. During the pre-recruitment period, researchers posted articles of interest to young adults with cancer, pictures, and inspirational messages related to perseverance, gratitude, and young adult cancer topics. Additionally, researchers participated in twitter 
chats through the \#ayascm (adolescent and young adult social movement), \#bcsm (breast cancer social movement), \#lcsm (lung cancer social movement), and \#mayacc (metastatic and advanced young adult cancer community) networks. All efforts were made to engage in the existing social networks of young adults with cancer to try to build awareness and anticipation of the study among potential participants. Researchers continued to post and participate throughout the recruitment period.

At the opening of recruitment, MyGratefulSelf's Facebook page had 110 likes, mostly within the social network of the researcher. MyGratefulSelf's Twitter account had approximately 98 followers, almost exclusively users whose Twitter content related to cancer, young adult cancer, cancer research, or cancer advocacy, including some individual young adults with cancer. MyGratefulSelf's Instagram account had 50 followers, also mostly related to subject matter of the study.

At the start of the recruitment period, researchers posted an IRB approved recruitment poster (see Appendix G) and IRB approved social media posts, examples of which can be seen in Figures 6-10, on all social networking profiles letting followers know that recruitment was officially open. The IRB approved poster was also posted in the comments sections on public Facebook pages including, among others, Stupid Cancer, Young Survival Coalition, Young Adult Cancer Canada, and The Ulman Fund for Young Adults. The recruitment poster was shared by several Twitter accounts in addition to the study's own account including Medivizor, Young Survival Coalition, Critical Mass, and other young adult cancer researchers. Additionally, researchers contacted account administrators for other online forums including Stupid Cancer, The Ulman Fund for Young Adults, The Testicular Cancer Society, The Leukemia and 
Lymphoma Society, Hope and Cope, Cancer Fight Club, Young Adult Cancer Canada, The SamFund, Young Survival Coalition to post the recruitment poster on their websites, Facebook pages and Twitter accounts. Researchers also contacted young adult cancer programs at hospitals around the country in states including Massachusetts, New York, Texas, California, Washington, Oregon, Michigan, Minnesota, Ohio, Kentucky, Florida, Washington DC, and Pennsylvania to raise awareness for the study and engage clinicians to help with recruitment.

Over the course of the recruitment period, during 4 non-consecutive weeks, paid Facebook advertisements were used (see Figure 6). The Facebook ads, which were different during each week they were used, focused on (1) promoting the study's Facebook page, (2) promoting a post on the Facebook page that advertised the study itself, (3) a specific ad promoting the study, and (4) promoting the study website (www.mygratefulself.org). The total amount spent on Facebook ads was \$375.34. Combined, the paid Facebook advertisements reached a total of 60,863 people, and resulted in 124 website clicks, 130 page likes, and 318 post engagements (likes or comments). The average cost per engagement (clicks, likes, or comments) was $\$ 0.59$.

Over the course of the 4-month recruitment period, the researchers began personalizing the study's Instagram and Twitter accounts including personal photos and self-disclosure. This yielded several more followers and increased the researcher's ability to connect with individuals through the social networks, but may not have resulted in any study participation. By the end of the recruitment period, 02/19/2016, the study's Facebook page had 397 likes, the Twitter page had 245 followers, and the Instagram account had 84 followers. 
Over the first three months of recruitment, researchers attempted to contact administrators of private Facebook groups for disease and age specific cancers, to post the study poster with some limited success including Holly Kitchen and the Cancer Lifers, Metastatic Breast Cancer Network, and Cancer Fight Club. However, after several attempts to contact many group administrators, researchers were unable to gain access to these groups.

In the final six weeks of the recruitment period, the researcher began asking to join these private Facebook groups, introducing herself as a nursing doctoral student and explaining her interest in joining the group. She was welcomed by most groups, participated in those groups through comments and likes, and was able to post the recruitment poster directly on the discussion pages of these private groups so that it appeared on the newsfeeds of potential participants. The researcher joined a total of 31 private disease and age specific Facebook groups.

\section{Recruitment Results}

Recruitment took place over a 4-month period from October 2015 - February 2016. Overall, 26 potential participants expressed interest in the study. 24 completed online interest forms through the study website. 2 emailed the PI directly through the public study email address: mygratefulself@virginia.edu. By month, recruitment break down was as follows:

- October: 2 participants expressed interest

- November: 4 participants expressed interest

- December: 3 participants expressed interest

- January: 3 participants expressed interest 
- February: 14 participants expressed interest

A total of 19 participants were eventually enrolled in the study. Of those potential participants who expressed interest but were not enrolled, the reasons break down as follows:

- 3 were ineligible due to age or stage of cancer

- 4 decided not to participate in the study

- 1 because it "seemed like too much work"

- 1 because consent could not be completed easily on a mobile device

- 2 for unknown reasons

Based on self-report on the online interest form with confirmation at the time of consent, the ad venue of recruitment for each participant breaks down as follows:

- Paid Facebook Ads: 0

- MyGratefulSelf Facebook Page: 0

- Ads on Private Facebook Groups: 20

- Word of mouth facilitated by Social Networks: 3

- Twitter: 1

- Instagram: 0

- Other online forums: 2

\section{Participants}

A total of 19 participants were enrolled in the MyGratefulSelf study. All of the participants were self-identified through the study website's online interest form or 
through the study's public email address. Eligibility was confirmed for all participants through a video call with the PI using either Skype or FaceTime, depending on patient preference and all participants signed the online study consent form using their mouse.

Participant demographics are shown in Table 1.

Table 1: Participant Demographics

\begin{tabular}{|c|c|}
\hline \multicolumn{2}{|l|}{ Mean Age: 32.7 (21-39) } \\
\hline \multicolumn{2}{|c|}{ Mean Age at Dx: 30 (19-39) } \\
\hline & $n(\%)$ \\
\hline \multicolumn{2}{|l|}{ Gender } \\
\hline Male & $3(15.5)$ \\
\hline Female & $16(84.2)$ \\
\hline \multicolumn{2}{|l|}{ Ethnicity } \\
\hline Hispanic & $1(5.3)$ \\
\hline Non-Hispanic & $18(94.7)$ \\
\hline \multicolumn{2}{|l|}{ Race } \\
\hline White & $17(89.5)$ \\
\hline African-American & $1(5.3)$ \\
\hline Other & $1(5.3)$ \\
\hline \multicolumn{2}{|l|}{ Geographic Region } \\
\hline Northeast & $1(5.3)$ \\
\hline Mid-Atlantic & $6(31.6)$ \\
\hline Southeast & $3(15.8)$ \\
\hline Midwest & $2(10.5)$ \\
\hline Southwest & $1(5.3)$ \\
\hline West & $1(5.3)$ \\
\hline International & $5(26.3)$ \\
\hline \multicolumn{2}{|l|}{ Marital Status } \\
\hline Married/Partnered & $13(64.8)$ \\
\hline Single & $5(26.3)$ \\
\hline In a Relationship & $1(5.3)$ \\
\hline \multicolumn{2}{|l|}{ Dependent Children } \\
\hline Yes & $12(63.2)$ \\
\hline No & $7(36.8)$ \\
\hline \multicolumn{2}{|c|}{ Total Annual Household Income } \\
\hline$<10,000$ & $2(10.5)$ \\
\hline$\$ 21,000-30,999$ & $2(10.5)$ \\
\hline$\$ 31,000-50,999$ & $5(26.3)$ \\
\hline$\$ 51,000-99,999$ & $6(31.6)$ \\
\hline$>\$ 100,000$ & $4(21.1)$ \\
\hline \multicolumn{2}{|l|}{ Cancer Diagnosis } \\
\hline Breast & $9(47.4)$ \\
\hline Germ Cell Tumors & $2(10.5)$ \\
\hline Leukemia/Lymphoma & $1(5.3)$ \\
\hline
\end{tabular}




\begin{tabular}{|ll|}
\hline Colon & $2(10.5)$ \\
\hline Other & $6(26.3)$ \\
\hline Current Cancer Stage & \\
\hline III & $5(26.3)$ \\
\hline IV & $14(73.3)$ \\
\hline ECOG Score & \\
\hline 2 & $11(57.9)$ \\
\hline 3 & $8(42.1)$ \\
\hline
\end{tabular}

Additionally, 10 participants (52.6\%) had experienced a relapse of their disease prior to entering the study. All participants were considered to have metastatic or advanced disease depending on their disease-specific staging. 14 participants $(73.7 \%)$ were currently on active treatment, 0 were on a drug trial, and $1(5.3 \%)$ participant was receiving experimental treatment that was not under FDA supervision. 2 participants $(10.5 \%)$ were ever seen or consulted by a palliative care team, and 18 participants (94.7\%) had health insurance. Cancers in the "other" category include: renal cell carcinoma (1 participant $(5.3 \%)$, cervical cancer (2 participants $(10.5 \%)$, thyroid cancer (1 participants $(5.3 \%)$, pancreatic cancer (1 participant $(5.3 \%)$, and uterine cancer $(1$ participant (5.3\%). One participant was diagnosed with both breast and thyroid cancer at the time of her consent.

\section{Attrition}

3 participants were lost follow-up. Two participants ( 1 experimental, 1 control) dropped out during the intervention timeframe, completing only the initial measures. A third participant in the control group was lost to follow-up during the 30-day day followup period, completing the pre- and post-intervention measures, but not the 30 -day followup measures. Total attrition for this study was $15.8 \%$. Figure 11 is a full CONSORT diagram outlining the total study participation: 


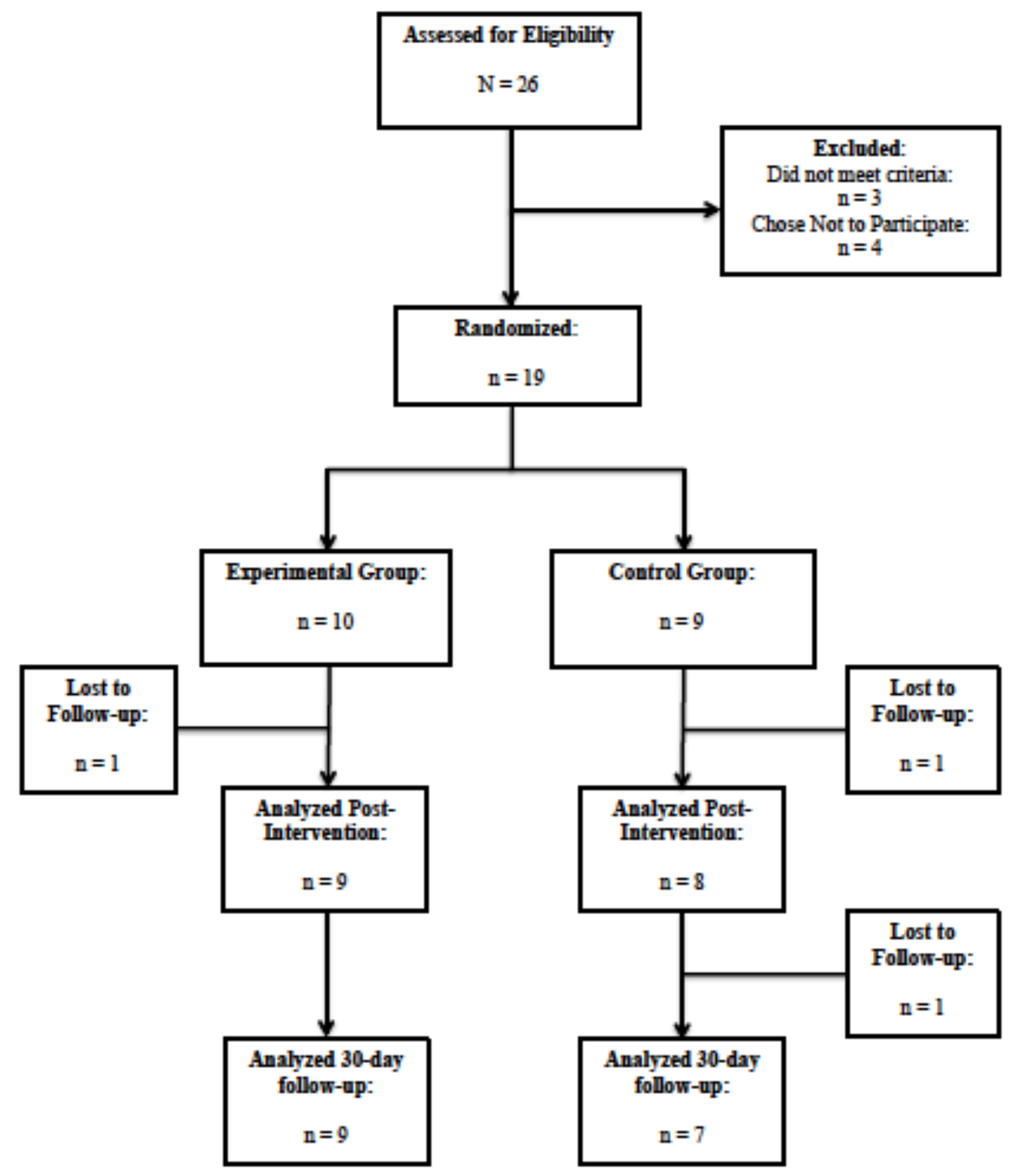

Fidelity of Intervention

Participants were instructed to write in their online journals daily for 21-days and received daily email reminders to write. However, given the circumstances of this 
population including potential for worsening illness, hospitalization, and death, researchers sought to evaluate how many times during the 21-day period, participants were actually able to $\log$ in to the system and write. Additionally, to explore any relationship between length of entry and secondary outcome measures, researchers collected average word count for all journal entries. The mean number of times participants logged in to write was 13 (range 1-21), including one participant who dropped out of the study after only writing once. The mean number of times participants logged in to write, not including the participant who dropped out of the study was 14.3 (range 5-21). The average word count for all journal entries was 185.9 (range 2-996) with most journal entries falling in the range of $150-400$ words.

Although the content of the journals has not been formally analyzed, there are some deviations in content from the instructed prompt with several entries falling more in line with general expressive writing than reflection on gratitude. Occasional journal entries also included negative emotional expression described by the participant as "venting."

\section{Intervention Usability}

Utility of the MyGratefulSelf system was evaluated using the Internet Evaluation and Utility Questionnaire (Ritterband et al., 2008; Thorndike et al., 2008). Complete results of this questionnaire are in Table 2. Overall the intervention was well received by participants. All of the participants (9/9) indicated that the program was mostly or very easy to use (ratings of 3 and 4 on the $0-4$ Likert scale, respectively), and 89\% (8/9 participants) described it as mostly or very convenient to use. $89 \%$ (8/9 participants) 
indicated that the program was mostly or very enjoyable to use and 77\% (7/9

participants) said they thought that the Internet was a mostly or very good way of delivering this intervention. Additionally, $89 \%$ (8/9 participants) were only slightly or not at all worried about their privacy while using the program. 89\% (8/9 participants) felt that the program was a somewhat, mostly, or very good fit for them and 77\% (7/9 participants) reported that the program somewhat, mostly, or very much kept their interest, with the most common comment regarding interest being a desire for more and varying writing prompts.

\section{Table 2: Internet Evaluation and Utility Questionnaire}

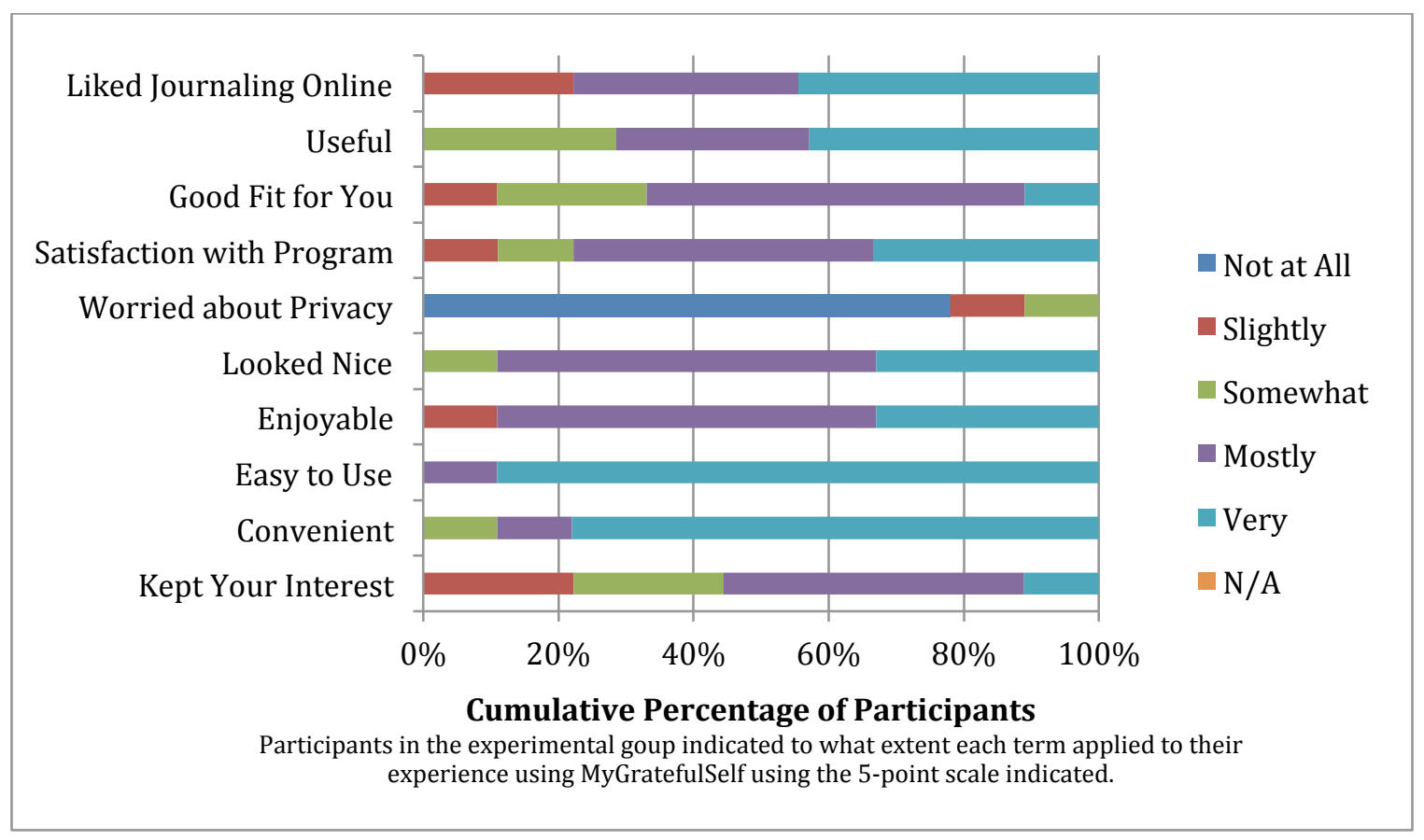

Open Ended Questions: Responses

\section{What was the most helpful part of the program?}

1. The daily announcements to that I knew I had reached the end of the journaling aspect. 
2. I think the most helpful part of the web program is the ability to deliver it over a distance with little cost.

3. The example of how you could word out your feelings above the empty box.

4. I thought it was helpful to have the reminder to write.

5. It was a safe way to say whatever is on your mind.

6. It was very easy to use and it forced me to really think about things that were maybe not just on a surface level. While I thought about just writing a sentence sometimes, I would write things that would make me think and try to get my feelings out.

7. Reassessing the day.

\section{What was the least helpful part of the program?}

1. I think that if the prompts changed a bit from day to day, it would have peaked more interest...meaning having a different topic or focus based around the concept of being grateful or mindful.

2. For me, typing my journal entries into a computer was not as meaningful as handwriting entries into a journal. I'm not sure why other than writing in a book kind of feels like putting something in a box or in it's place whereas typing into an online journal did not give me the same positive feeling. I felt disconnected from my online journal. In many ways, the web journal was very convenient, but for me, it didn't offer the same convenience as a physical journal. I keep my journal in the place where I typically end my day and it fits well into my bedtime routine. In contrast, making entries into the web program meant locating my password and moving to the computer. I don't typically feel like sitting at the computer right 
before bed, so doing the entries meant trying to find time during the day.

Although, I could have made my entries on my phone or iPad, it would have been difficult without a keyboard and that's why I opted for the computer.

3. I liked it a lot. As a visual learner, I would suggest to add something like more color, graphics or nature pictures, or something that makes it look more like your "safe haven" journal.

4. I wished I could go back more than one day to write, I had days I wasn't able to write but I wanted to reflect on things and would have gone back to write more.

5. I would have liked different prompts everyday. It would have made it more interesting for me.

6. On days when I was stuck for something to write, the prompt which was meant to 'inspire' a thought to write about never changed, it was always the same which I found frustrating. While I understand that I was supposed to find something to be grateful for to write about, the website was meant for young adults who have/have had cancer and I know that I am not the only person who struggles and I think having some different thoughts to write about for those about us when we're stuck for things to write about- or when we're in a really low place.

7. Making an entry online only. I'm more a pen and paper, or audio recording, than type only person, unless its text or chat.

Specific Aim 2: To assess the preliminary effect of participating in an on-line gratitude intervention on well-being and emotional experience in young adults with advanced cancer. 


\section{Preliminary Efficacy Results}

\section{Baseline Statistics}

Demographics and baseline measures were collected from all consenting participants at the time of consent, prior to randomization into the experimental or control group. Data were analyzed using SPSS v. 22. The data were assessed for normality and found to be skewed, likely due to the small sample size. Level of significance for all analyses was set at $\leq 0.05$.

Mann-Whitney U tests were used to determine group equivalence for continuous demographic data including current age and age at diagnosis. There was no difference between the experimental and control group on current age $(p=0.497)$ or age at diagnosis $(p=0.720)$.

Chi-square tests were used to determine group equivalence for categorical demographic data. There was no difference between groups in any categorical demographic variables. Table 3 shows significance levels for all categorical demographic data.

Table 3: Group Equivalence

\begin{tabular}{|lll|}
\hline & Pearson's Chi-Square & $p$-value \\
\hline Gender & 0.532 & 0.466 \\
\hline Ethnicity & 0.950 & 0.330 \\
\hline Race & 2.012 & 0.366 \\
\hline Geographic Region & 5.496 & 0.482 \\
\hline Marital Status & 1.845 & 0.398 \\
\hline Dependent Children & 0.425 & 0.515 \\
\hline Health Insurance & 0.950 & 0.330 \\
\hline Total Household Income & 4.827 & 0.305 \\
\hline Cancer Diagnosis & 3.268 & 0.514 \\
\hline Stage at Diagnosis & 6.823 & 0.078 \\
\hline Current Stage & 0.148 & 0.701 \\
\hline Relapsed Disease & 0.059 & 0.809 \\
\hline Active Treatment & 2.898 & 0.089 \\
\hline Palliative Care & 0.006 & 0.937 \\
\hline ECOG Score & 0.038 & 0.845 \\
\hline
\end{tabular}


Mann Whitney $U$ tests were used to determine group equivalence on all baseline outcome measures. There was no difference between the experimental group and the control group on any of the baseline outcome measures. Table 4 shows the means and standard deviations for all baseline outcome measures for both the experimental and control groups as well as p-values.

Table 4: Baseline Means $\pm S D$ and Group Equivalence

\begin{tabular}{|llll|}
\hline Measure & $\begin{array}{l}\text { Experimental Group } \\
\text { Mean } \pm \text { SD }\end{array}$ & $\begin{array}{l}\text { Control Group } \\
\text { Mean } \pm \text { SD }\end{array}$ & $p$-value \\
\hline Health Literacy & $5.20 \pm 1.69$ & $4.00 \pm 1.12$ & 0.133 \\
\hline ECOG Score & $2.40 \pm 0.52$ & $2.44 \pm 0.53$ & 0.845 \\
\hline Gratitude Questionnaire & $27.8 \pm 5.1$ & $29.44 \pm 1.5$ & 0.243 \\
\hline Mindful Observation & $25.7 \pm 4.1$ & $26.89 \pm 4.1$ & 0.549 \\
\hline mDES Positive Emotion Subscale & $27.9 \pm 8.1$ & $25.89 \pm 5.7$ & 0.549 \\
\hline mDES Negative Emotion Subscale & $21.2 \pm 5.9$ & $22.56 \pm 6.9$ & 0.780 \\
\hline PANAS Positive Affect Subscale & $31.8 \pm 9.8$ & $28.33 \pm 4.3$ & 0.278 \\
\hline PANAS Negative Affect Subscale & $24.2 \pm 8.7$ & $27.78 \pm 7.9$ & 0.356 \\
\hline Self-Acceptance & $24.7 \pm 7.9$ & $26.33 \pm 6.3$ & 0.720 \\
\hline Purpose in Life & $30.2 \pm 8.3$ & $31.44 \pm 3.5$ & 0.968 \\
\hline Positive Relations with Others & $30.7 \pm 6.4$ & $29.00 \pm 4.9$ & 0.497 \\
\hline Personal Growth & $35.7 \pm 3.9$ & $35.89 \pm 3.4$ & 0.661 \\
\hline Environmental Mastery & $25.5 \pm 6.9$ & $24.67 \pm 7.1$ & 0.905 \\
\hline Autonomy & $32.9 \pm 4.7$ & $29.22 \pm 2.7$ & 0.113 \\
\hline
\end{tabular}

With a score of 10-15 on SBSQ-D representing a limited level of health literacy and a score of 9 being the cutoff for adequate health literacy, participants in both groups demonstrated excellent health literacy (Chew et al., 2004; Sarkar, Schillinger, López, \& Sudore, 2011). There was no difference between groups on health literacy.

ECOG scores for both groups hovered between 2 and 3, with each participant scoring 2 or 3 . This indicates that the average level of functioning for the total sample was around $50 \%$. Participants may have been able to perform self-care duties but were often confined to bed or chair, and were not able to work due to increased levels of pain 
and fatigue associated with ongoing treatments and significant disease burden (Oken et al., 1982).

At baseline, participants in both groups scored above average for their age groups on negative emotion (Fredrickson et al., 2003) and negative affect (Watson et al., 1988).

Of note, participants in both groups scored approximately 1.5-2 SD above the average range for their age group on negative affect (Watson et al., 1988). Additionally, at baseline, all participants scored below average for gratitude (Emmons \& McCullough, 2003a; McCullough et al., 2002), positive emotion (Watson et al., 1988), and positive affect (Fredrickson et al., 2003). Both groups scored within the average range for nonmeditating samples on the mindful observation subscale of the Five-Facet Mindfulness Scale (Baer et al., 2006; Baer et al., 2008). Participants in both groups scored below the average range for their age group on all subscales of the Ryff Psychological Well-Being scales, scoring, on average, $1-1.5$ SD below the norm for all scales except Personal Growth (Ryff, Seeman, \& Weinstein, 2013).

\section{Post-Intervention Efficacy Results}

Post-intervention measures were collected 21 days after randomization into the experimental or control group. Data were assessed for normality and found to be skewed due to small sample size. Two-way repeated measures ANOVA were conducted for each outcome measure to determine significance of any interaction effects of treatment group and time. No significant interactions were found for any of the secondary outcome measures.

Because the data were skewed, further analyses were conducted using nonparametric statistics. Wilcoxon matched pairs signed rank tests were used to determine 
differences in each outcome measure pre- and post-intervention for both the experimental and control groups. Mann Whitney U tests were used to determine post-intervention differences in each outcome measure between the experimental and control groups. Level of significance was set at $\leq 0.05$.

Those in the experimental group saw significant improvement in gratitude, mindful observation, negative emotion, negative affect, self-acceptance and personal growth. Means and standard deviations for all outcomes in the experimental group are shown in Table 5.

Table 5: Experimental Group Outcome Measures Pre v. Post-Intervention

\begin{tabular}{|llll|}
\hline Measure & $\begin{array}{l}\text { Pre-Intervention } \\
\text { Mean } \pm \text { SD }\end{array}$ & $\begin{array}{l}\text { Post- } \\
\text { Intervention } \\
\text { Mean } \pm \text { SD }\end{array}$ & $p$-value \\
\hline Gratitude Questionnaire & $27.8 \pm 5.1$ & $34.2 \pm 4.8$ & $0.043 * *$ \\
\hline Mindful Observation & $25.7 \pm 4.1$ & $31.3 \pm 4.5$ & $0.012^{* *}$ \\
\hline mDES Positive Emotion Subscale & $27.9 \pm 8.1$ & $32.1 \pm 10.5$ & 0.085 \\
\hline mDES Negative Emotion Subscale & $21.2 \pm 5.9$ & $16.3 \pm 5.6$ & $0.042^{* *}$ \\
\hline PANAS Positive Affect Subscale & $31.8 \pm 9.8$ & $35.7 \pm 10.1$ & 0.123 \\
\hline PANAS Negative Affect Subscale & $24.2 \pm 8.7$ & $17.9 \pm 5.6$ & $0.007 * *$ \\
\hline Self-Acceptance & $24.7 \pm 7.9$ & $30 \pm 9.1$ & $0.011 * *$ \\
\hline Purpose in Life & $30.2 \pm 8.3$ & $31.7 \pm 6.6$ & 0.553 \\
\hline Positive Relations with Others & $30.7 \pm 6.4$ & $31.7 \pm 6.9$ & 0.405 \\
\hline Personal Growth & $35.7 \pm 3.9$ & $38.1 \pm 2.4$ & $0.035^{* *}$ \\
\hline Environmental Mastery & $25.5 \pm 6.9$ & $27.7 \pm 9.5$ & 0.285 \\
\hline Autonomy & $32.9 \pm 4.7$ & $33.2 \pm 5.7$ & 0.779 \\
\hline
\end{tabular}

$* *$ = significant $p$-value

Those in the control group saw significant improvement only in Positive Relations with others $(p=0.041)$. Means and standard deviations for all outcomes in the control group are reported in Table 6.

Table 6: Control Group Outcome Measures Pre-v. Post-Intervention

\begin{tabular}{|llll|}
\hline Measure & $\begin{array}{l}\text { Pre-Intervention } \\
\text { Mean } \pm \text { SD }\end{array}$ & $\begin{array}{l}\text { Post-Intervention } \\
\text { Mean } \pm \text { SD }\end{array}$ & $p$-value \\
\hline Gratitude Questionnaire & $29.44 \pm 1.5$ & $30.13 \pm 2.4$ & 0.498 \\
\hline Mindful Awareness & $26.89 \pm 4.1$ & $26.00 \pm 2.5$ & 0.861 \\
\hline mDES Positive Emotion Subscale & $25.89 \pm 5.7$ & $26.25 \pm 6.6$ & 0.672 \\
\hline mDES Negative Emotion Subscale & $22.56 \pm 6.9$ & $24.75 \pm 5.7$ & 0.400 \\
\hline
\end{tabular}




\begin{tabular}{|llll|}
\hline PANAS Positive Affect Subscale & $28.33 \pm 4.3$ & $28.63 \pm 6.7$ & 0.888 \\
\hline PANAS Negative Affect Subscale & $27.78 \pm 7.9$ & $31.13 \pm 6.9$ & 0.440 \\
\hline Self-Acceptance & $26.33 \pm 6.3$ & $26.63 \pm 7.4$ & 0.891 \\
\hline Purpose in Life & $31.44 \pm 3.5$ & $29.38 \pm 3.1$ & 0.395 \\
\hline Positive Relations with Others & $29.00 \pm 4.9$ & $30.63 \pm 5.7$ & $0.041^{* *}$ \\
\hline Personal Growth & $35.89 \pm 3.4$ & $35.50 \pm 3.4$ & 0.490 \\
\hline Environmental Mastery & $24.67 \pm 7.1$ & $23.13 \pm 6.3$ & 0.344 \\
\hline Autonomy & $29.22 \pm 2.7$ & $30.63 \pm 2.4$ & 0.168 \\
\hline
\end{tabular}

$* *=$ significant $p$-value

At baseline, there were no differences between groups on any outcome measures.

Post-intervention, the experimental group scored significantly higher on gratitude and mindful observation, and significantly lower on negative affect and negative emotion.

Additionally, post-intervention, those in the experimental group scored within the average range for their age group in negative affect (Watson et al., 1988). Means and standard deviations for all outcome measures pre- and post-intervention for both groups are reported in Table 7.

Table 7: Experimental and Control Group Outcomes Pre-v. Post-Intervention

\begin{tabular}{|lllllll|}
\hline Measure & $\begin{array}{l}\text { Pre-Mean: } \\
\text { Exp. } \pm \text { SD }\end{array}$ & $\begin{array}{l}\text { Pre-Mean: } \\
\text { Control } \pm \text { SD }\end{array}$ & $\begin{array}{l}p \text {-value } \\
\text { Gratitude }\end{array}$ & $\begin{array}{l}\text { Post-Mean: } \\
\text { Exp: } \pm \text { SD }\end{array}$ & $\begin{array}{l}\text { Post-Mean: } \\
\text { Control } \pm \text { SD }\end{array}$ & $p$-value \\
Questionnaire & $27.8 \pm 5.1$ & $29.44 \pm 1.5$ & 0.243 & $34.22 \pm 4.8$ & $30.13 \pm 2.4$ & $0.036^{* *}$ \\
\hline $\begin{array}{l}\text { Mindful } \\
\text { Awareness }\end{array}$ & $25.7 \pm 4.1$ & $26.89 \pm 4.1$ & 0.549 & $31.33 \pm 4.5$ & $26 \pm 2.5$ & $0.011^{* *}$ \\
\hline $\begin{array}{l}\text { mDES Positive } \\
\text { Emotion Subscale }\end{array}$ & $27.9 \pm 8.1$ & $25.89 \pm 5.7$ & 0.549 & $32.11 \pm 10.5$ & $26.25 \pm 6.6$ & 0.200 \\
\hline $\begin{array}{l}\text { mDES Negative } \\
\text { Emotion Subscale }\end{array}$ & $21.2 \pm 5.9$ & $22.56 \pm 6.9$ & 0.780 & $16.33 \pm 5.6$ & $24.75 \pm 5.7$ & $0.006^{* *}$ \\
\hline $\begin{array}{l}\text { PANAS Positive } \\
\text { Affect Subscale }\end{array}$ & $31.8 \pm 9.8$ & $28.33 \pm 4.3$ & 0.278 & $35.67 \pm 10.1$ & $28.63 \pm 6.7$ & 0.167 \\
\hline $\begin{array}{l}\text { PANAS Negative } \\
\text { Affect Subscale }\end{array}$ & $24.2 \pm 8.7$ & $27.78 \pm 7.9$ & 0.356 & $17.89 \pm 5.6$ & $31.13 \pm 6.9$ & $0.001^{* *}$ \\
\hline Self-Acceptance & $24.7 \pm 7.9$ & $26.33 \pm 6.3$ & 0.720 & $30.0 \pm 9.1$ & $26.63 \pm 7.4$ & 0.370 \\
\hline Purpose in Life & $30.2 \pm 8.3$ & $31.44 \pm 3.5$ & 0.968 & $31.67 \pm 6.6$ & $29.38 \pm 3.1$ & 0.200 \\
\hline $\begin{array}{l}\text { Positive Relations } \\
\text { with Others }\end{array}$ & $30.7 \pm 6.4$ & $29.00 \pm 4.9$ & 0.497 & $31.67 \pm 6.9$ & $30.63 \pm 5.7$ & 0.815 \\
\hline $\begin{array}{l}\text { Personal Growth } \\
35.7 \pm 3.9\end{array}$ & $35.89 \pm 3.4$ & 0.661 & $38.11 \pm 2.4$ & $35.50 \pm 3.4$ & 0.093 \\
\hline $\begin{array}{l}\text { Environmental } \\
\text { Mastery }\end{array}$ & $25.5 \pm 6.9$ & $24.67 \pm 7.1$ & 0.905 & $27.67 \pm 9.5$ & $23.13 \pm 6.3$ & 0.236 \\
\hline Autonomy & $32.9 \pm 4.7$ & $29.22 \pm 2.7$ & 0.113 & $33.22 \pm 5.7$ & $30.63 \pm 2.4$ & 0.481 \\
\hline
\end{tabular}

$* *=$ significant $p$-value 
Effects sizes were calculated and presented for all measures because small sample sizes pose limitations to significance testing (Kline, 2004). Pre- to post-intervention effect sizes were computed as standardized mean differences (SMD) using means and pooled baseline SDs and Hedge's correction for small sample size (Durlak, 2009). These SMDs by group were used to compute an overall adjusted treatment effect size to account for changes in both groups with one statistic. The adjusted effect size was computed by subtracting the control group pre-post SMD from the experimental group pre-post SMD (Durlak, 2009). All effect sizes are presented so that a positive ES indicates improvement on the measure and negative ES indicates worsening on that measure. Results are reported using completer's analysis.

Using Cohen's convention (Cohen, 1992), large effect sizes were seen in gratitude, mindful observation, negative emotion, and negative affect. Medium effect sizes were seen in positive emotional experience, self-acceptance, purpose in life, personal growth, and environmental mastery. Of note, a negative effect size was detected in positive relations with others and autonomy, meaning that the control group improved more than the experimental group on those measures. This may be due to wide statistical variations related to the small sample size or could be related to changes in life circumstances within the control group that could not be controlled for in the study. Table 8: All Post-Intervention Outcome Measure Effect Sizes by Treatment Condition

\begin{tabular}{|c|c|c|c|c|c|c|}
\hline \multirow[b]{2}{*}{ Measure } & \multicolumn{2}{|c|}{ Experimental Group $(n=9)$} & \multicolumn{2}{|c|}{ Control Group $(n=7)$} & \multirow[b]{2}{*}{$p$-value ${ }^{c}$} & \multirow[b]{2}{*}{$\begin{array}{l}\text { Overall } \\
\text { Adjusted } \\
\text { ES }\end{array}$} \\
\hline & Mean $\pm \mathrm{SD}$ & $\begin{array}{l}\text { Within-Group } \\
\text { ES (d) }\end{array}$ & Mean \pm SD & $\begin{array}{l}\text { Within- } \\
\text { Group ES } \\
\text { (d) }\end{array}$ & & \\
\hline \multicolumn{7}{|l|}{$\begin{array}{l}\text { Gratitude } \\
\text { Questionnaire }\end{array}$} \\
\hline Pre-Intervention & $27.8 \pm 5.1$ & 1.58 & $29.44 \pm 1.5$ & .18 & $0.036 * *$ & 1.40 \\
\hline Post-Intervention & $34.2 \pm 4.8^{b}$ & & $30.13 \pm 2.4$ & & & \\
\hline $\begin{array}{l}\text { Mindful } \\
\text { Observation }\end{array}$ & & & & & & \\
\hline
\end{tabular}




\begin{tabular}{|c|c|c|c|c|c|c|}
\hline Pre-Intervention & $25.7 \pm 4.1$ & 1.30 & $26.89 \pm 4.1$ & -0.21 & $0.011 * *$ & 1.51 \\
\hline Post-Intervention & $31.3 \pm 4.5^{b}$ & & $26.00 \pm 2.5$ & & & \\
\hline \multicolumn{7}{|l|}{$\begin{array}{l}\text { mDES Positive } \\
\text { Emotion Subscale }\end{array}$} \\
\hline Pre-Intervention & $27.9 \pm 8.1$ & 0.58 & $25.89 \pm 5.7$ & 0.05 & 0.200 & 0.53 \\
\hline Post-Intervention & $32.1 \pm 10.5$ & & $26.25 \pm 6.6$ & & & \\
\hline \multicolumn{7}{|l|}{$\begin{array}{l}\text { mDES Negative } \\
\text { Emotion Subscale }\end{array}$} \\
\hline Pre-Intervention & $21.2 \pm 5.9$ & 0.72 & $22.56 \pm 6.9$ & -0.32 & $0.006 * *$ & 1.04 \\
\hline Post-Intervention & $16.3 \pm 5.6^{b}$ & & $24.75 \pm 5.7$ & & & \\
\hline \multicolumn{7}{|l|}{$\begin{array}{l}\text { PANAS Positive } \\
\text { Affect Subscale }\end{array}$} \\
\hline Pre-Intervention & $31.8 \pm 9.8$ & 0.48 & $28.33 \pm 4.3$ & 0.04 & 0.167 & 0.44 \\
\hline Post-Intervention & $35.7 \pm 10.1$ & & $28.63 \pm 6.7$ & & & \\
\hline \multicolumn{7}{|l|}{$\begin{array}{l}\text { PANAS Negative } \\
\text { Affect Subscale }\end{array}$} \\
\hline Pre-Intervention & $24.2 \pm 8.7$ & 0.72 & $27.78 \pm 7.9$ & -0.37 & $0.001 * *$ & 1.09 \\
\hline Post-Intervention & $17.9 \pm 5.6^{b}$ & & $31.13 \pm 6.9$ & & & \\
\hline \multicolumn{7}{|l|}{ Self-Acceptance } \\
\hline Pre-Intervention & $24.70 \pm 7.9$ & 0.71 & $26.33 \pm 6.3$ & 0.04 & 0.370 & 0.67 \\
\hline Post-Intervention & $30 \pm 9.1^{\mathrm{b}}$ & & $26.63 \pm 7.4$ & & & \\
\hline \multicolumn{7}{|l|}{ Purpose in Life } \\
\hline Pre-Intervention & $30.2 \pm 8.3$ & 0.23 & $31.44 \pm 3.5$ & -0.31 & 0.200 & 0.54 \\
\hline Post-Intervention & $31.7 \pm 6.6$ & & $29.38 \pm 3.1$ & & & \\
\hline \multicolumn{7}{|l|}{$\begin{array}{l}\text { Positive Relations } \\
\text { with Others }\end{array}$} \\
\hline Pre-Intervention & $30.7 \pm 6.4$ & 0.17 & $29.00 \pm 4.9$ & 0.27 & 0.815 & -0.10 \\
\hline Post-Intervention & $31.7 \pm 6.9$ & & $\begin{array}{l}30.63 \pm \\
5.7^{\mathrm{b}}\end{array}$ & & & \\
\hline \multicolumn{7}{|l|}{ Personal Growth } \\
\hline Pre-Intervention & $35.7 \pm 3.9$ & 0.63 & $35.89 \pm 3.4$ & -0.11 & 0.093 & 0.74 \\
\hline Post-Intervention & $38.1 \pm 2.4^{b}$ & & $35.50 \pm 3.4$ & & & \\
\hline \multicolumn{7}{|l|}{$\begin{array}{l}\text { Environmental } \\
\text { Mastery }\end{array}$} \\
\hline Pre-Intervention & $25.5 \pm 6.9$ & 0.30 & $24.67 \pm 7.1$ & -0.21 & 0.236 & 0.51 \\
\hline Post-Intervention & $27.7 \pm 9.5$ & & $23.13 \pm 6.3$ & & & \\
\hline \multicolumn{7}{|l|}{ Autonomy } \\
\hline Pre-Intervention & $32.9 \pm 4.7$ & 0.07 & $29.22 \pm 2.7$ & 0.32 & 0.481 & -0.25 \\
\hline Post Intervention & $33.2 \pm 5.7$ & & $30.63 \pm 2.4$ & & & \\
\hline
\end{tabular}

\section{Sustainability of Efficacy:}

Follow up measures were collected 30 days after completion of the intervention timeframe, or 51 days after randomization. At that time, participants in the experimental 
group were asked if they were still using the MyGratefulSelf program and/or if they were still keeping a journal, or making lists or notes related to gratitude. None of the participants continued to use the MyGratefulSelf program, however 55.5\% (5/9 participants) reported that they were continuing to journal or write on a regular basis. Their comments were as follows:

1. I have not [continued to use MyGratefulSelf]. I have been posting and sharing what I am going through on FB, and set up a new group page today.

2. I started keeping a journal outside of my grateful self. I have found a [hand] written journal to be most helpful for me. I strive to journal daily, but lately, I've been doing it on a weekly basis.

3. Not on the website, but ever since I did this, I write or print positive notes and put them on my computer monitor to remind me of good things.

4. I have not continued to use mygratefulself.com - I enjoyed the email reminders since I don't have anyone else to remind me to journal. I have been journaling outside of the website but without the reminder about positivity its difficult not to veer off into the very dark space.

5. I have not continued to use this program. I have continued journaling multiple times per week and I am even getting a few articles published soon!

The quantitative data were assessed for normality and found to be skewed due to small sample size. Wilcoxon matched pairs signed rank tests were used to determine differences in each outcome measure from pre-intervention to 30-day follow-up for both the experimental and control groups. Mann Whitney U tests were used to determine differences in each outcome measure at the 30-day follow-up between the experimental 
and control groups. Level of significance was set at $\leq 0.05$.

There were no significant differences in any outcome measures from preintervention to 30-day follow-up for the control group and the only significant difference for the experimental group was Gratitude $(p=0.021)$. Means and standard deviations for both groups at baseline and 30-day follow-up are reported in table 9.

Table 9: Experimental and Control Group Outcomes Pre- Intervention v. 30-day FollowUp

\begin{tabular}{|lllllll|}
\hline Measure & $\begin{array}{l}\text { Exp Pre- } \\
\text { Mean } \pm \\
\text { SD }\end{array}$ & $\begin{array}{l}\text { Exp 30-day } \\
\text { Mean } \pm \text { SD }\end{array}$ & $\begin{array}{l}p \text {-value } \\
\text { Gratitude Questionnaire }\end{array}$ & $\begin{array}{l}\text { Con Pre- } \\
\text { Mean: } \pm \\
\text { SD }\end{array}$ & $\begin{array}{l}\text { Con 30- } \\
\text { day Mean: } \\
\pm \text { SD }\end{array}$ & $\begin{array}{l}p \text { - } \\
\text { value }\end{array}$ \\
\hline Mindful Observation & $27.8 \pm 5.1$ & $35.00 \pm 6.3$ & $0.021 * *$ & $29.44 \pm 1.5$ & $31.00 \pm 1.7$ & 0.344 \\
\hline $\begin{array}{l}\text { mDES Positive Emotion } \\
\text { Subscale }\end{array}$ & $27.9 \pm 8.1$ & $34.78 \pm 11.5$ & 0.066 & $25.89 \pm 5.7$ & $28.00 \pm 6.3$ & 0.344 \\
\hline $\begin{array}{l}\text { mDES Negative Emotion } \\
\text { Subscale }\end{array}$ & $21.2 \pm 5.9$ & $16.67 \pm 7.7$ & 0.260 & $22.56 \pm 6.9$ & $24.14 \pm 5.3$ & 0.865 \\
\hline $\begin{array}{l}\text { PANAS Positive Affect } \\
\text { Subscale }\end{array}$ & $31.8 \pm 9.8$ & $35.56 \pm 12.2$ & 0.286 & $28.33 \pm 4.3$ & $29.43 \pm 7.9$ & 0.396 \\
\hline $\begin{array}{l}\text { PANAS Negative Affect } \\
\text { Subscale }\end{array}$ & $24.2 \pm 8.7$ & $17.89 \pm 7.7$ & 0.262 & $27.78 \pm 7.9$ & $29.86 \pm 7.1$ & 0.344 \\
\hline Self-Acceptance & $24.7 \pm 7.9$ & $28.78 \pm 10.5$ & 0.374 & $26.33 \pm 6.3$ & $26.57 \pm 2.9$ & 0.271 \\
\hline Purpose in Life & $30.2 \pm 8.3$ & $30.78 \pm 7.6$ & 0.726 & $31.44 \pm 3.5$ & $30.57 \pm 4.7$ & 0.528 \\
\hline Positive Relations with Others & $30.7 \pm 6.4$ & $31.89 \pm 6.2$ & 0.678 & $29.00 \pm 4.9$ & $30.43 \pm 5.9$ & 0.270 \\
\hline Personal Growth & $35.7 \pm 3.9$ & $37.22 \pm 4.8$ & 0.397 & $35.89 \pm 3.4$ & $34.14 \pm 4.8$ & 0.400 \\
\hline Environmental Mastery & $25.5 \pm 6.9$ & $29.56 \pm 8.1$ & 0.260 & $24.67 \pm 7.1$ & $24.71 \pm 3.9$ & 0.734 \\
\hline Autonomy & $32.9 \pm 4.7$ & $34.89 \pm 5.7$ & 0.514 & $29.22 \pm 2.7$ & $29.57 \pm 2.6$ & 0.933 \\
\hline
\end{tabular}

$* *$ = significant $p$-value

While at post-intervention there were significant differences between groups in gratitude, mindful observation, negative emotion, and negative affect, at the 30-day follow-up there were only significant differences between groups in gratitude $(p=0.016)$ and negative affect $(p=0.012)$. Figures $11-22$ show mean changes over time in both the experimental and control groups for each of the outcome measures. 
Figure 11: Mean Gratitude Over Time

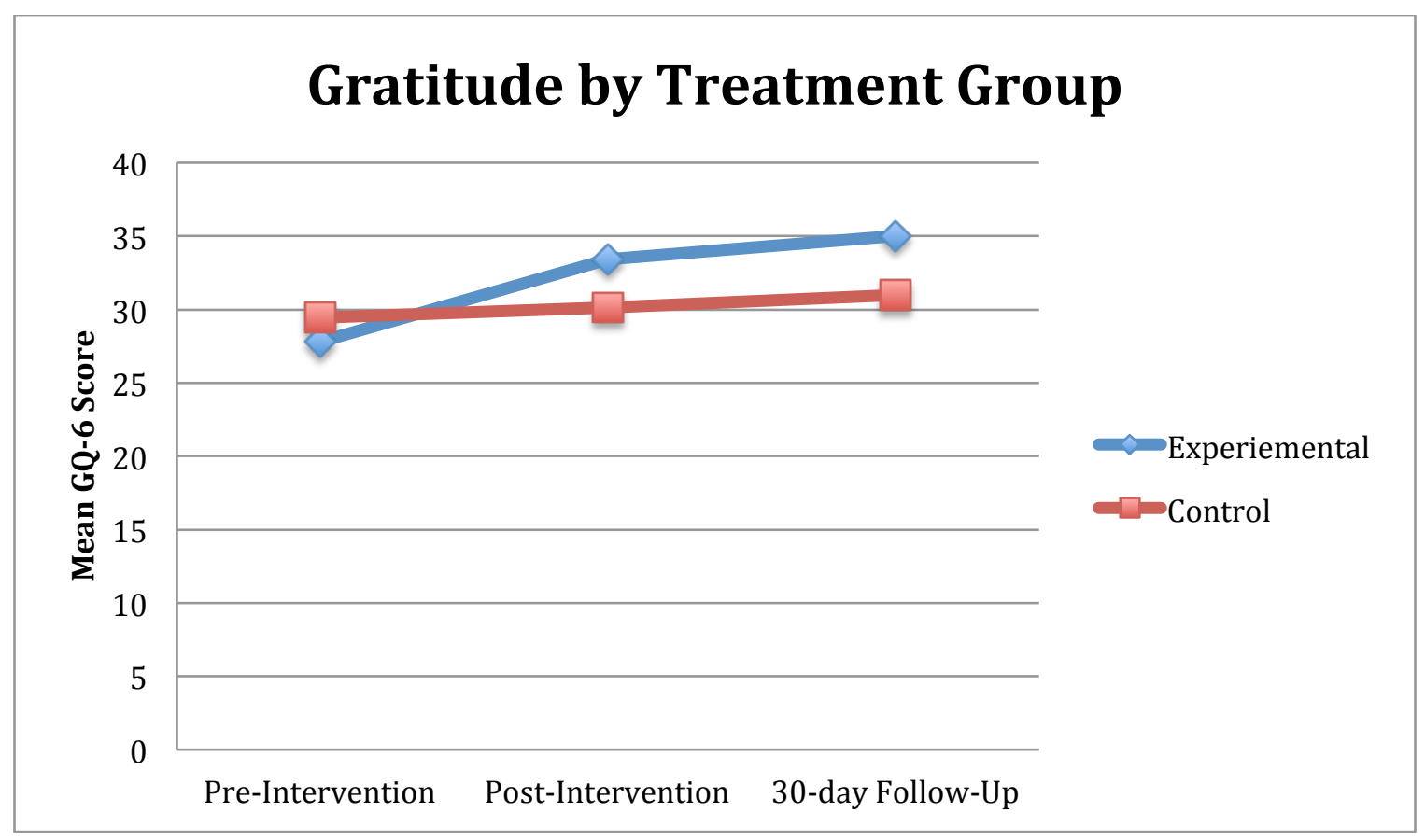

Figure 12: Mean Mindful Observation Over Time 


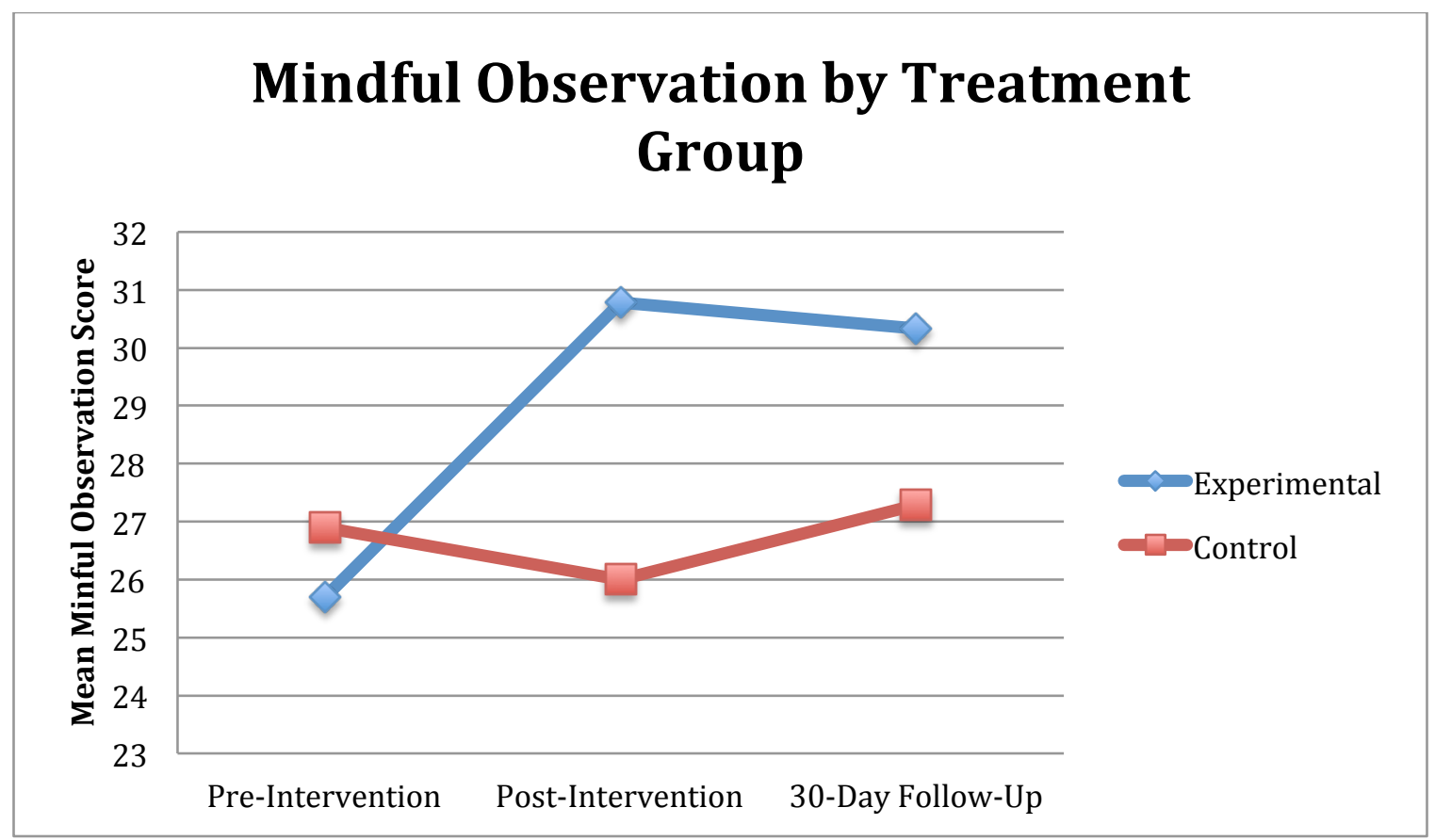

Figure 13: Mean Positive Emotion Over Time

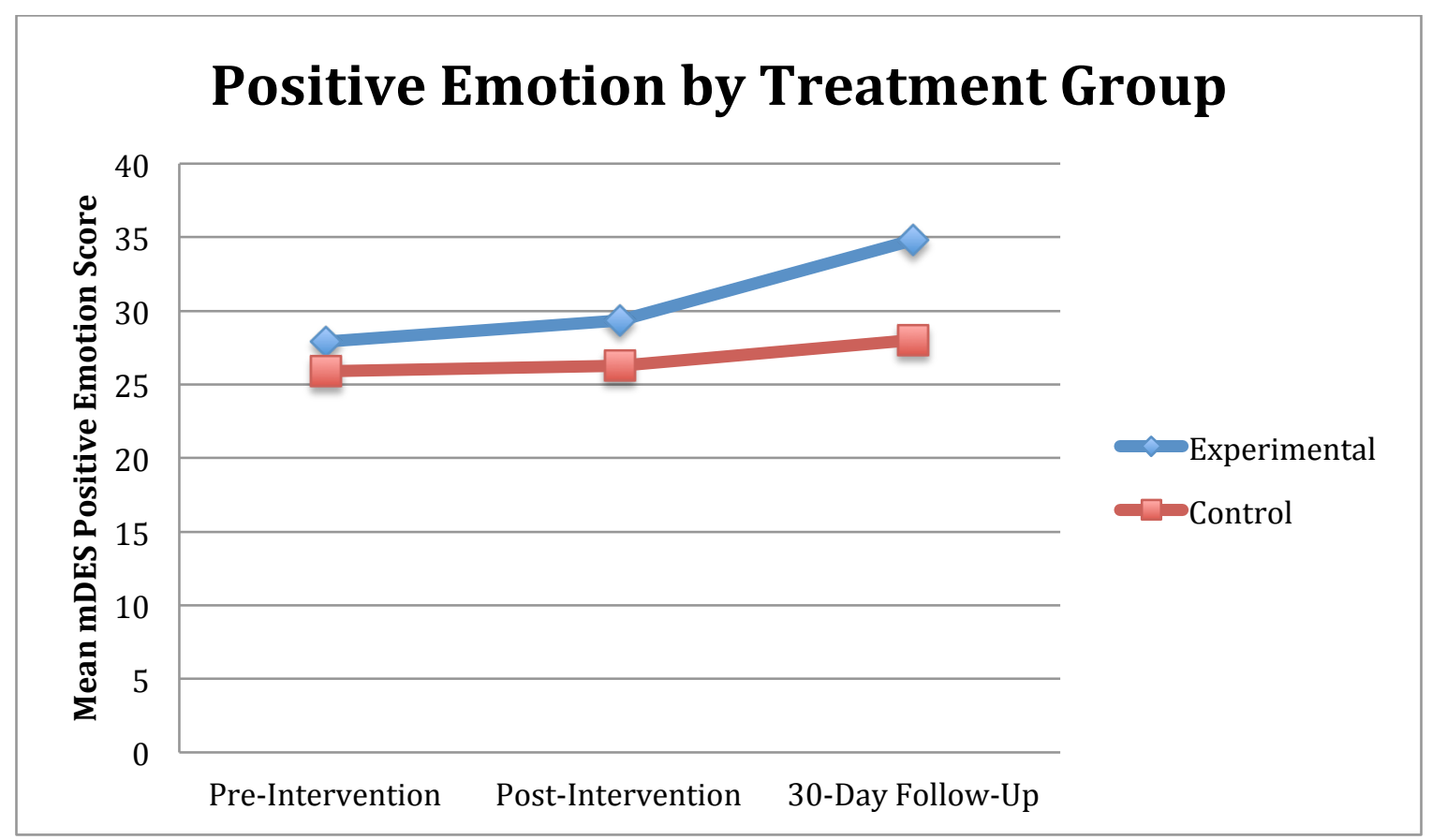

Figure 14: Mean Negative Emotion Over Time 


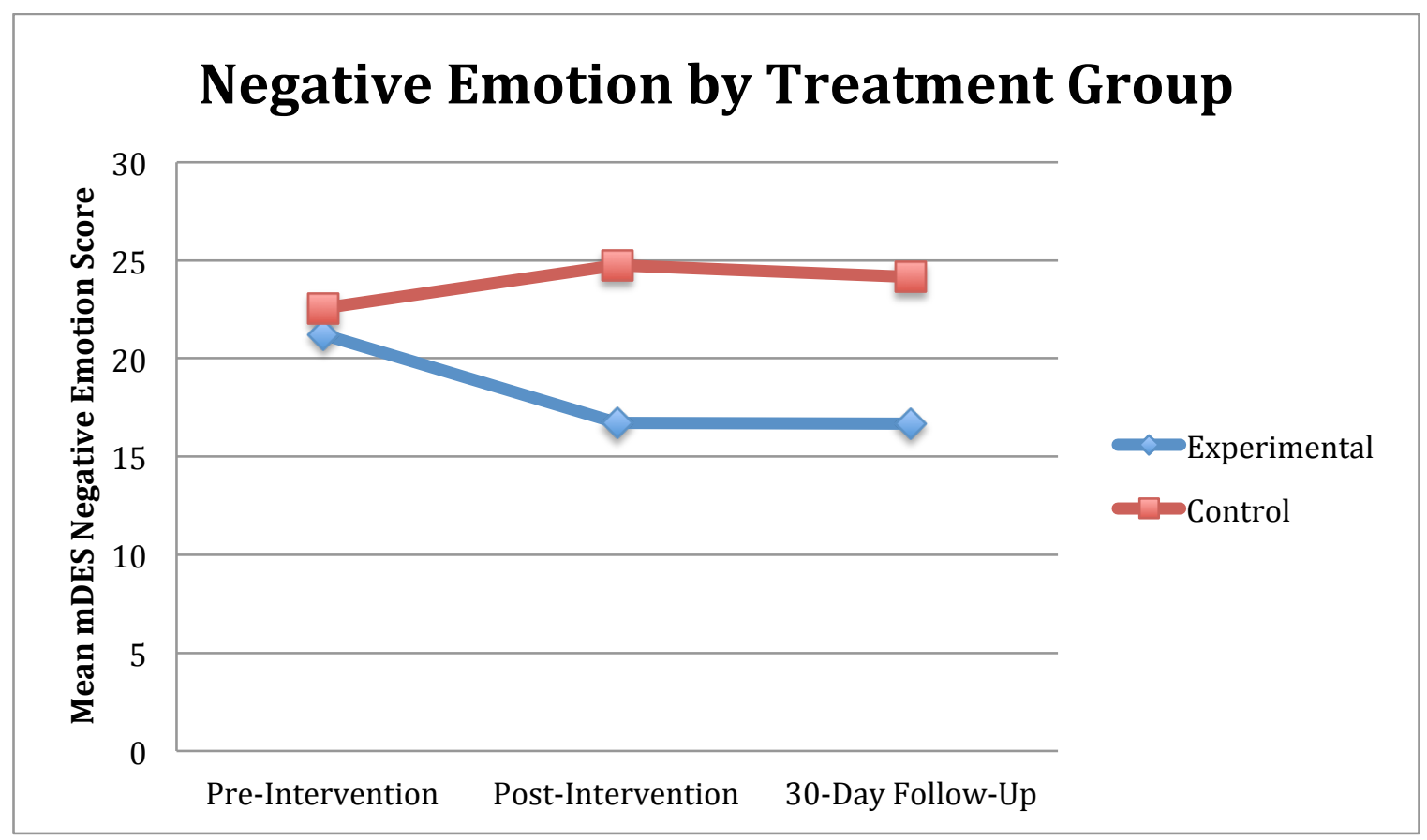

Figure 15: Mean Positive Affect Over Time

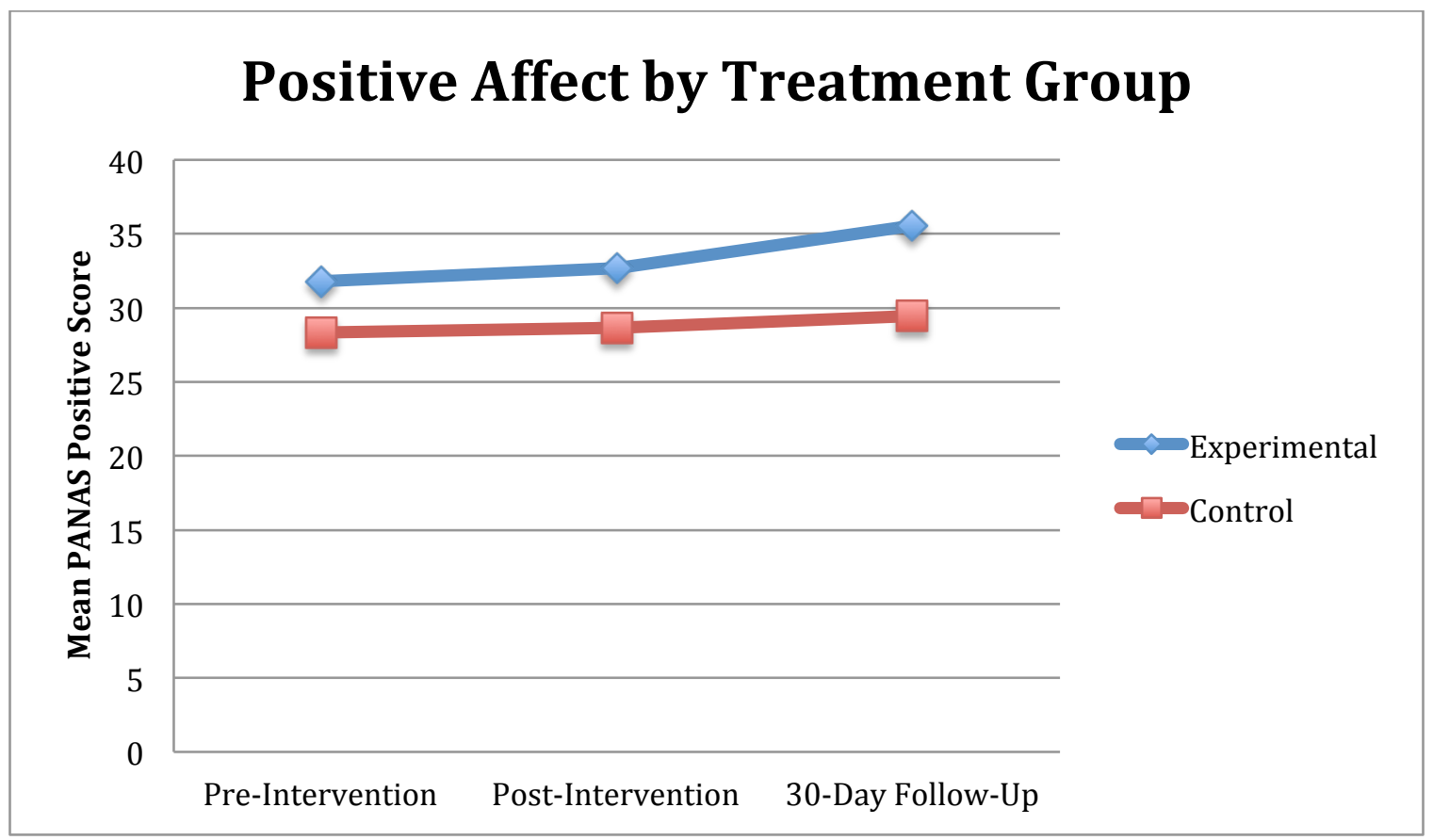

Figure 16: Mean Negative Affect Over Time 


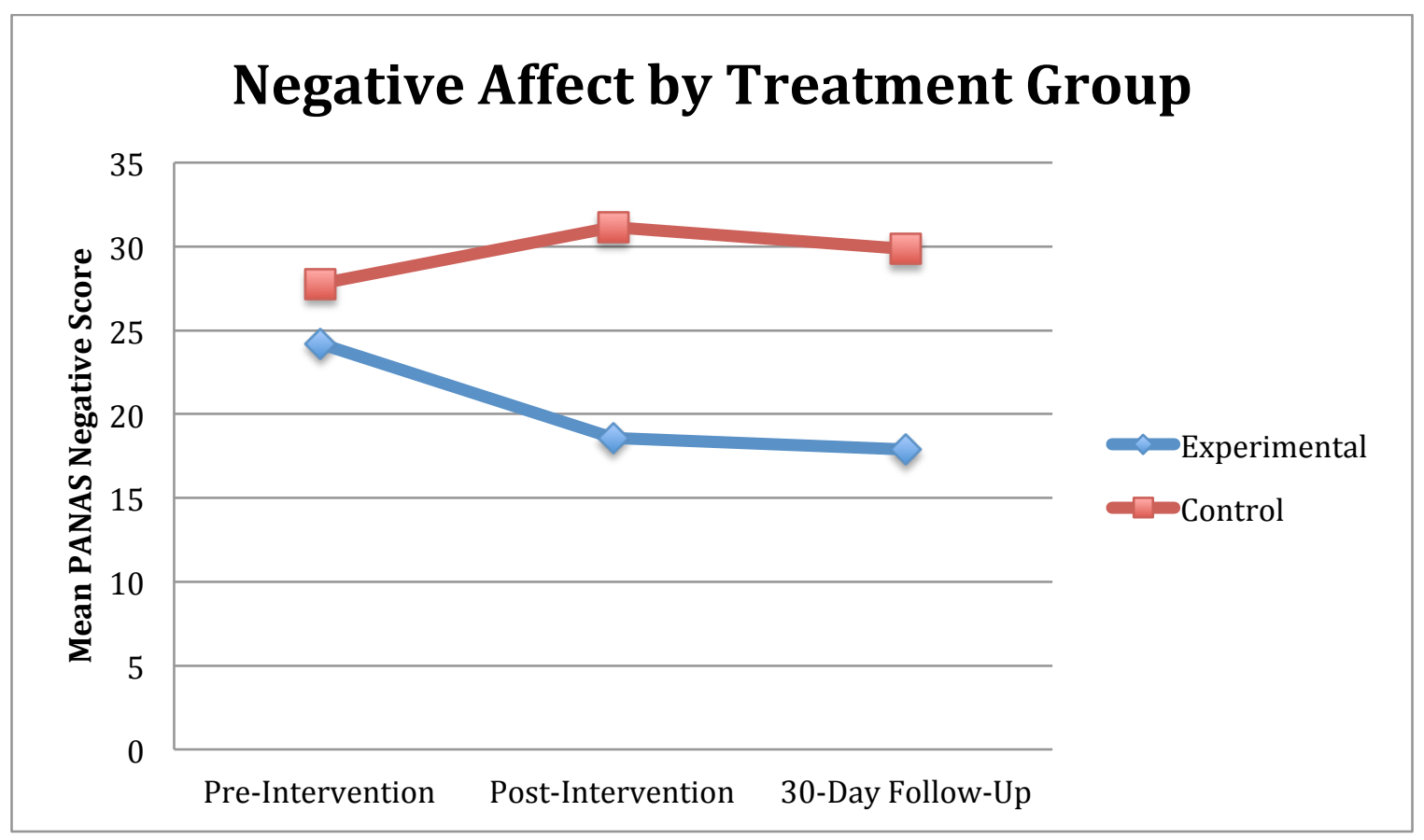

Figure 17: Mean Self-Acceptance Over Time

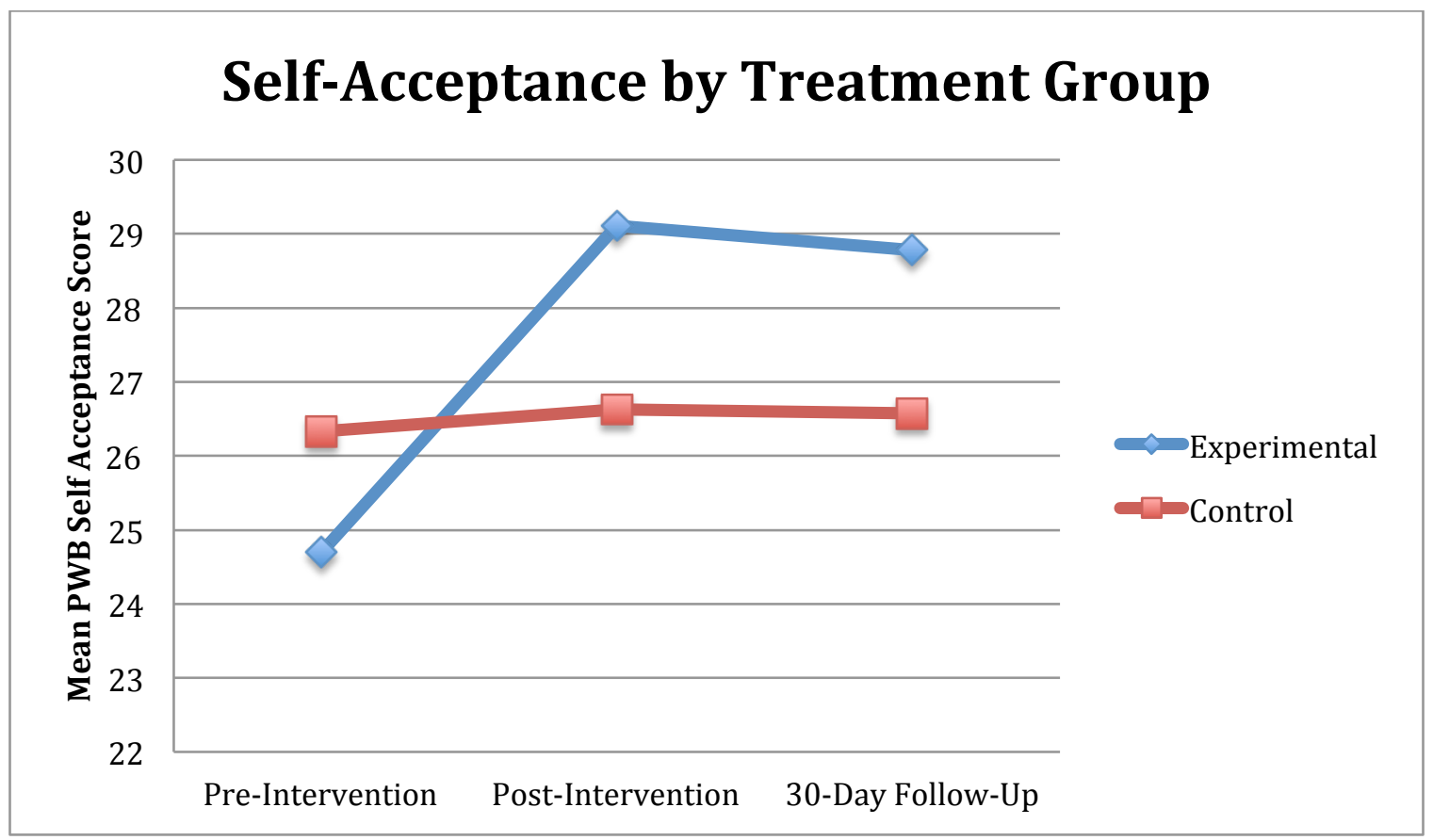

Figure 18: Mean Purpose in Life Over Time 


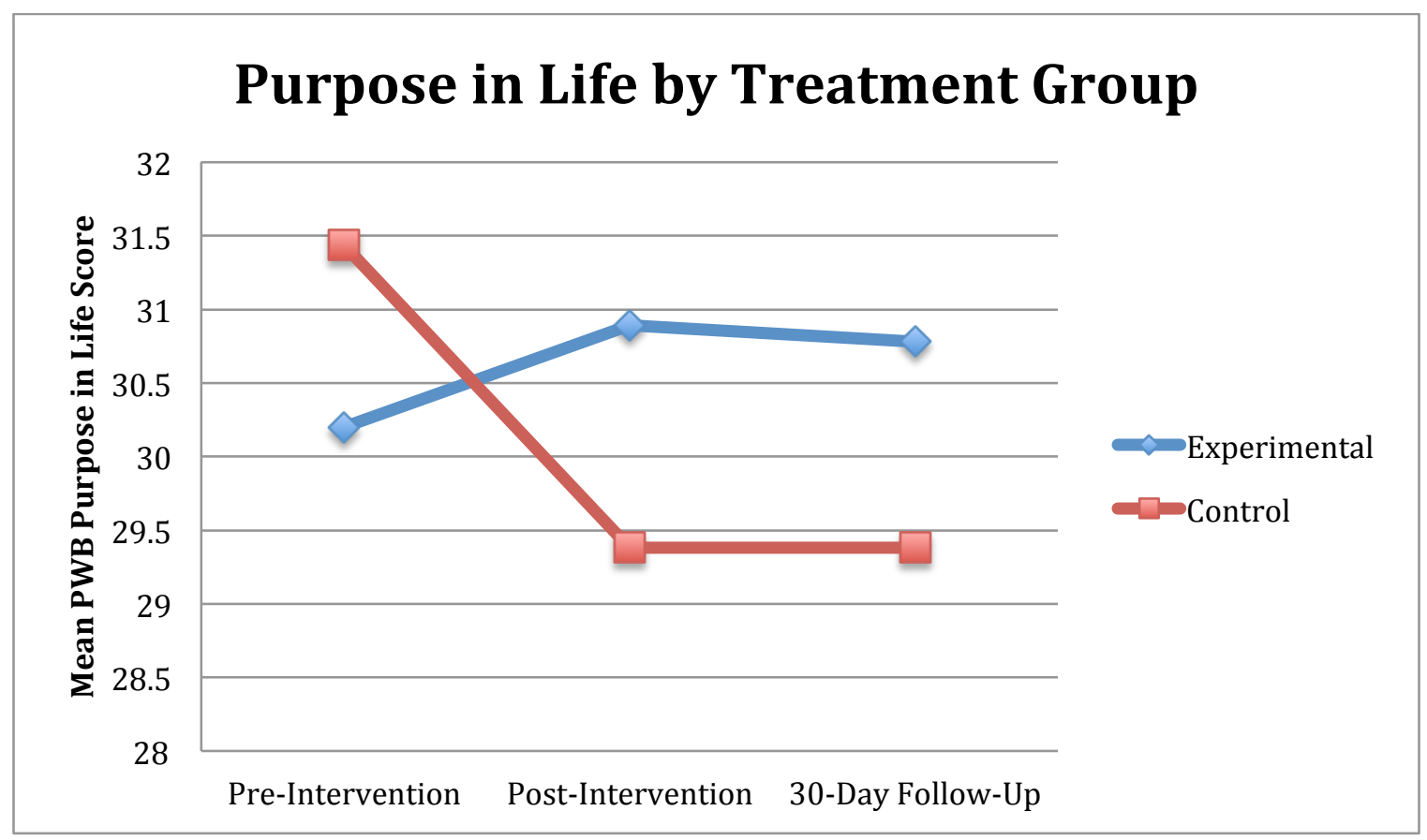

Figure 19: Mean Positive Relations Over Time

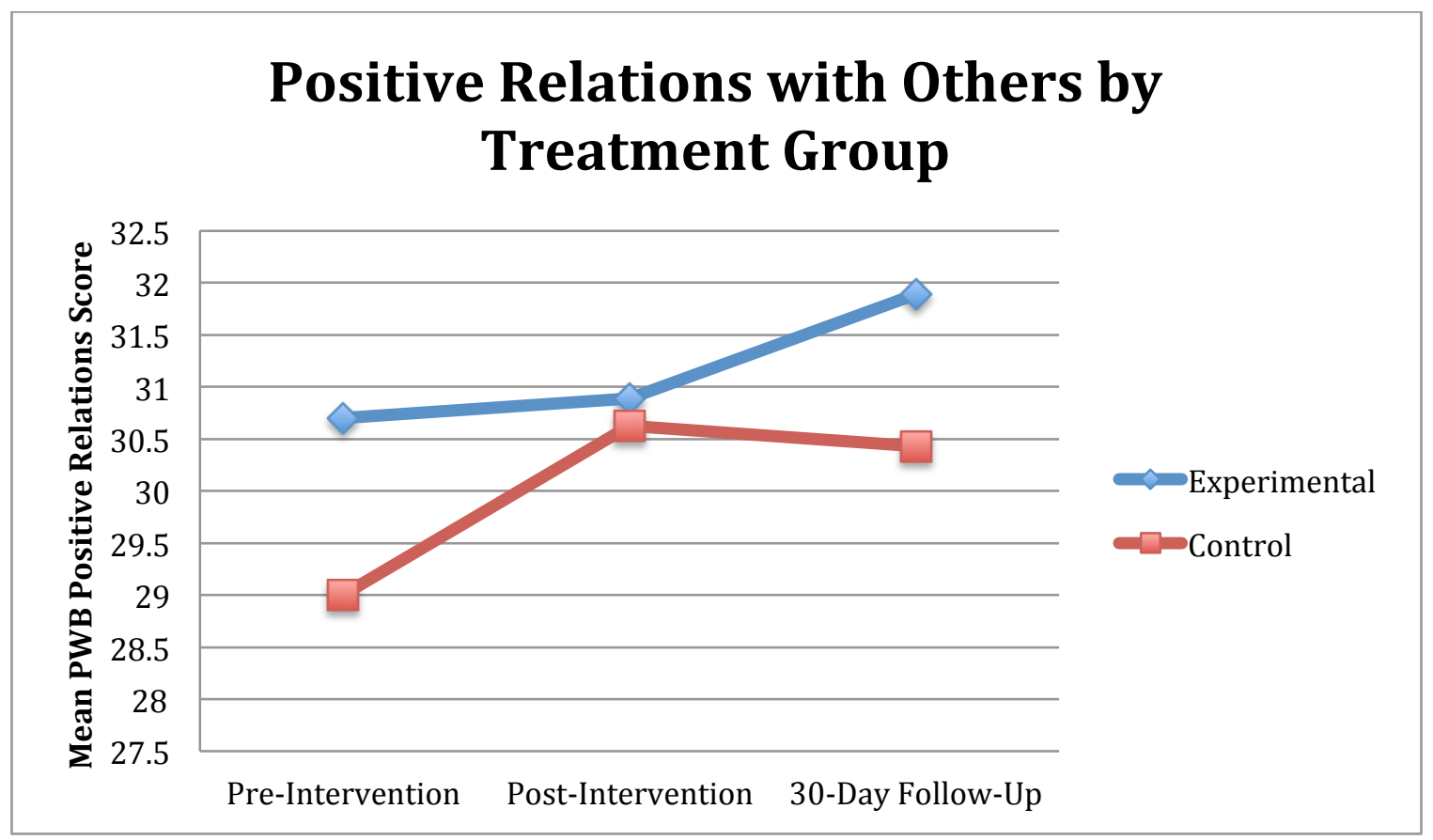

Figure 20: Mean Personal Growth Over Time 


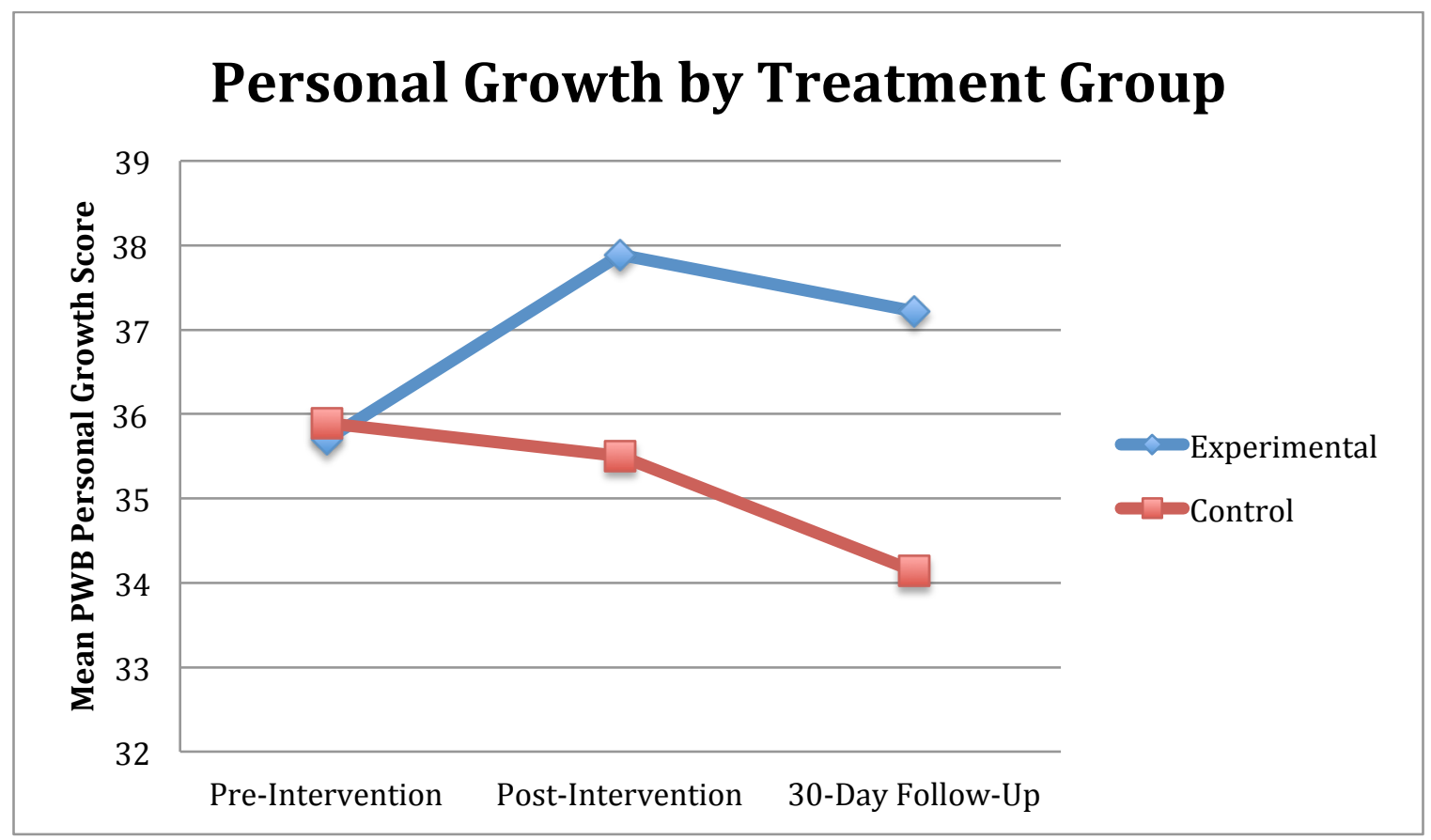

Figure 21: Mean Environmental Mastery Over Time

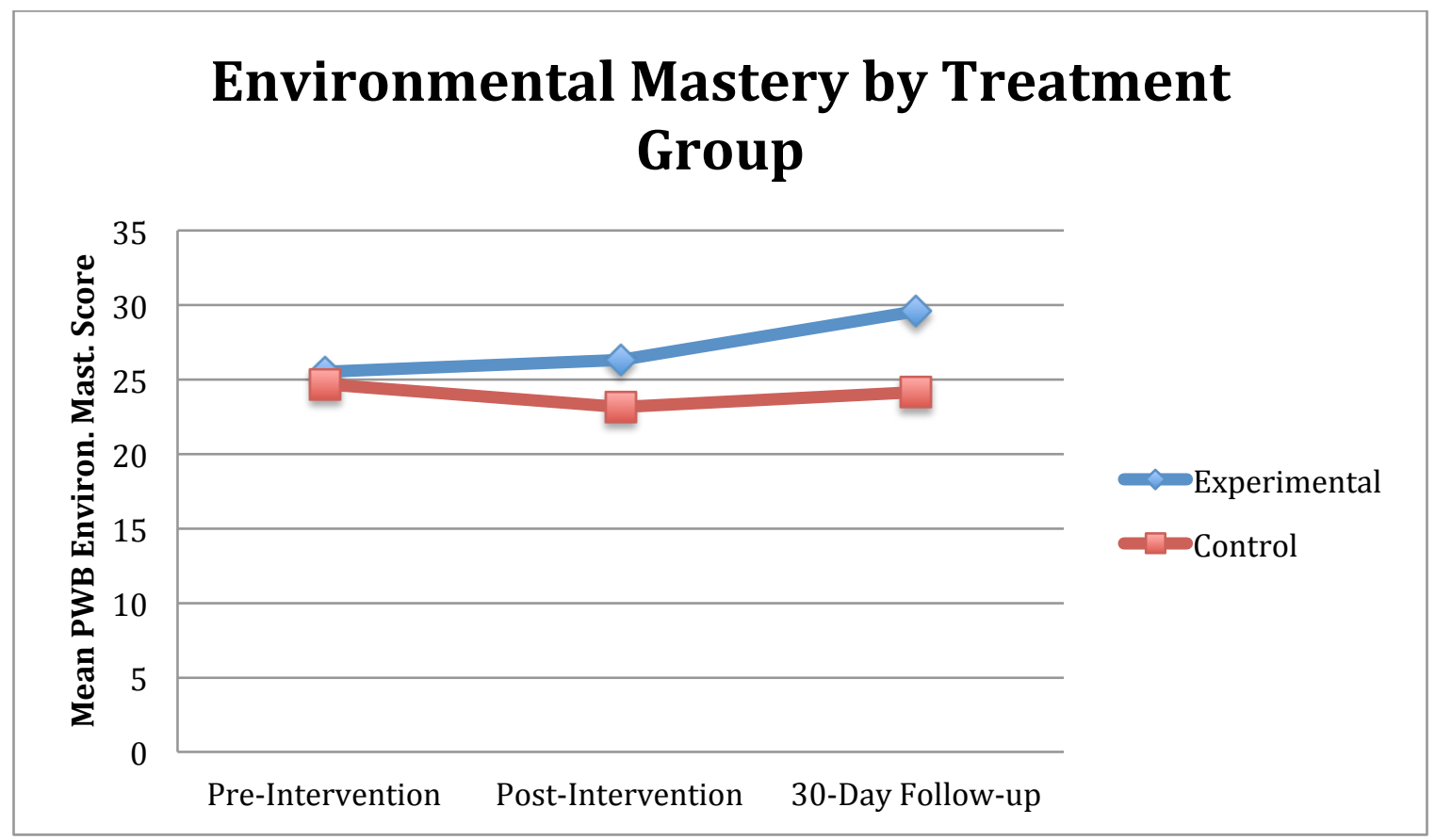

Figure 22: Mean Autonomy Over Time 


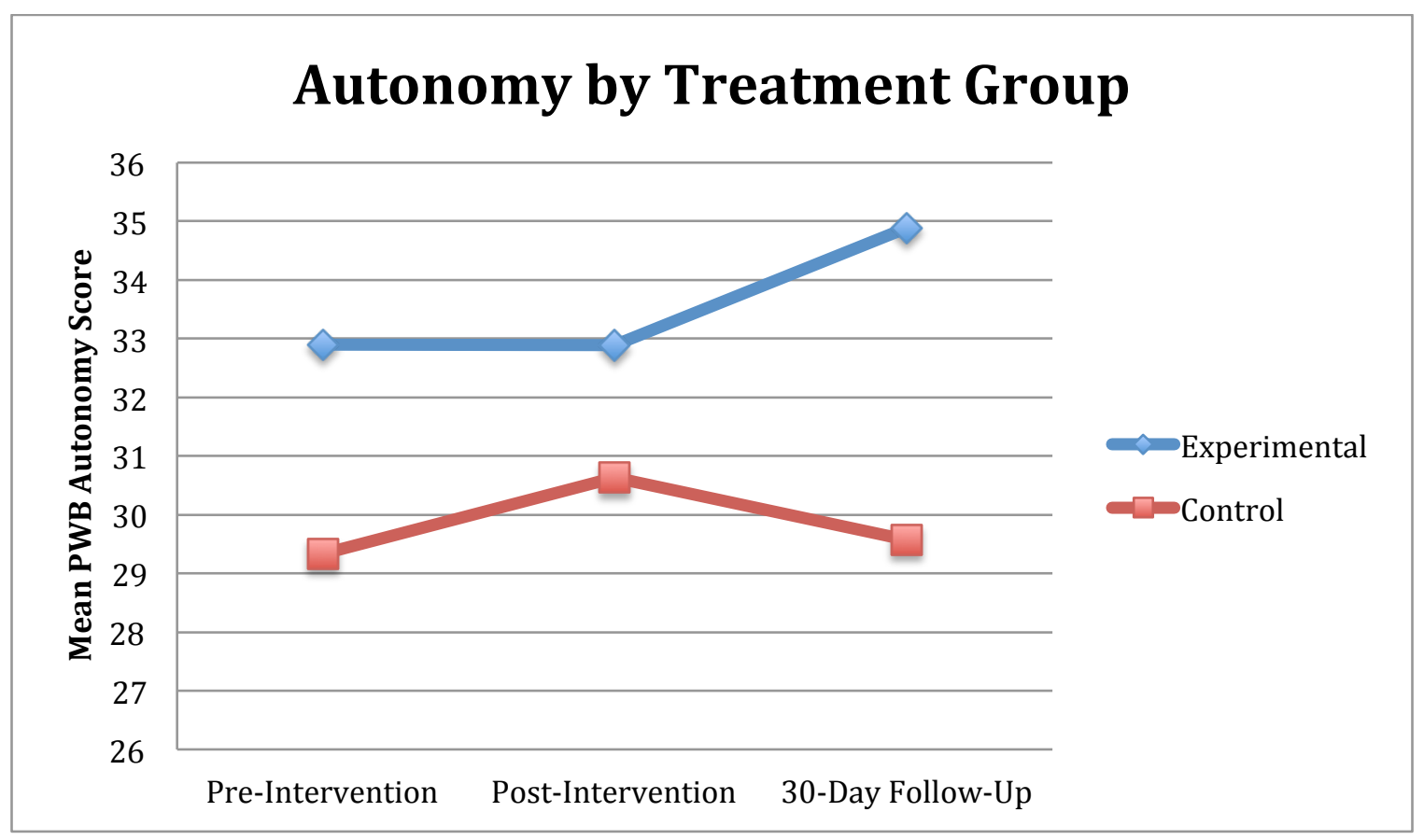

Effect sizes were again calculated using SMDs with a Hedge's correction and overall adjusted ESs were calculated. At the 30-day follow-up, adjusted ESs increased for gratitude, positive and negative emotional experience, positive relations with others, personal growth, environmental mastery, and autonomy. Very small increases in ESs were seen in gratitude, positive relations with others, and environmental mastery. It is also important to note that increases in ESs for negative emotional experience, negative affect, and personal growth are partially accounted for by large negative changes in the control group, as opposed to continued improvement in the experimental group. Baseline and 30-day follow up means and ESs are reported in Table 10.

Table 10: All 30-Day Follow-up Outcome Measure Effect Sizes by Treatment Condition

\begin{tabular}{|c|c|c|c|c|c|c|}
\hline & \multicolumn{2}{|c|}{ Experimental Group $(n=9)$} & \multicolumn{4}{|c|}{ Control Group $(n=7)$} \\
\hline Measure & Mean \pm SD & $\begin{array}{l}\text { Within-Group } \\
\text { ES (d) }{ }^{\mathrm{a}}\end{array}$ & Mean \pm SD & $\begin{array}{l}\text { Within-Group } \\
\text { ES }(d)\end{array}$ & $p$-value ${ }^{\mathrm{c}}$ & $\begin{array}{l}\text { Overall } \\
\text { Adjusted } \\
\text { ES }\end{array}$ \\
\hline
\end{tabular}




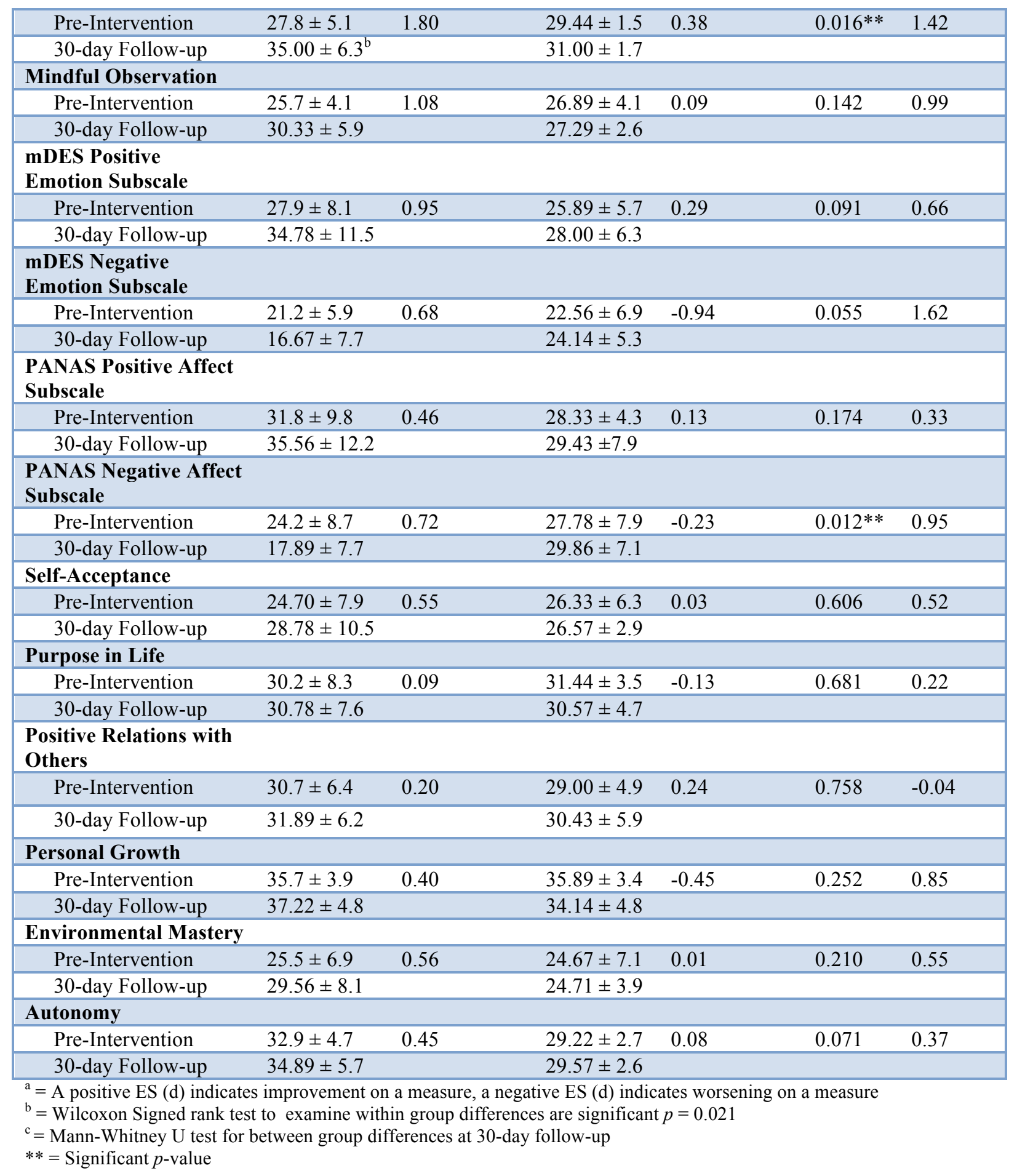


Figure 2: MyGratefulSelf Homepage 


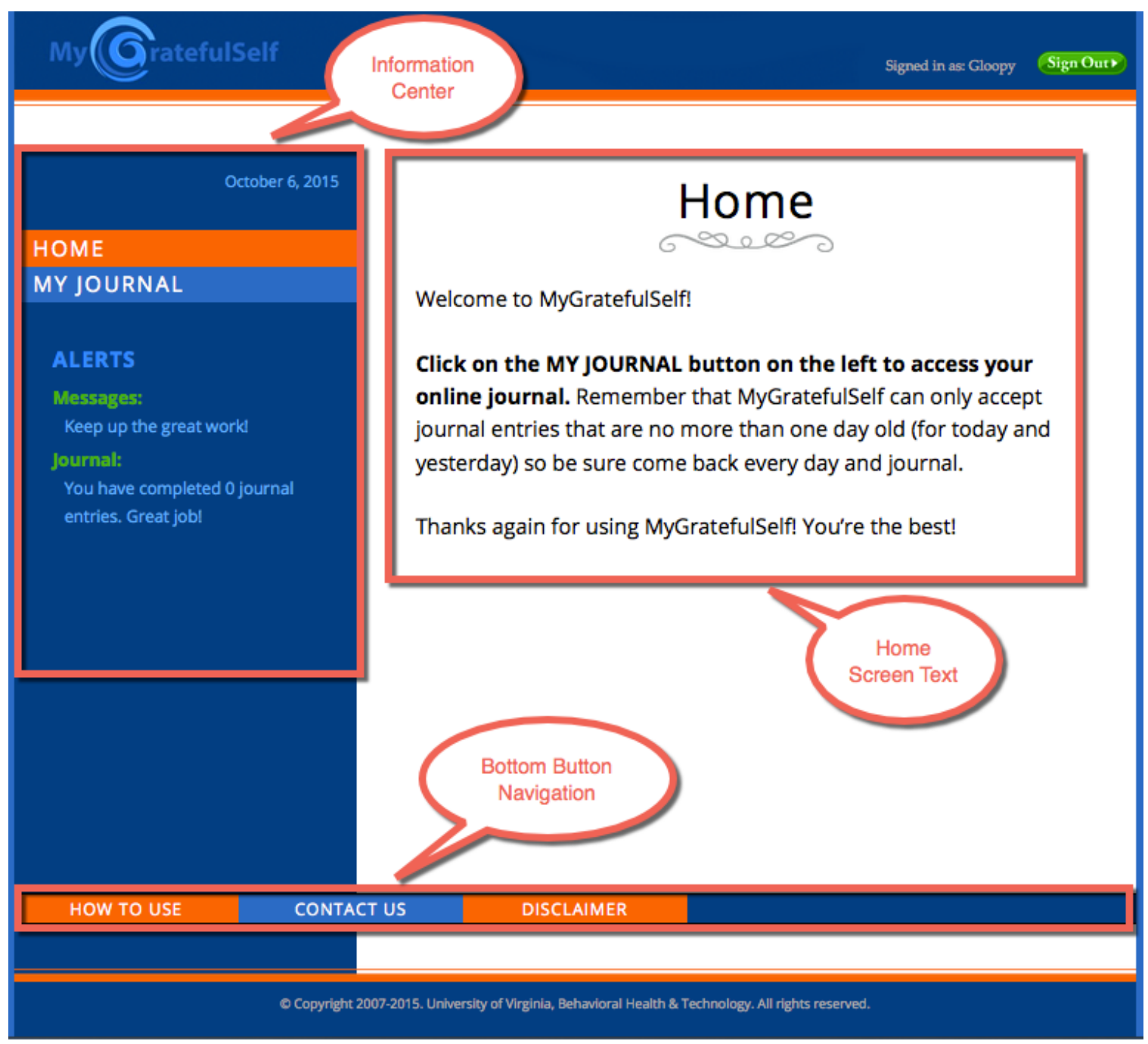


Figure 3: Information Center

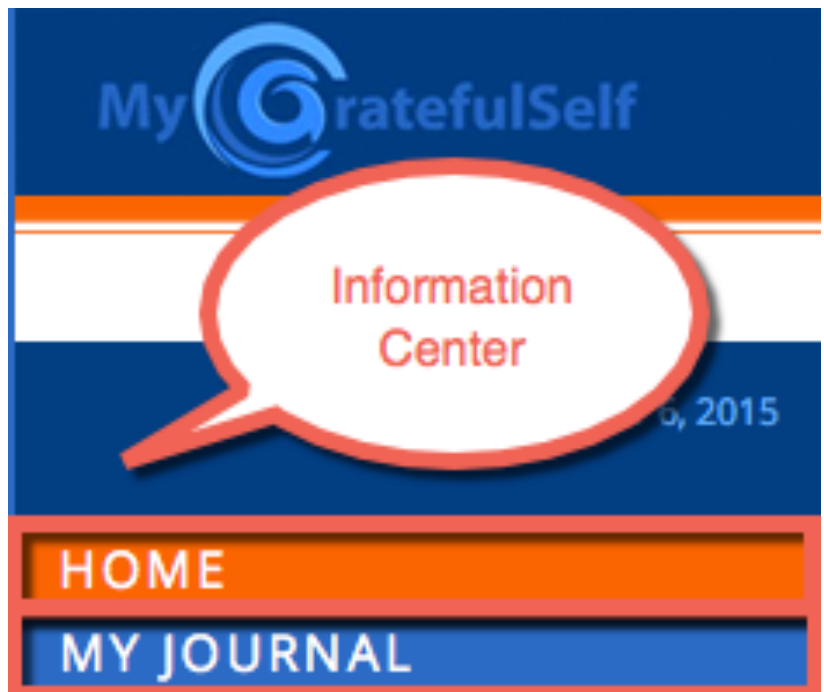

\section{ALERTS}

Messages:

Keep up the great work

Journal:

You have completed 0 journal entries. Great jobl 
Figure 4: Calendar Page

\section{Complete Your Journal}

Find today's date, or the date of the journal vou wish to enter. Click on that day to complete the journal entry. Click here to learn more about this calendar. MyGratefulSelf can only accept journatentries that are no more than one day old (for today and yesterday). So be sure to come back every day and make a journal entry!

$\hat{2}$

\section{October 2015}

\begin{tabular}{|c|c|c|c|c|c|c|}
\hline Sunday & Monday & Tuesday & Wednesday & Thursday & Friday & Saturday \\
\hline 27 & 28 & 29 & & Click & 2 & 3 \\
\hline 4 & 5 & 6 & & tart! & 9 & 10 \\
\hline 11 & 12 & 13 & 14 & 15 & 16 & 17 \\
\hline 18 & 19 & 20 & 21 & 22 & 23 & 24 \\
\hline 25 & 26 & 27 & 28 & 29 & 30 & 31 \\
\hline 1 & 2 & 3 & 4 & 5 & 6 & 7 \\
\hline
\end{tabular}


Figure 5: Journal Page

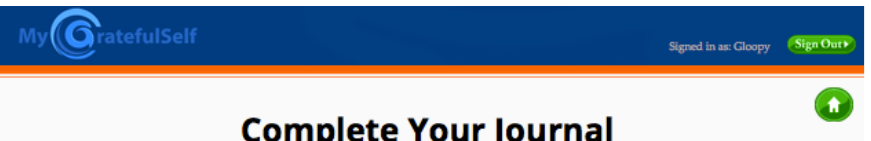

\section{Complete Your Journal}

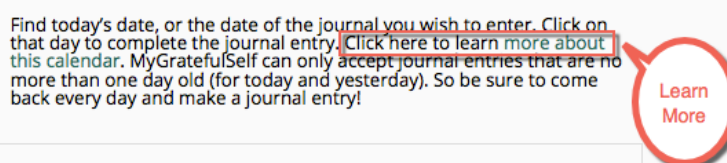

My Journal

$$
\triangleq
$$

\section{October 2015}

6

\begin{tabular}{|c|c|c|c|c|c|c|}
\hline Sunday & Monday & Tuesday & Wednesday & Thursday & Friday & Saturday \\
\hline 27 & 28 & 29 & & & 2 & 3 \\
\hline 4 & 5 & 6 & & & 9 & 10 \\
\hline 11 & 12 & 13 & 14 & & 16 & 17 \\
\hline 18 & 19 & 20 & 21 & 27 & 23 & \\
\hline 25 & 26 & 27 & 28 & 29 & 30 & 31 \\
\hline
\end{tabular}

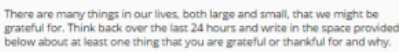
Be aware of your fecting and how you "rolith" or "svor" this giti in your.

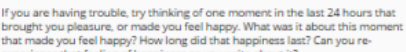

Type your Journal entry here. 
Figure 6: Example Paid Facebook Advertisement

Mygratefulself
Sponsored - $\odot$ MyGratefulSelf
MyGratefulSelf is a journaling project for young adults aged 20-39 with
advanced stage cancer!
Wikw.MYGRATEFULSELF.ORG
Iit Like Comment $\rightarrow$ Share

Figure 7: Example Instagram Post

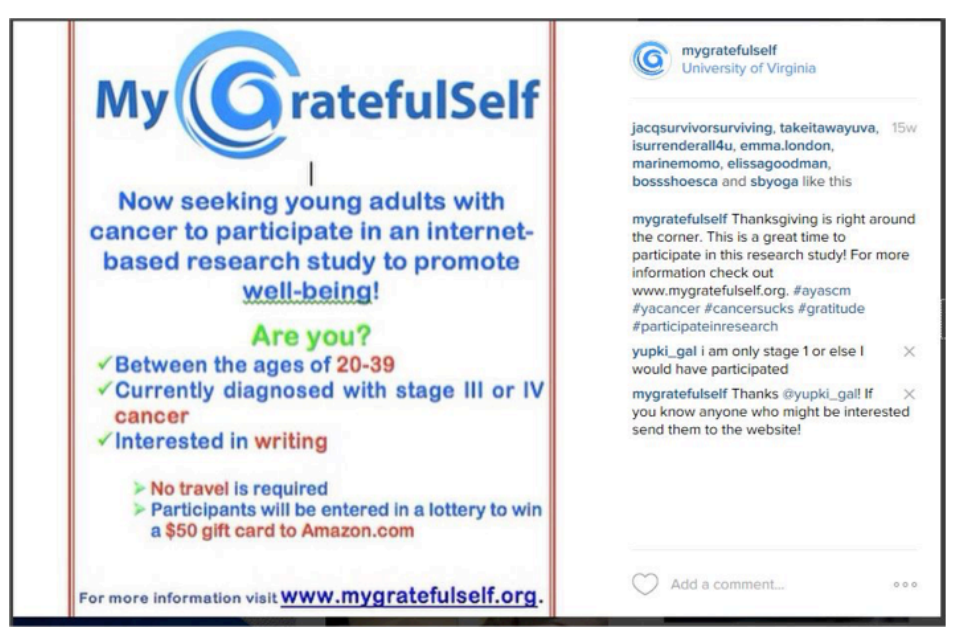


Figure 8: Example Tweet

MyGrateful Self 1 MyGratefullself $-\operatorname{Jan} 28$

Great research opportunity for young

adults with metastatic cancer especially if you like to write!

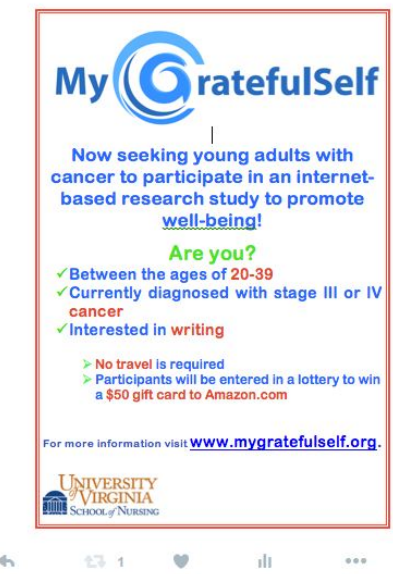

Figure 9: Example Private Facebook Post

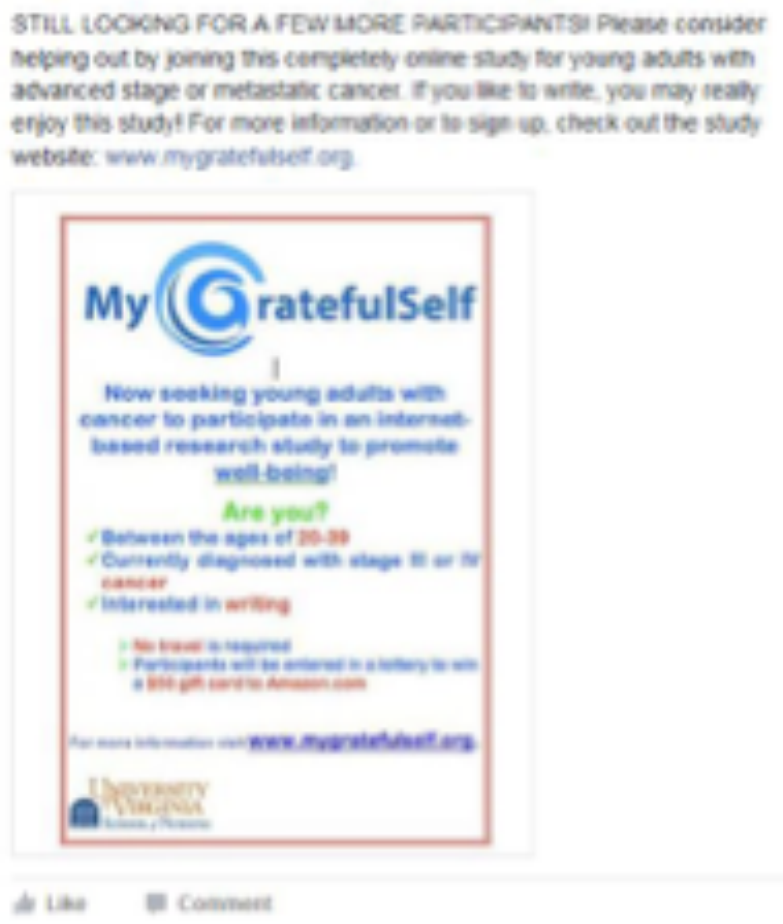


Figure 10: Example General MyGratefulSelf Facebook Wall Post

\section{Mygratefulself \\ February $17 \cdot \theta$}

Gratitude makes it all a little bit easier to face.

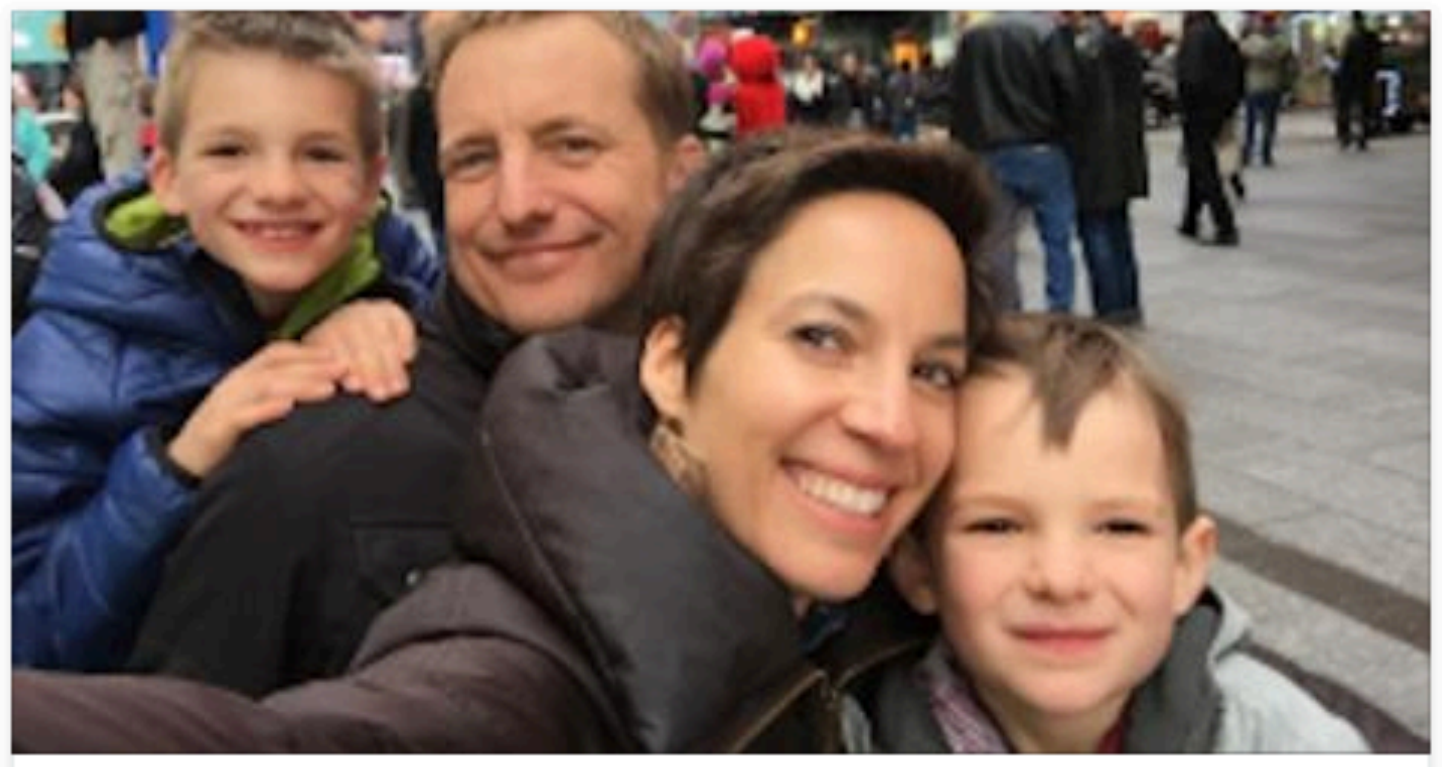

\section{Little Things I'm Thankful Cancer Couldn't Take} From Me

Her gratitude is beautiful, and contagious.

THEMIGHTY.COM I BY MELISSA FUOSS 
An Online Gratitude Intervention for Young Adults with Advanced Cancer

Chapter 5

Discussion 


\section{Introduction}

The following chapter will discuss and interpret the findings of the MyGratefulSelf study reported in the previous chapter. It will begin with an evaluation of the MyGratefulSelf system with recommendations for improvements to better suit the needs of the population. Then the recruitment and sample results will be discussed, followed by interpretation and discussion of the preliminary efficacy results. Lastly limitations of the current study, proposed manuscripts arising from this work, and potential secondary analyses from this data will be presented.

\section{MyGratefulSelf System}

Overall, participants in the MyGratefulSelf study found the system to be acceptable and usable. They particularly enjoyed the daily emails, reminding them to log in and complete their journals. They found that the system worked well, with minimal glitches and that the interface was easy to understand and user friendly. While they found it generally acceptable, participants did have some constructive feedback about the system.

Regarding the appearance of the website, in line with the framework used to design the intervention (Ritterband et al., 2009) researchers carefully designed the website to look professional, branded, and gender neutral so as to instill confidence in potential study participants sending information over the Internet. However, participants reported that they would have preferred a website design focused more on calming and soothing colors and designs that create more of a "safe haven" feeling for them to write. It would be appropriate to consider leaving the appearance of the interest site with a focus 
on professionalism and gender neutrality, while changing the design of the journaling site to produce a more peaceful and comforting virtual atmosphere for deep emotional engagement and continued use of the web program (Ritterband et al., 2009).

The current system, including the online interest form, the online consent form, and the journaling page, works best when viewed on a desktop or laptop computer. It is possible, but not easy or convenient, to complete the most of the tasks of the system on a mobile device such as a phone or tablet, but signing the consent forms was not possible on a mobile device. Several participants in the MyGratefulSelf study reported that they would have preferred to have the option to complete the study on a mobile device, or that they didn't write as often because it was inconvenient to sit at a computer at a time when then naturally felt like completing the journal. Additionally, one potential participant declined to participate in the study because she only accesses the Internet from her phone and did not feel that the study was feasible for her because of that. Evidence does suggest that more adolescents and young adults are accessing the Internet exclusively using their mobile devices. The Pew Research Center found that, in 2012, 50\% of adolescents aged $12-17$ and $45 \%$ of young adults aged $18-29$ reported that they use only their mobile devices access the Internet (Smith, 2012). Overall 17\% of smartphone owners do most of their online browsing on a phone rather than a computer (Smith, 2012). A more recent study from the Pew Research Center also notes that $10 \%$ of Americans own a smartphone but do not have broadband at home and that $15 \%$ own a smartphone but have limited options for going online other than their cell phones (Smith, 2015). This study also reports that those with lower household income, non-whites, and younger adults are disproportionately represented in the category of those who have few 
or no other options for accessing the Internet outside of their mobile devices (Smith, 2015). These results, in combination with the feedback from the MyGratefulSelf study, suggest making the system mobile-friendly by creating a mobile version of the website or creating an app available for download, is imperative in order to reach those in the target age group and to increase the diversity of MyGratefulSelf users.

While participants generally accepted the MyGratefulSelf system and several continued to journal in both written and digital formats, none of the participants in the experimental group continued to use the MyGratefulSelf system and only one participant in the waitlist-control group used the system regularly after completing the study. This may be due to the inconvenience of using the computer, rather than a more portable mobile device and not receiving daily email reminders to journal once the study ended. However, it is more likely due to the fact that MyGratefulSelf failed to deeply engage its users. Several participants reported that they would have felt more engaged with the program if there had been a variety of journal prompts. While the prompt was developed directly from the work of the leading researchers on gratitude (Emmons \& McCullough, 2003b; Emmons \& Stern, 2013; Froh et al., 2008) and was written in order to give participants several angles from which to write about gratitude, it did not change throughout the study and focused on only one type of gratitude intervention, the reflective journal. Again returning to the original framework used for creating an Internet-based intervention, this issue speaks to content and delivery, which are both important in order to achieve the ultimate goals of the intervention, in this case to improve overall wellbeing (Ritterband et al., 2009). Including other types of gratitude interventions, such as letters or lists, may diversify the prompts enough to engage participants more and 
encourage continued use of the system (Kaczmarek et al., 2015; Krejtz, 2014; Toepfer et al., 2012). Furthermore, a tailored approach to Internet-based interventions has also been shown to improve user engagement (Couper et al., 2012; Lustria, Cortese, Noar, \& Glueckauf, 2009). Because the content of this intervention, aside from the journaling prompt, is driven by the user, one method of tailoring or personalizing the content for each user would be to have the option to include videos, animation, sounds clips, GIF's, and photos within each journal entry. This may better mimic other types of online journals such as blogs or hand written journals (which allow for small drawings and doodles) to help express and work through emotions in other ways than simply written words. This might improve enjoyment and engagement in a younger population that is already used to seeing and using these modalities in their online lives (Keim-Malpass et al., 2013; Ritterband et al., 2009).

Lastly, while instructed to write daily for 21 days, participants were generally unable to $\log$ in to write every day. As reported, the average number of total journal entries was about 14 . Some participants reported that they were unable to write daily and when they were able to log in, they wished they could go back further than one day to complete previous entries. A dose effect calculation is important to determine the minimum number of times each participant should log in to gain the maximum improvement in well-being. It is possible that writing about the past 3 days or the past week instead of the past 48 hours would have a similar impact on well-being without the pressure to write daily. Length of intervention is a shortcoming of the scientific literature on gratitude overall. 21 days is the generally accepted length for a daily writing intervention despite the fact that there is little evidence that this is the minimum amount 
of time needed to improve gratitude and achieve other well-being outcomes. In fact, some studies do suggest that writing less than daily over a longer period of time may be as effective as writing daily over a short 21-day timeframe (Emmons \& McCullough, 2003b; Emmons \& Stern, 2013; Watkins, Uhder, \& Pichinevskiy, 2015). It maybe worth exploring other timeframes and dosing schedules for this intervention to determine the minimum number of times each participant can log in to achieve the best outcome, particularly because the target population may be limited by time and energy.

The current MyGratefulSelf system was generally well-received by the participants of this study. The aforementioned changes to the system, derived from user feedback, may help to improve user engagement and retention, and move the MyGratefulSelf system closer to achieving its goal of improving well being in YAs with advanced stage cancer over the long term.

\section{Recruitment}

The recruitment strategy for MyGratefulSelf was largely a trial and error process. Based on previous studies that reported successful recruitment using social media (Akard, Wray, \& Gilmer, 2015; Gorman et al., 2014; O'Connor, Jackson, Goldsmith, \& Skirton, 2014; Ramo, Rodriguez, Chavez, Sommer, \& Prochaska, 2014), researchers attempted to create an online presence for the MyGratefulSelf study prior to the recruitment period, with some success. Researchers were able to interact with some potential participants and other key stakeholders prior to the official opening of recruitment and there was some awareness of the study online prior to the beginning of recruitment. However researchers were limited by several factors including an inadequate understanding of the social 
networking capacity of Instagram and some difficulty reaching out to previously unknown potential participants on Facebook.

Once recruitment opened, MyGratefulSelf researchers relied on published literature regarding the use of social media for recruitment to devise a recruitment plan. One key strategy outlined in the literature on social media and participant recruitment was the use paid Facebook advertising (Akard et al., 2015; Ramo et al., 2014; Yuan, Bare, Johnson, \& Saberi, 2014). With the amount of money spent on advertising in these studies averaging \$5000, the MyGratefulSelf study was not able to take full advantage of this resource. Aside from being expensive, researchers discovered some other limitations to using paid advertising. Ads on Facebook are required to have very little text and rely heavily on pictures to get their point across. The recruitment poster explaining the purpose of the study did not meet the text requirements and so the ads for the study on Facebook contained very little explicit information about the study itself. Relying on a photo and limited text to advertise a complex, online research study was insufficient. Additionally, while Facebook offers the option to target specific populations through advertising, it is designed for retailers to target potential customers and identifying and targeting a very small clinical sub-population using Facebook's algorithms was very difficult. While the reach of the paid ads was large, many of the post engagements resulting from the paid ads were not from people in the target population.

In addition to the limitations of Facebook advertising and the researcher's insufficient understanding of Instagram, another difficulty encountered by the researchers included difficulty keeping up the with the pace of Twitter. Twitter has great potential as a way to widely disseminate information about a research study. MyGratefulSelf was 
able to follow many accounts and gained many followers, all of whom had some connection to cancer, cancer advocacy or education, or YA cancer issues. However, posting the research flyer had very little impact because each tweet gets lost quickly in the sea of tweets each minute. Individual users and tweets make an impact only in their number of retweets and mentions, meaning the number of times individuals re-post the original tweet (Cha, Haddadi, Benevenuto, \& Gummadi, 2010). While MyGratefulSelf did have several followers and received some retweets, with only one individual tweeting about the study an average of 2 times daily, the overall impact of the tweets was minimal and likely never reached many potential participants. Similarly, to Facebook, there is an option on Twitter to pay for advertising however due to the limited budget of this study, this option was not explored. More research is needed into the usefulness of paid advertising on Twitter and Instagram, how best to build and use social networks within Instagram, and the most effective way to promote a research study using a photo instead of text.

Another strategy employed by MyGratefulSelf was to direct message (DM) the administrators of private Facebook groups and ask for help promoting the study. A private Facebook group is one that each individual must request to join and is then admitted by an administrator, usually an individual who is or has been appointed by the person who started the group. Private Facebook groups exist for many different interests and communities including disease specific and age specific cancer groups. With limited success, researchers were able to reach the group administrators and the study flyer was posted, though researchers did experience difficulty getting in touch with group administrators due to blocks and limitations on private messaging on Facebook. 
Eventually, however, MyGratefulSelf researchers started requesting to join these groups, disclosing that MyGratefulSelf was research study designed to promote wellbeing in YA's with cancer. Most group administrators were very open to having MyGratefulSelf as a group member even when it was disclosed that MyGratefulSelf would be recruiting for a research study. In those groups that accepted MyGratefulSelf as a member, after spending some time engaging with the other members of the groups through likes and comments, researchers posted the study flyer on the group newsfeed with great success, up to 7 interest inquires in one week. Bolstered by this success, researchers joined more private groups on Facebook with a theme of cancer or young adult cancer and became an active participant in these groups mostly offering support to members going through difficult times and congratulations to members celebrating good news. Groups in which the researchers were most active yielded the most inquires regarding the study including Stupid Cancer Mid-Atlantic (4), Stupid Cancer Southeast (3), and Cervivor (2).

This strategy can be likened to a research methodology widely used in public health, Community-Based Participatory Research (CBPR). CBPR is a methodology that aims to reach underserved populations by engaging the community and facilitating mutual benefit among the community members and researchers by promoting reciprocal knowledge translation (Wallerstein \& Duran, 2010). In other words, the process of CBPR is to engage with a community and find out what it's values and practices are, what is most important to community members to learn about themselves, and how best to gain participation in research studies from them. In this way researchers are assured that the research they conduct will be useful to the community in which it is conducted 
and that community members will willingly and actively participate in that research (Wallerstein \& Duran, 2010). Similarly, MyGratefulSelf was particularly successful in recruiting participants into the study when researchers joined and actively participated in online communities, similar to the beginning steps of CBPR.

While young adults with cancer represent more of a clinical population than a community, we know that this population is forming community online (Keim-Malpass et al., 2013; Keim-Malpass \& Steeves, 2012; Love et al., 2012; Schiffman et al., 2008; Song et al., 2012). Researchers should consider entering or joining those online communities and engaging members in the kind of values-based discussions that have worked well in CBPR, creating an online version of CBPR focused on virtual communities formed by clinical populations, such as young adults with cancer. This could be done using Facebook events or Twitter chats. Armed with the knowledge of what is most important to this population and what they would like to know about themselves, researchers can then design studies that will be valuable to both participants and researchers and will ensure more "buy-in" and higher participation rates from the community. This could be a very important step in increasing young adult participation in clinical and behavioral cancer research.

Engagement with this clinical subpopulation did also reveal a particular interest among actively engaged community members for more clinical trials and increased access to clinical trials dedicated to cancers that affect them and targeted for their age group. As participation in trials remains low, there appears to be a gap in understanding and access to clinical trials developing among researchers and patients, with a distinct need for a better way to communicate availability and importance of ongoing clinical 
trials for this age group, as well as the development of protocols that meet the needs of this population.

\section{Sample}

The sample of participants in the MyGratefulSelf study had some homogeneity and some diversity. Gender and racial diversity was minimal with only 3 male participants and 2 participants who identified as non-white, and only one participant who identified as African American. This may be due to the fact that the incidence of cancer in young adults is higher in whites than in non-whites (A snapshot of adolescent and young adult cancers, 2013), but it is more likely a result of inadequate information dissemination regarding the study to African-Americans. Historically, researchers have thought that the strongest barrier to participation in research for African-Americans is mistrust of the healthcare system, followed by transportation issues, cost, family concerns, time, and commitment (Ford et al., 2008). However, one study found that mistrust was, in fact, not a barrier at all, but lack of awareness of clinical trials and the reasons for participating were the biggest reasons cited by African Americans for not participating in health research (Hatchett, Holmes, Duran, \& Davis, 2000). While the online recruitment strategy for MyGratefulSelf was targeted at a specific age group, it did not include explicit plans for ensuring gender and racial diversity, and thus may not have effectively reached men and non-whites. It may be important to further investigate the use of the Internet by non-whites and men (versus women and whites) for information seeking and community building in the young adult cancer population to assure that the 
information about research studies is being disseminated equally to all who might be interested.

Also, while the age of participants (21-39) spanned the almost the full range of eligibility, the mean age (32.7) falls on the older end of the spectrum. This likely represents a bias of the PI. The primary recruitment site was Facebook, due in large part to the comfort level of the PI, in addition to the published literature on online recruitment, which is largely focused on Facebook. There is some evidence that the users of Facebook are slightly older than the users on others social networking sites including Twitter and Instagram (Duggan, Ellison, Lampe, Lenhart, \& Madden, 2015). Because the PI's own age directly reflects the mean age of participants, it is likely due the relative comfort with Facebook, felt by the PI. Further research into the social networking and recruitment capacity of Instagram, Twitter, and other, newer social media may help diversify the ages represented in a study like this.

Because of the difference in social network use by age, and possibly by gender and race, it might be helpful for there to be one central online location where researchers and potential participants can come together to share information about research studies that are currently being conducted and brainstorm ideas for future research. Returning to the idea of online CBPR to improve engagement in studies and trials, this method might also improve awareness of current research being conducted which may, in fact, be one of the primary barriers to participation in research for young adults with cancer (ColonOtero et al., 2008; Fern \& Whelan, 2010; Hatchett et al., 2000; Weiss et al., 2015).

There was broad geographic diversity within the MyGratefulSelf sample. Because of the web-based recruitment strategy, all regions of the US were represented as 
well as Canada, the UK, and South America. This strengthens the results demonstrating that the effects of the intervention are not culturally specific. Additionally, participants in the MyGratefulSelf study included all income categories including 2 participants who reported annual incomes below $\$ 10,000$. Financial stressors may have a significant impact on overall well-being in YAs with cancer and well as an impact on the efficacy of gratitude to improve well-being. A secondary analysis of socio-demographic factors and their relationship to well-being and changes in well-being over time will be important in determining the magnitude of stress that finances represent in this population.

Finally, the participants in the MyGratefulSelf study had a variety of cancer

diagnoses, though breast cancer and cervical cancer were heavily represented. Both lung cancer and melanoma are absent from the sample even though they are cancers that are often found in YAs, particularly melanoma (Bleyer \& Barr, 2009). This could be because the sample was so heavily female, but it is most likely a result of the access the PI gained into the communities on Facebook. A broader investigation into the intricacies of these online communities would be merited to foster more diverse recruitment in the future.

\section{Preliminary Efficacy}

\section{Baseline Measurements}

At baseline, the participants in the MyGratefulSelf study showed significant distress. Participants in both the control and experimental groups scored below average for their age groups on all measures. The mean scores on gratitude and mindful observation were the closest to the normal range and fell within 0.5 to $1 \mathrm{SD}$ below normal (Baer et al., 2008; Emmons \& McCullough, 2003a). The low scores on mindful 
observation may simply be due to statistical variation and chance in sampling, as this quality, in the absence of the other four facets of mindfulness is not likely to be a symptoms or cause of decreased feelings of overall well-being (Baer et al., 2006; Dutton, 2008; Tacón, 2011). Lower scores on the GQ-6 however, may be a symptom of overall cancer-related distress and decreased well-being (McCullough et al., 2002; Wood et al., 2008; Wood et al., 2009).

Participants scored lower than average for their age group on all measures of psychological well-being. Participants scored particularly low $(1-1.5$ SD below the mean for their age group) on Self-Acceptance and Environmental Mastery (Ryff et al., 2013). According to Ryff (1995), those with low scores on Environmental Mastery subscale may not feel a sense of control over their life and may have some difficulty managing their daily lives and those with low scores on the Self-Acceptance scale may feel dissatisfied with past life events, or may be troubled about various personal qualities, wishing to be different than they are. These findings are in keeping with previous literature describing the psychosocial and emotional consequences of cancer in the young adult population (Keim-Malpass \& Steeves, 2012; Trevino et al., 2011; Trevino et al., 2012; Zebrack, 2011). Additionally, while the MyGratefulSelf participants'scores on the other subscales of psychological well-being weren't as dramatically low, they did score below the normal range on positive relations with others, autonomy, personal growth, and purpose in life. Low scores on these subscales indicate that participants were likely feeling isolated, pressured to act in a certain way or reliant on the judgment of others to make major decisions, a sense of personal stagnation, and difficulty finding meaning or direction in life (Ryff et al., 2013; Ryff \& Keyes, 1995). Again these findings are 
consistent with the literature on young adults with cancer, and particularly those with advanced cancer who are actively confronting their own mortality (Bauer-Wu \& Farran, 2005; Keim-Malpass \& Steeves, 2012; Shaha \& Bauer-Wu, 2009; Trevino et al., 2012)

Participants also scored extremely high (1.5-2 SD above the normal range for their age group) on negative emotional experience and negative affect (Cohn et al., 2009; Fredrickson et al., 2008; Watson et al., 1988). Negative emotions such as "sad," "fearful," and "overwhelmed" were most commonly ranked as being felt quite a bit (4) or extremely often (5) by all participants at baseline. Negative affective states such as "upset," "scared," and "irritable" were very highly rated among participants at baseline. In addition to these negative emotional and affective states, participants also rated lower than average on positive emotional experience and affect, though not as dramatically so as they ranked negative emotions. Participants often cited that they had not frequently experienced such emotional states as "fun-loving," "optimistic," or "peaceful" in the past two weeks nor had they often felt affective states such as "enthusiastic," "proud," or "inspired."

Overall the baseline measurements indicated that the MyGratefulSelf sample was highly distressed which is in keeping with previous literature on the well-being of young adults with cancer. Further exploration of the correlations among these outcome measures may yield a more sophisticated understanding of the psycho-emotional states of young people with advanced stage cancer. This could be investigated through a correlational analysis of baseline levels of gratitude with other measures of well-being to see if gratitude predicts well-being in a highly distressed clinical population. A correlational analysis of socio-demographic factors and well-being in this population may 
also help determine the relative impact of financial burden, family structure, and cancer diagnosis on measures of well-being. This would help guide future interventions to be more tailored to the needs of each individual participant based on their unique life circumstances.

\section{Post-Intervention}

Post-intervention measures indicated that the MyGratefulSelf intervention had a significant, immediate impact on well-being. The experimental group saw improvement in their scores on all outcome measures with statistically significant improvement in gratitude, mindful observation, negative emotional experience, negative affect, selfacceptance, and personal growth. The control group saw very small improvement, though not statistically significant, in gratitude, positive emotion, and autonomy and saw statistically significant improvement, only in positive relations with others. Conversely, the control group saw a worsening of symptoms in negative emotional experience, negative affect, purpose in life, and environmental mastery, though these changes were not statistically significant. The adjusted overall effect sizes for each measure indicate that the MyGratefulSelf intervention had a large positive effect on gratitude, mindful observation, negative emotional experience, and negative affect. The intervention had a medium positive effect on positive emotional experience, self-acceptance, purpose in life, personal growth, and environmental mastery. It had a small positive effect on positive affect. The intervention appears to have had a small negative effect on positive relations with other and autonomy, however, given that the experimental group did see some gains 
in those areas, this is likely a consequence of small sample size. It could also represent a real change in the lives of the control participants that the study was unable to control for. Compared to other gratitude interventions, these results demonstrate a larger positive impact on well-being. A recent meta-analysis of gratitude interventions broken down by type of control group (measurement only, alternative activity, and activitymatched comparison) found that effect sizes for both outcomes of gratitude and psychological well-being were limited (Davis et al., 2016). The authors found that, overall, the effects of gratitude interventions including letters, lists, and reflective journaling, when compared with a measurement only control (also used in the MyGratefulSelf study), average $0.20(-0.04-0.44)$ for the outcome of gratitude and 0.31 $(0.04-0.58)$ for the outcome of psychological well-being (Davis et al., 2016). These are substantially lower than the post-intervention effect sizes seen in the MyGratefulSelf study (gratitude $=1.40$, psychological well-being $=-0.25-0.74$ ). The authors of this meta-analysis conclude that enthusiasm for the impact of gratitude interventions should be tempered until further research can be conducted focusing on previous holes and weaknesses in the existing literature including the need for more studies with participants in clinical populations and those having trouble regulating emotions (e.g. depression, grief, trauma), so that there may be more potential for change (Davis et al., 2016). The MyGratefulSelf study speaks to these gaps in the literature by targeting a clinical population with great room for improvement on measures of gratitude and psychological well-being. The large effect sizes found in the MyGratefulSelf study should not be dismissed as aberrant or simply a result of small sample size because the participant sample was so highly distressed at baseline, leaving great potential for change. 
Of note, the experimental group experienced a profound decrease in negative emotional experience and negative affect, decreasing from 1.5 - 2 SD above the normal range to well within the normal range. Returning to the research conceptual model posed in Chapter 1 (Figure 1.), the MyGratefulSelf intervention appears to have had a large impact on the bottom of the upward spiral. Participants saw improvements in gratitude, increased awareness of the positive things in their lives (mindful observation and increased positive emotional experience and affect), and decreased negative emotion, when compared with the control group. While the improvements in psychological wellbeing were limited in this study, it is possible that with a longer intervention or a more comprehensive intervention, as suggested in the evaluation of the system, greater improvement in the upper levels of the spiral could be achieved by continuing to promote positive emotions and allowing them time to build on one another over time (Fredrickson, 2004b).

\section{0-Day Follow-Up}

The 30-day follow-up measures are slightly more difficult to interpret than the immediate post-intervention results. This is due in part to the fact that several participants in the experimental group did indicate that they were continuing to journal but were not using the MyGratefulSelf system. This does not allow for comparison of journal content and one participant even mentioned that she was having difficulty keeping her focus on positive emotions, rather than negative emotions. Additionally, several participants in the experimental group indicated that they were no longer keeping a journal of any kind. With these limitations in mind, the results of the 30-day follow-up 
measures represent a mixed picture. Overall effect sizes indicate that the intervention resulted in continued improvement in gratitude, positive emotional experience and affect, positive relations with others, personal growth, environmental mastery, and autonomy. A leveling or decreased improvement was seen in mindful observation, positive and negative affect, self-acceptance, and purpose in life. Some of the increased effect sizes (negative emotion and personal growth) are related to increased negative change in the control group rather that continued improvement in the experimental group. Overall, areas that did see sustained improvement, saw only small growth from post-intervention to 30-day follow up.

Because gratitude is known to be both a state and trait, it would follow that increased trait gratitude would lead to sustained positive effects on well-being (McCullough et al., 2002; Wood et al., 2010). However the literature is unclear on how long it takes to actually improve trait gratitude and how long that change would last without consistent gratitude practice. In terms of gratitude, the results of the MyGratefulSelf study suggest that trait gratitude can in increased in a period of 21 days, with at least 14 days of focused gratitude practice. Additionally, the results suggest that gratitude may continue to increase over 30 days with or without continued practice, however a correlational analysis of those who continued to journal versus, those who did not, may illuminate this topic further. With regard to psychological well-being, it appears that the effects of gratitude are less likely to persist over time with or without continued gratitude practice.

It is also worthwhile to note that, while the effect size did not improve from postintervention to 30-day follow-up, negative affect remained in the normal range for 
participants in the experimental group at the 30-day follow-up (Watson et al., 1988).

This finding is of interest because it supports Fredrickson's theory that focus on positive emotion can undo the effects of negative emotion and that the effect of gratitude practice on negative emotional experience is sustainable at least one month after discontinuing formal gratitude practice (Fredrickson, 2004a). In other words, the broadening effect of gratitude practice served to build the personal resources of the experimental group enough to maintain a lower level of negative emotional experience and a slightly enhanced level of positive emotional experience even after discontinuing practice. Over the same time period, those in the control group continued to experience very high levels of negative emotion and relatively low levels of positive emotion. Another study found that gratitude orientation reduced death anxiety in a population of Chinese college students, but did not have any effects on affect (Lau \& Cheng, 2012). This study provides an interesting counterpoint to the MyGratefulSelf study, which did not measure death anxiety, but found that gratitude practice had a considerable impact on affect in a population of similar age that was actively confronting death. This provides convincing evidence that gratitude practice has the potential to substantially improve emotional experience in a very distressed population of young adults who are living with stressful circumstances and grappling with their own pre-mature mortality. Overall, the results of the MyGratefulSelf study are very encouraging regarding the impact of a simple, accessible, and cost-effective intervention to promote well-being in young adults with advanced stage cancer.

\section{Limitations}


There are several limitations to this study. The first, and most important limitation, is that of sample size. Because the MyGratefulSelf study was a feasibility study with a primary aim of testing a new recruitment strategy, researchers were not able to recruit their goal sample size of 52. This limits the generalizability of the efficacy results. Future research should aim for a fully powered study to better estimate the true effects of gratitude practice on this population.

In addition, this study is limited by self-selection and self-report bias. Participants in the MyGratefulSelf study were already online and looking for support and community and may have been predisposed to believe a writing intervention would be helpful. Particularly in the case of reporting gratitude levels, social desirability and self-report bias become an important limitation. Participants likely read the questionnaire and knew what the desirable responses would be. Given the low scores on the baseline gratitude questionnaire and the dramatic change over time, including a sustained increase even after the intervention, it is possible that the intervention group over-reported their gratitude levels post-intervention and at 30-day follow-up. This is a difficult limitation to address in future research and should be acknowledged when designing studies that measure gratitude, which can be perceived as a virtue.

Because the study was conducted entirely online and medical records were not accessed, researchers had limited ability to confirm diagnosis and treatment details. However, given the recruitment methods, the video calls to confirm eligibility, and the limited compensation for participation, researchers felt fairly certain that participants were representing themselves honestly and that the sample demographics are accurate. 
Finally, researchers had limited control over what the participants were writing in both the experimental and control groups. The contents of the journals suggest that participants in the experimental group were writing true gratitude journals some of the time, but that occasionally journal entries were more expressive writing or negative emotional expression. On occasion, there were journal entries with content so limited as to simply be categorized as a placeholder. The researchers asked those in the control group not to journal about anything during the study timeframe, but were unable to know if they actually didn't write.

\section{Publications and Continued Analysis}

Three manuscripts addressing the specific aims of this study are being planned and prepared for publication. Authors, journals, and titles are presented in Table 11:

Table 11: Manuscripts for Publication

\begin{tabular}{|l|l|l|}
\hline Authors & Target Journal & Title \\
\hline $\begin{array}{l}\text { Adelstein, K., Keim-Malpass, J., } \\
\text { Erickson, J., Haizlip, J., } \\
\text { Ritterband, L., Bauer-Wu, S. }\end{array}$ & $\begin{array}{l}\text { PsychoOncology, special issue on } \\
\text { technology in psychosocial } \\
\text { oncology care }\end{array}$ & $\begin{array}{l}\text { Effects of an Online Gratitude } \\
\text { Intervention to Promote Well- } \\
\text { Being in Young Adults with } \\
\text { Advanced Cancer }\end{array}$ \\
\hline Adelstein, K., Ritterband, L. & Internet Interventions & $\begin{array}{l}\text { Development and Utility of an } \\
\text { Online Gratitude Intervention to } \\
\text { Promote Well-being in Young } \\
\text { Adults with Advanced Cancer }\end{array}$ \\
\hline $\begin{array}{l}\text { Adelstein, K., Keim-Malpass, J., } \\
\text { Ritterband, L., Bauer-Wu, S. }\end{array}$ & $\begin{array}{l}\text { Journal of Adolescent and Young } \\
\text { Adult Oncology }\end{array}$ & $\begin{array}{l}\text { Joining versus Using Social } \\
\text { Networks to Recruit Young } \\
\text { Adults for an Online Behavioral } \\
\text { Intervention Study }\end{array}$ \\
\hline
\end{tabular}

Additionally, to fully explore the data and answer some of the questions raised by the data, several secondary analyses are planned. In order to add to the literature on length of intervention and minimal time needed for effect, a dose-effect analysis will be 
completed. To better understand the experiences of the participants in this study, a qualitative analysis of the gratitude journals themselves will be conducted. Additionally, to help tease out the effects of expressive writing versus true gratitude practice, a mixed method analysis correlating the contents of the journals and the change over time in wellbeing will be conducted. Lastly, several correlational analyses between sociodemographics and outcome measures, as well as correlational analyses among the outcome measures will be completed to better understand the intricacies of well-being in this population and inform future intervention studies to promote well-being. These analyses will be grouped into several manuscripts and published in appropriate journals.

\section{Conclusion}

The MyGratefulSelf study is a promising pilot study of an online intervention to promote well-being in young adults with advanced cancer. The results of this study suggest that the Internet is an excellent place to recruit participants for research studies. However, the Internet shouldn't be treated as a virtual bulletin board for research flyers but rather as the dwelling place of virtual communities that should be approached and engaged in similar ways to other communities that dwell in the non-virtual world. The MyGratefulSelf system was a usable website and functioned extremely well for administering a study remotely. The system itself needs to be broadened and tailored to its target population to increase engagement and retention and to maximize the potential for promoting well-being through a self-directed Internet intervention. Gratitude appears to have a substantial impact on the well-being of highly distressed young adults with advanced cancer. It has shown particular influence on negative emotional experience and 
may have the potential to reduce negative emotions even after daily practice has been discontinued. These findings have the potential to add significantly to the literature in the following areas:

Young Adult Oncology: While there has been an increase in research on this distinct population over the past 10-15 years, young adults with cancer are still not seeing the gains in survival that pediatric and adult oncology patients have seen (Bleyer, 2011). Due to their developmental stage, special consideration needs to be made when developing and testing psychosocial interventions for this population (Zebrack, 2011). Many interventions have been developed and tested for young adults during the early stages of treatment and moving into the survivorship phase, however there is a gap in the literature regarding developmentally appropriate psychosocial interventions to promote well-being in young adults who may be facing the end of their lives (D'Agostino et al., 2011; Trevino et al., 2011; Trevino et al., 2012; Zebrack \& Isaacson, 2012a; Zebrack \& Isaacson, 2012b). The MyGratefulSelf study has provided evidence for the preliminary efficacy of an accessible, cost-effective, private, and developmentally appropriate intervention to promote well-being and reduce negative emotion in this population.

Moreover, historically, young adult oncology patients have been very difficult to recruit into clinical trials and even more difficult to recruit into behavioral research trials (Burke et al., 2007; Cantrell et al., 2012; Fern \& Whelan, 2010; Hendricks-Ferguson et al., 2013; Moyer, Knapp, Oliver, Sohl, Schnieder, \& Floyd, 2009). The current literature suggests that using paid advertising on social network sites frequented by young adults is an effective way to bring these patients into research (Akard et al., 2015; Gorman et al., 2014; Ramo et al., 2014). The MyGratefulSelf study expands on this existing literature 
demonstrating that joining and engaging in these virtual communities is also an effective way to recruit young adults into behavioral research, without spending thousands of dollars. It also suggests that care providers and researchers should engage with clinical populations in the same way we engage with communities, seeking out their gathering places and coming to them, to find out what they need in order to improve their health through true partnerships.

Internet-Delivered Behavioral Interventions: Internet-delivered behavioral interventions have immense potential to improve mental health and well-being. Many studies over the last 10 years have demonstrated the efficacy of online CBT for anxiety (Olthuis, Watt, Bailey, Hayden, \& Stewart, 2016) and Internet based interventions have shown great promise for addressing previously difficult to treat problems such as pain (Buhrman, Gordh, \& Andersson, 2016), insomnia (Ritterband et al., 2009), depression (Meyer et al., 2015), and substance abuse (Elison, Davies, \& Ward, 2015). Given the success of Internet-based interventions in treating mental health issues, there has been a call for more Internet-based interventions to promote mental health and well-being in the oncology population (Leykin et al., 2012). The MyGratefulSelf study answers that call by describing the development, usability, and preliminary efficacy of a simple Internetdelivered intervention to improve well-being in a highly distressed oncology subpopulation. While the MyGratefulSelf system has some room for improvement, most notably the need for tailoring to improve engagement and retention, it demonstrates that simple, accessible interventions delivered over the Internet have the potential to dramatically improve well-being in the oncology population. Future studies of this, and other Internet interventions in the oncology population, should build on the simplicity of 
the MyGratefulSelf model adding the opportunity for more personalization, greater variety of writing prompts, and capitalizing on the social connection the Internet can offer for very isolated patients.

Positive Psychology: The study of positive psychology is grounded in the idea that we have a great deal to learn from people who flourish and that human flourishing is possible even in the most dire of circumstances (Seligman \& Csikszentmihalyi, 2000). Over the past decade, there have been several studies describing the distinguishing qualities of those who are resilient in face of challenges and, more recently, there have been studies examining ways to improve well-being and happiness (Duckworth et al., 2005; Seligman, 2008; Seligman, Steen, Park, \& Peterson, 2005). The promotion of positive emotions, particularly gratitude, has shown some very promising results in improving health and well-being (Emmons, 2010; Emmons \& McCullough, 2003a; Emmons \& Stern, 2013; Froh et al., 2008; Kerr, 2014; Krejtz, 2014; Watkins et al., 2015; Wood et al., 2009). However, a recent meta-analysis of gratitude interventions suggests that researchers should moderate their enthusiasm for the efficacy of gratitude until several holes in the literature can be filled (Davis et al., 2016). One such hole, the authors conclude, is the testing of gratitude in clinical populations that show very high levels of distress or have trouble regulating their emotions.

The MyGratefulSelf study contributes to the forward momentum of gratitude research by providing preliminary evidence that the promotion of gratitude may have a positive impact on the well-being of a highly distressed population. Moreover, it demonstrates a substantial impact on negative emotional experience and some improvement in positive emotion (other than gratitude) in young people who are coping 
with extremely stressful life circumstances and actively confronting their own mortality. While the sample is small, and the results are limited in their generalizability, the MyGratefulSelf study lays groundwork for future, fully powered, research on the effects of daily gratitude practice in a highly distressed population. In this way, it builds on the fundamental principle of positive psychology; that human beings can continue to grow, to fulfill their potential, and to find happiness, even in the darkest of times.

\section{References}

Abbott, R. A., Ploubidis, G. B., Huppert, F. A., Kuh, D., \& Croudace, T. J. (2010). An evaluation of the precision of measurement of Ryff's psychological well-being scales in a population sample. Social Indicators Research, 97(3), 357-373. doi:10.1007/s11205-009-9506-X.

Akard, T. F., Wray, S., \& Gilmer, M. J. (2015). Facebook advertisements recruit parents of children with cancer for an online survey of web-based research preferences. Cancer Nursing, 38(2), 155-161. doi:10.1097/NCC.0000000000000146

Alaka, R., Block, S. D., Friedlander, R. J., Zhang, B., Maciejewski, P. K., \& Prigerson, H. G. (2006). Peaceful awareness in patients with advanced cancer. Journal of Palliative Medicine, 9(6), 1359-1368. doi:10.1089/jpm.2006.9.1359

Baer, R. A., Smith, G. T., Hopkins, J., Krietemeyer, J., \& Toney, L. (2006). Using selfreport assessment methods to explore facets of mindfulness. Assessment, 13, 27-45. 
Baer, R. A., Smith, G. T., Lykins, E., Button, D., Krietemeyer, J., Sauer, S., . . Williams, M. G. (2008). Construct validity of the five facet mindfulness questionnaire in meditating and non-meditating samples. Assessment, 15, 329-342.

Barling, J. A., Stevens, J. A., \& Davies, K. M. (2014a). The reality of hospitalisation: Stories from family members of their hospital experience for adolescents and young adults living with and dying from cancer. Contemporary Nurse: A Journal for the Australian Nursing Profession, 46(2), 150-160. doi:10.5172/conu.2014.46.2.150

Barr, R. D., Ferrari, A., Ries, L., Whelan, J., \& Bleyer, W. A. (2016). Cancer in Adolescents and Young Adults: A Narrative Review of the Current Status and a View of the Future. JAMA pediatrics, 170(5), 495-501.

Bauer-Wu, S., \& Farran, C. J. (2005). Meaning in life and psycho-spiritual functioning: A comparison of breast cancer survivors. Journal of Holistic Nursing, 23(2), 172-190.

Bleyer, A. (2011). Latest estimates of survival rates of the 24 most common cancers in adolescent and young adults. J Adolesc Young Adult Oncol, 1(1), 37-42. doi:10.1089/jayao.2010.0005

Bleyer, A., \& Barr, R. (2009). Cancer in young adults 20 to 39 years of age: Overview. Semin Oncol, 36(3), 194-206. doi:doi:10.1053/j.seminoncol.2009.03.003

Bleyer, A., Barr, R., Hayes-Lattin, B., Thomas, D., Ellis, C., \& Anderson, B. (2008). The distinctive biology of cancer in adolescents and young adults. National Review of Cancer, 8(4), 288-298. doi:10.1038/nrc2349 
Block, S. D. (2006). Psychological issues in end-of-life care. Journal of Palliative Medicine, 9(3), 751-772. doi:10.1089/jpm.2006.9.751

Boyle, G. J. (1984). Reliability and validity of izard's differential emotions scale. Personality and Individual Differences, 5(6), 747-750. doi:http://dx.doi.org/10.1016/0191-8869(84)90124-7

Breitbart, W., Gibson, C., Poppito, S. R., \& Berg, A. (2004). Psychotherapeutic interventions at the end of life: A focus on meaning and spirituality. Canadian $J$ Psych, 49(6), 366-372.

Buhrman, M., Gordh, T., \& Andersson, G. (2016). Internet interventions for chronic pain including headache: A systematic review. Internet Interventions, 4, Part 1, 17-34. doi:http://dx.doi.org/10.1016/j.invent.2015.12.001

Burgoyne, M. J., Bingen, K., Leuck, J., Dasgupta, M., Ryan, P., \& Hoffmann, R. G. (2015). Cancer-related distress in young adults compared to middle-aged and senior adults. Journal of Adolescent and Young Adult Oncology, 4(2), 56-63.

Burke, M. E., Albritton, K., \& Marina, N. (2007). Challenges in the recruitment of adolescents and young adults to cancer clinical trials. Cancer, 110(11), 2385-2393. doi:10.1002/cncr.23060

Cantrell, M., Ann, Conte, T., Hudson, M., Shad, A., Ruble, K., Herth, K., . . Kemmy, S. (2012). Recruitment and retention of older adolescent and young adult female 
survivors of childhood cancer in longitudinal research. Oncology Nursing Forum, 39(5), 483-490.

Cha, M., Haddadi, H., Benevenuto, F., \& Gummadi, K. P. (2010). Measuring user influence of twitter: The million follower fallacy. Proceedings of the Fourth International AAAI Conference on Weblogs and Social Media, 4(1) 10-17.

Chew, L. D., Bradley, K. A., \& Boyko, E. J. (2004). Brief questions to identify patients with inadequate health literacy. Family Medicine, 36(8), 588-594.

Cho, E.,A., \& Oh, H. E. (2011). Effects of laughter therapy on depression, quality of life, resilience and immune responses in breast cancer survivors. $J$ Korean Acad Nurs, 41(3), 285-293.

Cleary, E. H., \& Stanton, A. L. (2014). Mediators of an internet-based psychosocial intervention for women with breast cancer. Health Psychology, No Pagination Specified. doi:10.1037/hea0000170

Cohen, J. (1992). A power primer. Psychological Bulletin, 112(1), 155-159.

Cohen-Gogo, S., Marioni, G., Laurent, S., Gaspar, N., Semeraro, M., Gabolde, M., . . . Brugières, L. (2011). End of life care in adolescents and young adults with cancer: Experience of the adolescent unit of the Institut Gustave Roussy. European Journal of Cancer, 47(18), 2735-2741. doi:http://dx.doi.org.proxy.its.virginia.edu/10.1016/j.ejca.2011.09.008 
Cohn, M. A., Fredrickson, B. L., Brown, S. L., \& Mikels, J. A. (2009). Happiness unpacked: Positive emotions increase life satisfaction by building resilience. Emotion, 9(3), 361-368.

Colon-Otero, G., Smallridge, R. C., Solberg, L. A., Keith, T. D., Woodward, T. A., Willis, F. B., \& Dunn, A. N. (2008). Disparities in participation in cancer clinical trials in the United States. Cancer, 112(3), 447-454. doi:10.1002/cncr.23201

Couper, M. P., Alexander, G. L., Maddy, N., Zhang, N., Nowak, M. A., McClure, J. B., . .. Cole, J. C. (2012). Engagement and retention: Measuring breadth and depth of participant use of an online intervention. Journal of Medical Internet Research, 12(4), e52. doi:doi:10.2196/jmir.1430

Curtis, B. L. (2014). Social networking and online recruiting for HIV research: Ethical challenges. Journal of Empirical Research on Human Research Ethics, 9(1), 58-70.

D'Agostino, N. M., \& Edelstein, K. (2013). Psychosocial challenges and resource needs of young adult cancer survivors: Implications for program development. Journal of Psychosocial Oncology, 31(6), 585-600. doi:10.1080/07347332.2013.835018

D'Agostino, N. M., Penney, A., \& Zebrack, B. (2011). Providing developmentally appropriate psychosocial care to adolescent and young adult cancer survivors. Cancer, 117(S10), 2329-2334. doi:10.1002/cncr.26043

Davis, D. E., Choe, E., Meyers, S., Varjas, K., Gifford, A., Quinn, A., . . Worthington, E. L. (2016). Thankful for the little things: A meta-analysis of gratitude 
interventions. Journal of Counseling Psychology, 63(1), 20-31. doi:10.1037/cou0000107

Digdon, N., \& Koble, A. (2011). Effects of constructive worry, imagery distraction, and gratitude interventions on sleep quality: A pilot trial. Applied Psychology: Health and Well-Being, 3(2), 193-206. doi:10.1111/j.1758-0854.2011.01049.x

Duckworth, A. L., Steen, T. A., \& Seligman, M. E. P. (2005). Positive psychology in clinical practice. Annual Review of Clinical Psychology, 1, 629-651. doi: 10.1146/annurev.clinpsy.1.102803.144154

Duggan, M., Ellison, N. B., Lampe, C., Lenhart, A., \& Madden, M. (2015). Social media update 2014. Washington, DC: Pew Research Center: Internet, Science, and Tech.

Durlak, J. A. (2009). How to select, calculate, and interpret effect sizes. Journal of Pediatric Psychology, 34(9), 917-928. doi:10.1093/jpepsy/jsp004

Dutton, G. R. (2008). The role of mindfulness in health behavior change. ACSM'S Health \& Fitness Journal, 12(4), 7-12. doi:10.1249/FIT.0b013e31817bf5db

Ekkekakis, P. (2012). Affect, mood, and emotion. In G. Tenenbaum, R. C. Eklund \& A. Kamata (Eds.), Measurement on sports and exercise psychology (1st ed., pp. 321332). Champaign, IL: Human Kinetics.

Elison, S., Davies, G., \& Ward, J. (2015). Effectiveness of computer-assisted therapy for substance dependence using breaking free online: Subgroup analyses of a 
heterogeneous sample of service users. Jounral of Medical Internet Research Mental Health, 2(2), e13. doi:10.2196/mental.4355

Emmons, R. A. (2010). Why gratitude is good. Retrieved from http://greatergood.berkeley.edu/article/item/why_gratitude_is_good

Emmons, R. A., \& Kneezel, T. T. (2005). Giving thanks: Spiritual and religious correlates of gratitude. Journal of Psychology and Christianity, 24(2), 140-148.

Emmons, R. A., \& McCullough, M. E. (2003a). Counting blessings versus burdens: An experimental investigation of gratitude and subjective well-being in daily life. Journal of Personality and Social Psychology, 84(2), 377-389. doi:10.1037/00223514.84.2.377

Emmons, R. A., \& McCullough, M. E. (2003b). Counting blessings versus burdens: An experimental investigation of gratitude and subjective well-being in daily life. Journal of Personality and Social Psychology, 84(2), 377-389. doi:10.1037/00223514.84.2.377

Emmons, R. A., \& Stern, R. (2013). Gratitude as a psychotherapeutic intervention. Journal of Clinical Psychology, 69(8), 846-855. doi:10.1002/jclp.22020

Fern, L. A., \& Whelan, J. S. (2010). Recruitment of adolescents and young adults to cancer clinical Trials-International comparisons, barriers, and implications. Seminars in Oncology, 37(2), e1-e8. doi:http://dx.doi.org.proxy.its.virginia.edu/10.1053/j.seminoncol.2010.04.002 
Ferrari, A., Montello, M., Budd, T., \& Bleyer, A. (2008). The challenges of clinical trials for adolescents and young adults with cancer. Pediatric Blood \& Cancer, 50(S5), 1101-1104. doi:10.1002/pbc.21459

Ford, J. G., Howerton, M. W., Lai, G. Y., Gary, T. L., Bolen, S., Gibbons, M. C., . . Bass, E. B. (2008). Barriers to recruiting underrepresented populations to cancer clinical trials: A systematic review. Cancer, 112(2), 228-242. doi:10.1002/cncr.23157

Fredrickson, B. L. (2004a). The broaden and build theory of positive emotions. Philsophical Transactions: Biological Sciences, 359(1449), 1367-1377. doi:10. 1098/rstb.2004.1512

Fredrickson, B. L. (2004b). Gratitude, like other positive emotions, broadens and builds. In R. A. Emmons, \& M. E. McCullough (Eds.), The psychology of gratitude (pp. 145-166). Oxford, England: Oxford University Press.

Fredrickson, B. L., Cohn, M. A., Coffey, K. A., Pek, J., \& Finkel, S. M. (2008). Open hearts build lives: Positive emotions, induced through loving-kindness meditation, build consequential personal resources. Journal of Personality and Social Psychology, 95(5), 1045-1062. doi:doi:10.1037/a0013262

Fredrickson, B. L., Tugade, M. M., Waugh, C. E., \& Larkin, G. R. (2003). What good are positive emotions in crises? A prospective study of resilience and emotions following the terrorist attacks on the United States on September 11th, 2001. Journal of Personality and Social Psychology, 84(2), 365-376. 
Fredrickson, B. L., \& Joiner, T. (2002). Positive emotions trigger upward spirals toward emotional well-being. Psychological Science, 13(2), 172.

Froh, J. J., Sefick, W. J., \& Emmons, R. A. (2008). Counting blessings in early adolescents: An experimental study of gratitude and subjective well-being. Journal of School Psychology, 46(2), 213-233. doi:http://dx.doi.org/10.1016/j.jsp.2007.03.005

Geraghty, A. W. A., Wood, A. M., \& Hyland, M. E. (2010). Attrition from self-directed interventions: Investigating the relationship between psychological predictors, intervention content and dropout from a body dissatisfaction intervention. Social Science \& Medicine, 71(1), 30-37. doi:10.1016/j.socscimed.2010.03.007

Gorman, J. R., Roberts, S. C., Dominick, S. A., Malcame, V. L., Dietz, A. C., \& Su, H. I. (2014). A diversified recruitment approach incorporating social media leads to research participation among young adult-aged female cancer survivors. Journal of Adolescent and Young Adult Oncology, 3(2), 59-65. doi:10.1089/jayao.2013.0031

Hatchett, B. F., Holmes, K., Duran, D. A., \& Davis, C. (2000). African Americans and research participation: The recruitment process. Journal of Black Studies, 30(5), 664-675. doi:10.1177/002193470003000502

Hendricks-Ferguson, V. L., Cherven, B. O., Burns, D. S., Docherty, S. L., PhillipsSalimi, C. R., Roll, L., . . Haase, J. E. (2013). Recruitment strategies and Rates of a multi-site behavioral intervention for adolescents and young adults with cancer. 
Journal of Pediatric Health Care, 27(6), 434-442.

doi:http://dx.doi.org.proxy.its.virginia.edu/10.1016/j.pedhc.2012.04.010

Hertzog, M. A. (2008). Considerations in determining sample size for pilot studies. Research in Nursing \& Health, 31(2), 180-191. doi:10.1002/nur.20247

Holland, J. C., Kelly, B. J., \& Weinberger, M. I. (2010). Why psychosocial care is difficult to integrate into routine cancer care: Stigma is the elephant in the room. Journal of the National Comprehensive Cancer Network: JNCCN, 8(4), 362-366. doi:8/4/362 [pii]

Hui, D., Glitza, I., Chisholm, G., Yennu, S., \& Bruera, E. (2013). Attrition rates, reasons, and predictive factors in supportive care and palliative oncology clinical trials. Cancer, 119(5), 1098-1105. doi:10.1002/cncr.27854

Ishibashi, A., Okamura, J., Ueda, R., Sunami, S., Kobayashi, R., \& Ogawa, J. (2015). Psychosocial Strength Enhancing Resilience in Adolescents and Young Adults With Cancer. Journal of Pediatric Oncology Nursing, doi:1043454214563935.

Jerome, L. W., DeLeon, P. H., James, L. C., Folen, R., Earles, J., \& Gedney, J. J. (2000). The coming of age of telecommunications in psychological research and practice. American Psychologist, 55(4), 407-421. doi:10.1037/0003-066X.55.4.407

Kaczmarek, L. D., Kashdan, T. B., Drazkowski, D., Enko, J., Kosakowski, M., Szäefer, A., \& Bujacz, A. (2015). Why do people prefer gratitude journaling over gratitude letters? The influence of individual differences in motivation and personality on 
web-based interventions. Personality and Individual Differences, 75, 1-6. doi:10.1016/j.paid.2014.11.004

Kashdan, T. B., Uswatte, G., \& Julian, T. (2006). Gratitude and hedonic and eudaimonic well-being in Vietnam War veterans. Behaviour Research and Therapy, 44(2), 177199. doi:http://dx.doi.org.proxy.its.virginia.edu/10.1016/j.brat.2005.01.005

Kazak, A. E., Derosa, B. W., Schwartz, L. A., Hobbie, W., Carlson, C., Ittenbach, R. F., . .. Ginsberg, J. P. (2010). Psychological outcomes and health beliefs in adolescent and young adult survivors of childhood cancer and controls. Journal of Clinical Oncology, 28(12), 2002-2007. doi:http://dx.doi.org/10.1200/JCO.2009.25.9564

Keim-Malpass, J., Baernholdt, M., Erickson, J. M., Ropka, M. E., Schroen, A. T., \& Steeves, R. H. (2013). Blogging through cancer: Young women's persistent problems shared online. Cancer Nursing, 36(2), 163-172. doi:10.1097/NCC.0b013e31824eb879

Keim-Malpass, J. \& Steeves, R. H. (2012). Talking with death at a diner: Young women's online narratives of cancer. Oncology Nursing Forum, 39(4), 373-378.

Kerr, S. L., O'Donovan, A., \& Pepping, C. A. (2014). Can gratitude and kindness interventions enhance well-being in a clinical sample? Journal of Happiness Studies, Online Exclusive (January) doi:10.1007/s10902-013-9492-1

Killen, A., \& Macaskill, A. (2014). Using a gratitude intervention to enhance well-being in older adults. Journal of Happiness Studies, 15(3). doi:10.1007/s10902-014-9542-3 
Kline, R. (2004). Beyond significance testing: Reforming data analysis methods in behavioral research. Washington, DC: American Psychological Association.

Krejtz, I. (2014). Counting one's blessings can reduce the impact of daily stress. Journal of Happiness Studies. Online Exclusive (January).

Kwak, M., Zebrack, B. J., Meeske, K. A., Embry, L., Aguilar, C., Block, R., ... \& Cole, S. (2013). Trajectories of psychological distress in adolescent and young adult patients with cancer: a 1-year longitudinal study. Journal of clinical oncology, 31(17), 2160-2166.

Lambert, N. M., Graham, S. M., \& Fincham, F. D. (2009). A prototype analysis of gratitude: Varieties of gratitude experiences. Personality and Social Psychology Bulletin, 35(9), 1193-1207. doi:10.1177/0146167209338071

Lange, A., van de Ven, J., Schrieken, B., \& Emmelkamp, P. M. G. (2001). Interapy. treatment of posttraumatic stress through the internet: A controlled trial. Journal of Behavior Therapy and Experimental Psychiatry, 32(2), 73-90. doi:http://dx.doi.org.proxy.its.virginia.edu/10.1016/S0005-7916(01)00023-4

Lau, R. W. L., \& Cheng, S. (2012). Gratitude orientation reduces death anxiety but not positive and negative affect. Omega: Journal of Death \& Dying, 66(1), 79-88.

Lawson, L. M., Williams, P., Glennon, C., Carithers, K., Schnabel, E., Andrejack, A., \& Wright, N. (2012). Effect of art making on cancer related symptoms of blood and 
marrow transplantation recipients. Oncology Nursing Forum, 39(4), E353-E360. doi:10.1188/12.ONF.E353-E360

Leykin, Y., Thekdi, S. M., Shumay, D. M., Muñoz, R., Riba, M., \& Dunn, L. B. (2012). Internet interventions for improving psychological well-being in psycho-oncology: Review and recommendations. Psycho-Oncology, 21(9), 1016-1025. doi:http://dx.doi.org/10.1002/pon.1993

Lobb, E. A., Clayton, J. M., \& Price, M. A. (2006). Suffering, loss and grief in palliative care. Australian Family Physician, 35(10), 772-775.

Love, B., Crook, B., Thompson, C. M., Zaitchick, S., Knapp, J., LeFebvre, L., . . . Rechis, R. (2012). Exploring psychosocial support online: A content analysis of messages in an adolescent and young adult cancer community. Cyberpsychology, Behavior and Social Networking, 15(10), 555-559. doi:10.1089/cyber.2012.0138

Lustria, M. L. A., Cortese, J., Noar, S. M., \& Glueckauf, R. L. (2009). Computer-tailored health intervention delivered over the web: Review and analysis of key components. Patient Education \& Counseling, 74(2), 156-173. doi:http://dx.doi.org/10.1016/j.pec.2008.08.023

McCullough, M. E., Emmons, R. A., \& Tsang, J. (2002). The grateful disposition: A conceptual and empirical topography. Journal of Personality and Social Psychology, 82(1), 112-127. doi:10.1037/0022-3514.82.1.112 
Meyer, B., Bierbrodt, J., Schröder, J., Berger, T., Beevers, C. G., Weiss, M., . . Klein, J. P. (2015). Effects of an internet intervention (deprexis) on severe depression symptoms: Randomized controlled trial. Internet Interventions, 2(1), 48-59. doi:http://dx.doi.org/10.1016/j.invent.2014.12.003

Morgan, S., Davies, S., Palmer, S., \& Plaster, M. (2010). Sex, drugs, and rock 'n' roll: Caring for adolescents and young adults with cancer. Journal of Clinical Oncology : Official Journal of the American Society of Clinical Oncology, 28(32), 4825-4830. doi:10.1200/JCO.2009.22.5474 [doi]

Moyer, A., KnappOliver, S. K., Sohl, S. J., Schnieder, S. D. P., \& Floyd, A. H. L. (2009). Lessons to be learned from 25 years of research investigating psychosocial interventions for cancer patients. Cancer Journal, 15(5), 345-351. doi:10.1097/PPO.0b013e3181bf51fb

O'Connor, A., Jackson, L., Goldsmith, L., \& Skirton, H. (2014). Can I get a retweet please? Health research recruitment and the twittersphere. Journal of Advanced Nursing, 70(3), 599-609. doi:10.1111/jan.12222

Oken, M. M., Creech, R. H., Tormey, D. C., Horton, J., Davis, T. E., McFadden, E. T., \& Carbone, P. P. (1982). Toxicity and response criteria of the eastern cooperative oncology group. American Journal of Clinical Oncology, 5, 649-655.

Olthuis, J. V., Watt, M. C., Bailey, K., Hayden, J. A., \& Stewart, S. H. (2016). Therapistsupported internet cognitive behavioral therapy for anxiety disorders in adults. 
Cochrane Database Systematic Review, 12(3), CD011565. doi:10.1002/14651858.CD011565.pub2

Prigerson, H. G., \& Maciejewski, P. K. (2008). Grief and acceptance as opposite sides of the same coin: Setting a research agenda to study peaceful acceptance of loss. The British Journal of Psychiatry: The Journal of Mental Science, 193(6), 435-437. doi:10.1192/bjp.bp.108.053157 [doi]

Prince-Paul, M. (2008). Relationships among communicative acts, social well-being, and spiritual well-being on the quality of life at the end of life in patients with cancer enrolled in hospice. J Palliative Med, 11(1), 20-25. doi:10.1089/jpm.2007.0119

Ramo, D. E., Rodriguez, T. M. S., Chavez, K., Sommer, M. J., \& Prochaska, J. J. (2014). Facebook recruitment of young adult smokers for a cessation trial: Methods, metrics, and lessons learned. Internet Interventions, 1(2), 58-64. doi:http://dx.doi.org/10.1016/j.invent.2014.05.001

Ritterband, L. M., Thorndike, F. P., Gonder-Frederick, L. A., Magee, J. C., Bailey, E. T., Saylor, D. K., \& Morin, C. M. (2009). Efficacy of an internet-based behavioral intervention for adults with insomnia. Archives of General Psychiatry, 66(7), 692698. doi:10.1001/archgenpsychiatry.2009.66

Ritterband, L. M., Ardalan, K., Thorndike, F. P., Magee, J. C., Saylor, D. K., Cox, D. J., . . . Borowitz, S. M. (2008). Real world use of an internet intervention for pediatric encopresis. Journal of Medical Interet Research, 10(2), e16. 
Ritterband, L. M., Thorndike, F. P., Cox, D. J., Kovatchev, B. P., \& Gonder-Frederick, L. A. (2009). A behavioral change model for internet interventions. Ann Behav Med, 38, 18-27. doi:10.1007/s12160-009-9133-4

Ruini, C., \& Vescovelli, F. (2013). The role of gratitude in breast cancer: Its relationship with post-traumatic growth, psychological well-being, and distress. Journal of Happiness Studies, 14(1), 263-274. doi:10.1007/s10902-012-9330-х

Ryff, C. D., Seeman, T. \& Weinstein, M. (2013). National survey of midlife development in the united states (MIDUS II): Biomarker project, 2004-2009. ICPSR29282-v6. Ann Arbor, MI: Inter-university consortium for political and social research [distributor]. doi:10.3886/ICPSR29282.v6

Ryff, C. D., \& Keyes, C. L. M. (1995). The structure of psychological well-being revisited. Journal of Personality and Social Psychology, 69(4), 719-727. doi:10.1037/0022-3514.69.4.719

Sarkar, U., Schillinger, D., López, A., \& Sudore, R. (2011a). Validation of self-reported health literacy questions among diverse English and Spanish-speaking populations. Journal of General Internal Medicine, 26(3), 265-271. doi:doi:10.1007/s11606-010$1552-1$

Schiffman, J. D., Csongradi, E., \& Suzuki, L. K. (2008). Internet use among adolescent and young adults (AYA) with cancer. Pediatr Blood Cancer, 51, 410-415. doi:10.1002/pbc.21616 
Seligman, M. E. P. \& Csikszentmihalyi, M. (2000). Positive psychology: An introduction. American Psychologist, 55(1), 5-14. doi:10.1037/0003-066X.55.1.5

Seligman, M. E. P. (2008). Positive health. Applied Psychology: An International Review, 57, 3-18. doi:doi: 10.1111/j.1464-0597.2008.00351.x

Seligman, M. E. P., Steen, T. A., Park, N., \& Peterson, C. (2005). Positive psychology progress: Empirical validation of interventions. American Psychologist, 60(5), 410421. doi:10.1037/0003-066X.60.5.410

Shaha, M., \& Bauer-Wu, S. M. (2009). Early adulthood uprooted: Transitoriness in young women with breast cancer. Cancer Nursing, 32(3), 246-255. doi:10.1097/NCC.0b013e31819b5b2e

Smith, A. (2012). Cell internet use 2012. Retrieved from http://www.pewinternet.org/2012/06/26/cell-internet-use-2012/

Smith, A. (2015). U.S. smartphone use in 2015. Retrieved from http://www.pewinternet.org/2015/04/01/us-smartphone-use-in-2015/

Smith, A. W., Bellizzi, K. M., Keegan, T. H., Zebrack, B., Chen, V. W., Neale, A. V., .. . Lynch, C. F. (2013). Health-related quality of life of adolescent and young adult patients with cancer in the united states: The adolescent and young adult health outcomes and patient experience study. Journal of Clinical Oncology : Official Journal of the American Society of Clinical Oncology, 31(17), 2136-2145. doi:10.1200/JCO.2012.47.3173 [doi] 
A snapshot of adolescent and young adult cancers. (2013). Retrieved from http://www.cancer.gov/researchandfunding/snapshots/adolescent-young-adult

Song, H., Nam, Y., Gould, J., Sanders, W., S., McLaughlin, M., Fulk, J., . . Ruccione, K., S. (2012). Cancer survivor identity shared in a social media intervention. Journal of Pediatric Oncology Nursing, 29(2), 80-91. doi:http://dx.doi.org/10.1177/1043454212438964

Tacón, A., M. (2011). Mindfulness: Existential, loss, and grief factors in women with breast cancer. Journal of Psychosocial Oncology, 29(6), 643-656. doi:10.1080/07347332.2011.615382

Thorndike, F. P., Saylor, D. K., Bailey, E. T., Gonder-Frederick, L. A., Morin, C. M., \& Ritterband, L. M. (2008). Development and perceived utility and impact of an internet intervention for insomnia. E-Journal of Applied Psychology, 4(2), 32-42.

Toepfer, S. M., Cichy, K., \& Peters, P. (2012). Letters of gratitude: Further evidence for author benefits. Journal of Happiness Studies, 13(1), 187-201. doi:10.1007/s10902$011-9257-7$

Treadgold, C. L., \& Kuperberg, A. (2010). Been there, done that, wrote the blog: The choices and challenges of supporting adolescents and young adults with cancer. Journal of Clinical Oncology, 28(32), 4842-4849. doi:http://dx.doi.org/10.1200/JCO.2009.23.0516 
Trevino, K. M., Maciejewski, P. K., Fasciano, K., \& Prigerson, H. G. (2011). Grief and life disruption in young adults with advanced cancer. J Adolesc Young Adult Oncol, 1(4), 168-172. doi:10.1089/jayao.2011.0024

Trevino, K. M., Maciejewski, P. K., Fasciano, K., Greer, J., Partridge, A., Kacel, E. L., . . . Prigerson, H. G. (2012). Coping and psychological distress in young adults with advanced cancer. The Journal of Supportive Oncology, 10(3), 124-130. doi:10.1016/j.suponc.2011.08.005 [doi]

Tsang, J., Schulwitz, A., \& Carlisle, R. D. (2012). An experimental test of the relationship between religion and gratitude. Psychology of Religion and Spirituality, 4(1), 40-55. doi:10.1037/a0025632

Wallerstein, N., \& Duran, B. (2010). Community-based participatory research contributions to intervention research: The intersection of science and practice to improve health equity. American Journal of Public Health, 100(1), S40-S46. doi:10.2105/AJPH.2009.184036

Watkins, P. C., Scheer, J., Ovnicek, M., \& Kolts, R. (2006). The debt of gratitude: Dissociating gratitude and indebtedness. Cognition and Emotion, 20(2), 217-241. doi:10.1080/02699930500172291

Watkins, P. C., Uhder, J., \& Pichinevskiy, S. (2015). Grateful recounting enhances subjective well-being: The importance of grateful processing. The Journal of Positive Psychology, 10(2), 91-98. doi:10.1080/17439760.2014.927909 
Watson, D., Clark, L. A., \& Tellegen, A. (1988). Development and validation of brief measures of positive and negative affect: The PANAS scales. Journal of Personality and Social Psychology, 54(6), 1063-1070.

Wein, S., Pery, S., \& Zer, A. (2010). Role of palliative care in adolescent and young adult oncology. Journal of Clinical Oncology : Official Journal of the American Society of Clinical Oncology, 28(32), 4819-4824. doi:10.1200/JCO.2009.22.4543 [doi]

Weiner, B. (1985). An attributional theory of achievement motivation and emotion. Psychological Review, 92(4), 548-573. doi:10.1037/0033-295X.92.4.548

Weiss, A. R., Hayes-Lattin, B., Kutny, M. A., Stock, W., Stegenga, K., \& Freyer, D. R. (2015). Inclusion of adolescents and young adults in cancer clinical trials. Seminars in Oncology Nursing, 31(3), 197-205. doi:http://dx.doi.org/10.1016/j.soncn.2015.05.001

Winzelberg, A. J., Eppstein, D., Eldredge, K. L., Wilfley, D., Dasmahapatra, R., Dev, P., \& Taylor, C. B. (2000). Effectiveness of an internet-based program for reducing risk factors for eating disorders. Journal of Consulting and Clinical Psychology, 68(2), 346-350. doi:10.1037/0022-006X.68.2.346

Wood, A. M., Froh, J. J., \& Geraghty, A. W. A. (2010). Gratitude and well-being: A review and theoretical integration. Clinical Psychology Review, 30(7), 890-905. doi:http://dx.doi.org/10.1016/j.cpr.2010.03.005 
Wood, A. M., Joseph, S., \& Maltby, J. (2009). Gratitude predicts psychological wellbeing above the big five facets. Personality and Individual Differences, 46(4), 443447. doi:http://dx.doi.org/10.1016/j.paid.2008.11.012

Wood, A. M., Maltby, J., Gillett, R., Linley, P. A., \& Joseph, S. (2008). The role of gratitude in the development of social support, stress, and depression: Two longitudinal studies. Journal of Research in Personality, 42(4), 854-871. doi:http://dx.doi.org/10.1016/j.jrp.2007.11.003

Yuan, P., Bare, M. G., Johnson, M. O., \& Saberi, P. (2014). Using online social media for recruitment of human immunodeficiency virus-positive participants: A crosssectional survey. Journal of Medical Internet Research, 16(5), e117. doi:10.2196/jmir.3229

Zebrack, B., \& Isaacson, S. (2012). Psychosocial care of adolescent and young adult patients with cancer and survivors. Journal of Clinical Oncology, 30(11), 12211226.

Zebrack, B., Mathews-Bradshaw, B., \& Siegel, S. (2010). Quality cancer care for adolescents and young adults: A position statement. Journal of Clinical Oncology, 28(32), 4862-4867. doi:http://dx.doi.org/10.1200/JCO.2010.30.5417

Zebrack, B. J. (2011). Psychological, social, and behavioral issues for young adults with cancer. Cancer, 117(S10), 2289-2294. doi:10.1002/cncr.26056 
Zebrack, B. J., Corbett, V., Embry, L., Aguilar, C., Meeske, K. A., Hayes-Lattin, B., . . . Cole, S. (2014). Psychological distress and unsatisfied need for psychosocial support in adolescent and young adult cancer patients during the first year following diagnosis. Psycho-Oncology, , n/a-n/a. doi:10.1002/pon.3533 
FRAMEWORK FOR MyGratefulSelf

Table of Contents for this document:

Section 1: $\quad$ Study Design

Section 2: Definitions

Section 3: $\quad$ System Flowchart

Section 4: Study "Step by Step"

Section 5: Web Program Schematic

Section 6: Website Content

Section 7: $\quad$ Email Prompts

Section 8: $\quad$ Tracking/Reporting

Section 9: Online Consent 


\section{STUDY DESIGN}

Design:

○ 2 Groups: Experimental vs. Control x 3 Assessment (pre-intervention, immediate postintervention, 1-month post-intervention)

Subject contact / human involvement:

$\circ$ At pre assessment, PI video calls participant to complete screening interview and on-line consent.

- PI may contact participants on an as needed basis via manual email and phone contact to remind him/her to complete the assessment

- At post-assessment, PI contacts participant on days 29 and 31 if they have not filled out PostQ

- PI may contact participants on an as needed basis via manual email and phone contact to remind him/her to complete the assessment

Recruitment / Screening:

- Potential particpants are self-identified through targeted ads on social media sites

- Potential participants are directed, through the ad, to a URL containing study information and inclusion criteria, an interest form, and an intial consent

- After "Interest Form and consent" are submitted, PI will contact the potential participant directly to conduct a screening interview and initiate the on-line consent process

- After on-line consent is obtained PI will email participant a link to pre-intervention questionnaires and, for those randomized to the treatment condition, a username and password to access the online journals.

Sample size:

○ Target of 52 participants total, (26 per group (Experimental vs. Control)

- Recruitment will commence in October 2015 and is expected to be completed by February 2016 (4 months) 


\section{DEFINITONS}

- $\quad$ Flow $=$ The study flow for a user is as follows:

- Screening (done through internet call prior to any study activities)

- Pre-intervention Assessment (both groups, through outside survey mechanism)

- The experimental and patient condition paths will be utilized:

- Experimental condition (intervention)

- Patient condition (control participants will be moved to the patient pathway at the end of the study)

- Immediate Post-Assessment (both groups, through outside survey mechanism)

- 1 Month Post-Assessment (both groups, through outside survey mechanism)

- $\quad$ Timing

- Participants in the experimental group are given access to the Journals (Diary) when pre-intervention assessment is complete. The participants will be sent a username and password at that time.

- Journals are available for 21 days from first login.

- Daily email reminders to login and journal are received by the participants

- On day 22 after first login participants receive cores_complete email

- Post-intervention assessment link is emailed to participants on day 22 after first login

- Assessment - All assessments will take place outside of RICE

- The Pre and Post Assessment items are included in a separate Measures spreadsheet. Higher level info on measures is below.

- Screening and Eligibility Assessment (via internet/phone call)

- Background and Medical History Questions (developed by the PI)

- ECOG Performance Scale, administered orally

- Pre-Intervention Assessment

- Health Literacy Questionnaire

- Psychological Well-Being Scales

- PANAS-SF

- mDES

- Observation Subscale of the 5-Facet Mindfulness Scale

- Gratitude Questionnaire

- Immediate Post-intervention Assessment

- Psychological Well-Being Scales

- PANAS-SF

- mDES

- Observation Subscale of the 5-Facet Mindfulness Scale

- Gratitude Questionnaire

- Internet evaluation and utility questionnaire

- Post 1 month assessment

- Psychological Well-Being Scale

- PANAS-SF

- $\mathrm{mDES}$ 
- Observation Subscale of the 5-Facet Mindfulness Scale

- Gratitude Questionnaire

- Gratitude Journal $=$ Simple journal function accessed by the experimental group only. Using the calendar function - Participants will have access to the current day's journal and to the previous day's journal. Participants will be able to read, but not edit, previous journal entries.

- Emails $\quad=$ Per protocol logic, automated emails are sent based on Subjects' progress through the program. Record of these emails is saved and tracked in BeStudy Manager under Emails tab. Non-automated emails are sent by the PI and logged under Contact Log tag. 
Study Flowchart

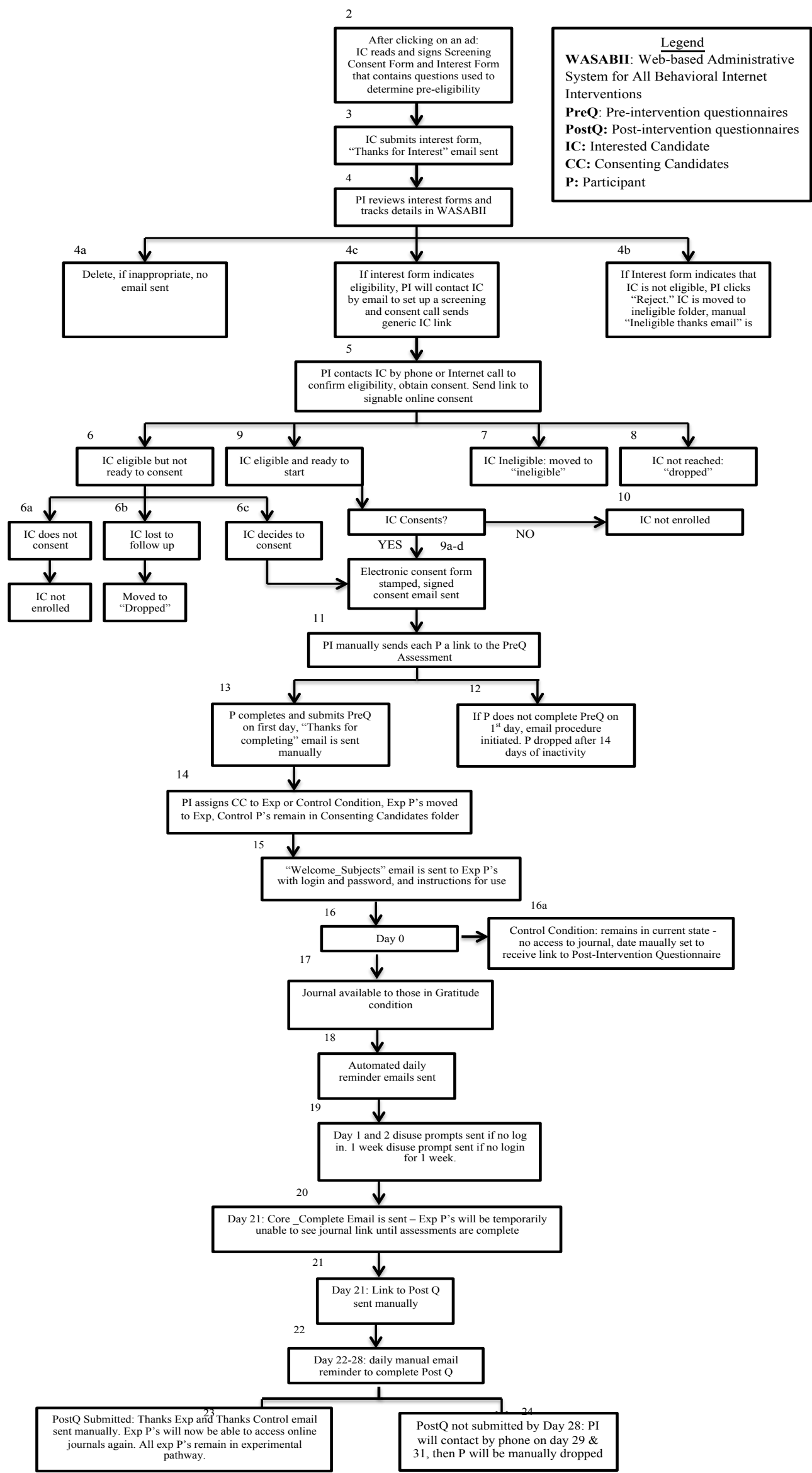




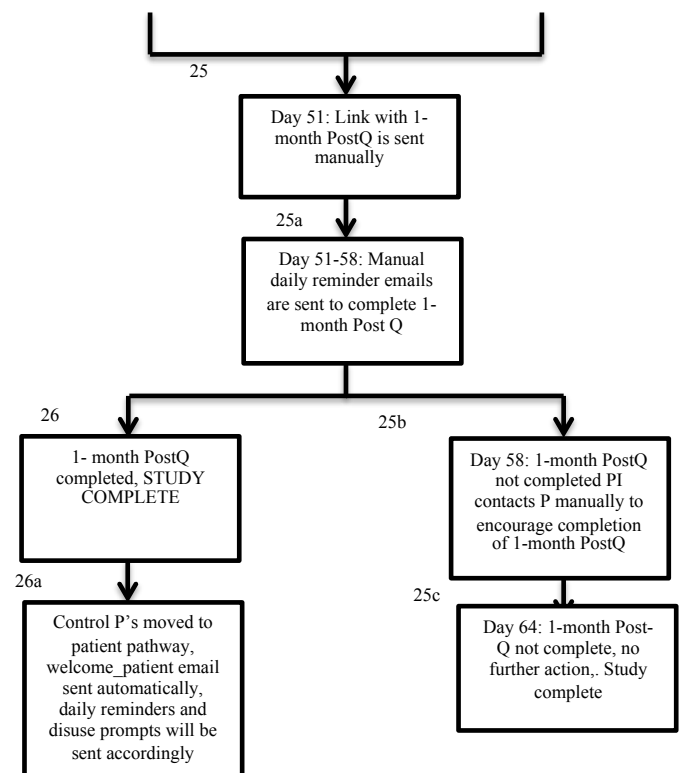




\section{STUDY PROCEDURES STEP-BY-STEP}

1. Interested Candidates (IC) view advertisement for study on social media website.

2. After entering the web address or clicking on the URL, the IC is taken to an interest form contained in the study website that includes information about the study, basic demographic information, contact information and consent to be contacted by the study team.

3. An automated email is sent to the IC thanking him/her for his/her interest and letting $\mathrm{him} /$ her know someone will follow up soon. Automated interest form thank you email is sent.

4. The PI reviews all ICs each day and makes an initial eligibility decision.

a) For inappropriate interest forms (e.g., those that appear 'fake' or should not be in the system at all such as dummy users, joke users), the PI will click "Delete Application" button. This IC then automatically moves to the Deleted Subjects branch under Deleted folder. No email is sent when this occurs.

b) For interest forms where candidates are obviously not eligible (i.e., do not meet age criteria), the PI "Rejects the Interested Candidate" and IC is moved automatically to the Ineligible Candidates branch under the Screening folder. The IC sends a manual email indicating the IC is ineligible and thanking him/her for his/her interest. Ineligible Email manually sent.

c) If the IC seems Eligible, the PI clicks the "Send Contact E-Mail" button and the IC receives an email indicating that we would like to set up a time to talk by phone or internet phone call. Generic IC link Email is sent (by PI).

d) For interested candidates whose eligibility status is not clear, the PI also contacts the candidate using Generic IC link Email.

5. The PI then calls the IC and reviews the Interest Form and determines eligibility using background and medical history questionnaire, and ECOG Performance Scale, administered orally.

6. If the IC is eligible but not ready to consent, the IC will stay in the Interested Candidate branch until:

a) IC actively decides not to consent, then not enrolled in study

b) IC becomes lost to follow up and is then moved to "Dropped" branch under screening folder

c) IC decides to consent, move to step 9.

7. If the IC is not eligible, Reject Application is clicked, and the PI manually sends the Candidate an email thanking them for their interest. The Rejected Candidate is moved automatically to the Ineligible Candidates branch under Screening folder. Ineligible Email manually sent.

8. If the PI is unable to reach the IC after numerous tries, the application is rejected. The PI may send an email, and the IC is automatically placed in the "Dropped" branch under the Screening folder.

9. If the IC is eligible, the PI sends the Signable IC link Email

a) During Phone Interview following eligibility determination, PI sends an email to the IC by clicking the "Send Consent Form" button on study website which contains a link to an online Consent Form. 
b) After receiving and clicking this link, IC receives access to the online Consent Form. At the top of the Consent Form, IC is prompted to enter his/her name. At the end of the Consent Form, there is a box for the IC to check confirming their consent. There is also an electronic signature box for IC to sign.

c) After the Consent Form is submitted, it is automatically stamped with date, time, and PI's signature. The individual then appears in the Consenting Candidates (CC) branch under Screening folder on study website. The Consent Form will be viewable as a .pdf under the Candidate Info tab once the $\mathrm{CC}$ is assigned to a treatment group. The signature is also viewable under this Tab.

d) A copy of the signed consent form (with PI's signature) is automatically emailed to the CC. Signed Consent Email sent.

10. If the IC does not sign the consent, he/she is not enrolled and is "dropped".

11. PI manually emails each participant a link to the study Pre-Questionnaires and instructions for completing assessments.

12. If the $\mathrm{CC}$ does not submit the PreQ on the first day, it is available...

$\circ \mathrm{CC}$ will receive a manual email each day for the following 2 days prompting $\mathrm{CC}$ to complete the PreQ.

- PI will manually send reminders after day 2 prompting $\mathrm{CC}$ to complete the PreQ until day 14 with no activity.

○ 4 and 7 days from the day the PreQ is available, the PI will call the CC to encourage him/her to complete the PreQ if not complete.

- After 14 days of no activity, the PI will manually Drop the CC. The Dropped CC remains in Consented folder but their status changes to Dropped. No further emails will be sent from the system.

13. CC completes and submits the PreQ

a) Thanks for completing the PreQ email is sent manually.

14. PI assigns the $\mathrm{CC}$ to either the Gratitude or Control condition according to a predetermined randomized order separate from WASABII. PI manually moves the CC into his/her respective Subjects branch under the Subjects folder (Control - stays in Consenting Candidates, Experimental - moves to Experimental Pathway).

15. Once the $\mathrm{CC}$ has been moved into the assigned condition, an automated Welcome_Subjects email is sent thanking the Exp P for joining the study, reviewing the study procedures, and providing a link to the website, login and password, and instructions to log into the site. Control P's are sent a manual email with instructions.

16. Day 0 Begins when the $P$ has been assigned to a condition, receives instructions for logging into the system, and has logged in:

a) A date will be set for those assigned to the Waitlist Control condition to be sent a link to complete the Post Questionnaire (PostQ). Manual email with link to PostQ will be sent on Day 22.

17. Those assigned to the Gratitude condition, now have access to the online journaling capabilities.

18. The Intervention Diary Reminder email is sent every day during the intervention.

a) This is a reminder to $\log$ in to system and complete the daily Gratitude exercise.

19. Disuse Prompts sent: on days 1 and 2 of no login, and after 1 week of disuse.

20. After 21 calendar days, cores_complete Email is sent. Day 22, regardless of how many daily entries the P has completed. At this time, Exp. P's will temporarily lose access to 
their journals. They will not see the journal link on the homepage, which does explain this to them. When they complete the post-Q's, PI will manually restore access to the journals. All Exp. P's will remain in the experimental pathway.

21. Gratitude and Control Ps will receive a manual email containing a link to complete postintervention questionnaires.

22. Gratitude and Control Ps will receive a manual email daily during week 4 (or up to 28 days from day 0) thanking them for completing or reminding them to complete PostQ.

23. P completes and submits the PostQ. Thanks Post Prompt Exp sent and Thanks Post Prompt Controls sent manually. PI manually restores access to online journals. P's remain in the experimental pathway.

24. If the P does not submit the PostQ by day 28 (from Day 0):

b) PI will contact the $\mathrm{P}$ by phone on days 29 and 31 to encourage him/her to complete the PostQ.

c) After this, the PI will manually drop the P. The dropped P remains in their respective subjects folder but their status changes to 'Dropped.'

These Ps will fall under PostQ report until PostQ is complete

$\circ \quad$ Report located in: Activity Folder $\rightarrow$ Reports Folder $\rightarrow$ Post Questionnaire Report

- Report displays each Ps login ID, Last Name, First Name, Deadline, Last Login Date, Last Item in Q completed, last contact date, and last contact notes

25. On day 51 following PI will send each participant a link to complete 1-month follow-up questionnaires.

a) Manual reminder/thank you email will be generated and sent on days 54 and 57 .

b) If $\mathrm{P}$ does not complete the 1-month follow up questionnaires by day 57, PI will contact the participant by phone on day 58. Nothing else is required of the automated system at that time.

c) If $\mathrm{P}$ does not complete 1-month follow-up questionnaires by day 64 , no more action is required.

26. Study Complete

a) Control $\mathrm{P}$ are moved to the patient pathway and the welcome_patient email is sent containing username and password information. All intervention emails will commence at that time. 


\section{PROGRAM (MyGratefulSelf) SCHEMATIC}

The design for the MyGratefulSelf program is similar to CancerCope (in that a journal is used for the diary). The HOME page is the main screen of the program. Users will be able to jump to MY JOURNAL, and back to HOME from this page.

Users can be classified as Experimental participants or Control participants. See STUDY STEPBY-STEP for differences.

\section{MyGratefulSelf \\ Online \\ Intervention}

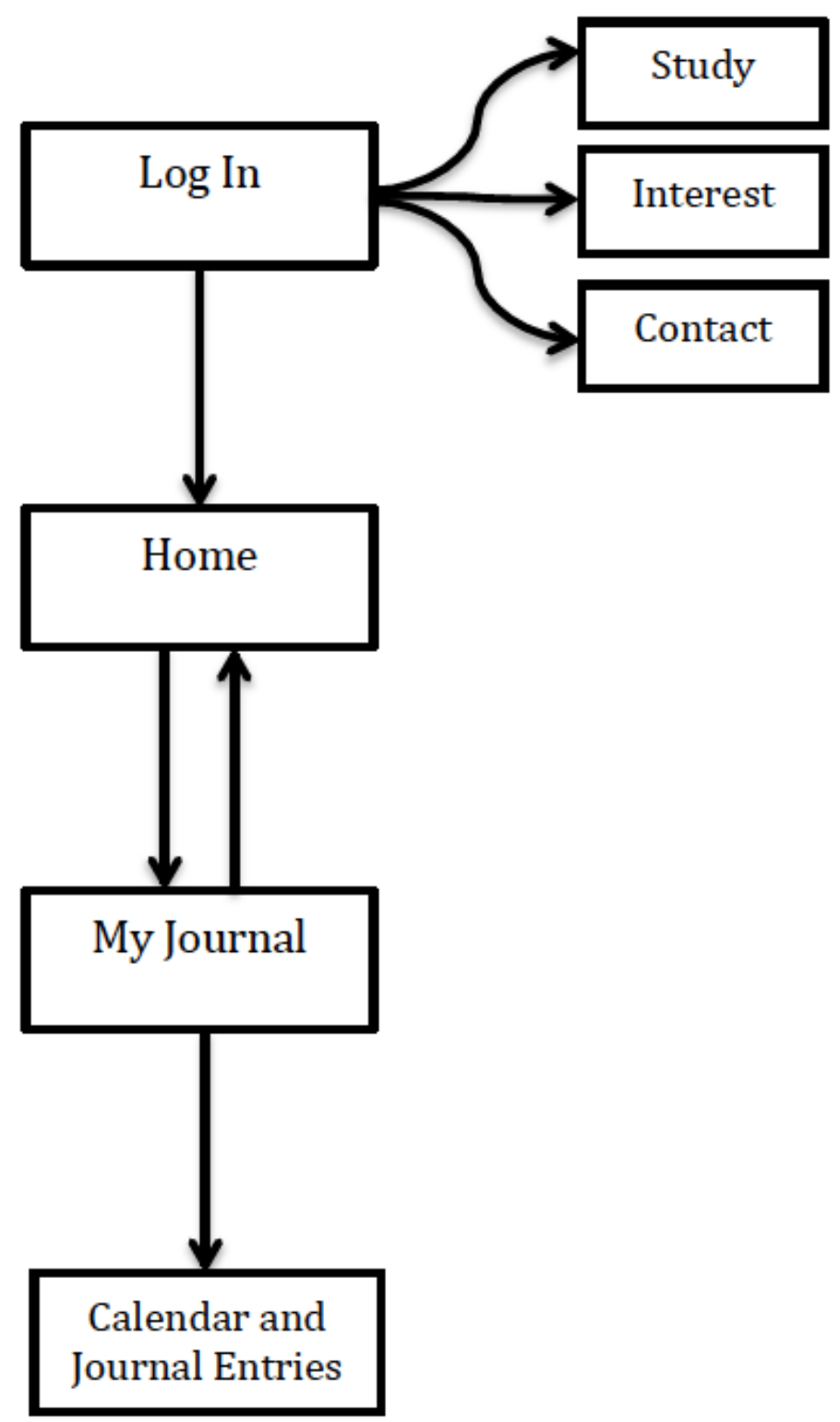




\section{WEBSITE CONTENT: MyGratefulSelf / LOGIN}

From the LOGIN page, several things can happen:

- Log In: There will be an ID and Password box.

o If successful, User is directed to Home screen.

- If User does not have a valid password, "invalid username or password" is shown.

- Forgot password: Ability to retrieve ID and password if need be.

- Change password: Ability to change password

- Also:

- STUDY

- INTEREST

- CONTACT

- There will be a LINK off the HOMEPAGE users can go to, once logged in: Off Left Navigation Bar:

○ HOME: Returns user to HomeScreen

- My JOURNAL: Users can click to submit a journal entry (stamped with date and time when submitted) and view previous entries.

Off Bottom Navigation Bar:

- How to use: A tutorial on the program

- Contact Us: Some information on how to contact us if needed. 


\section{EMAIL PROMPTS}

This explains all emails associated with MyGratefulSelf. It provides the timing and text for these emails. There are 2 groups: experimental, and control. Experimental and controls will receive emails about assessments manually and automatically. Experimental subjects will also receive various emails while receiving access to MyGratefulSelf (e.g., Daily reminder Prompt). . All emails are associated with Steps in the Flowchart. These are indicated in parentheses after each email.

*See MyGratefulSelf_Emails_DATE.doc for email content.

\begin{tabular}{|c|c|c|}
\hline Experimental & Control & Patient \\
\hline Interest form thank you (3) & Interest form thank you (3) & \\
\hline Not Eligible Thanks (4b) & Not Eligible Thanks (4b) & \\
\hline Send Contact Email (4c) & Send Contact Email (4c) & \\
\hline Signable IC link $(4 c)$ & Signable IC link $(4 \mathrm{c})$ & \\
\hline Signed Consent (5) & Signed Consent (5) & \\
\hline Ineligible Thanks (9b) & Ineligible Thanks (9b) & \\
\hline $\begin{array}{l}\text { Interest_form_thank_you (4b \& } 7 \text { - } \\
\text { MANUAL) }\end{array}$ & $\begin{array}{l}\text { Interest_form_thank_you (4b \& } 7 \text { - } \\
\text { MANUAL) }\end{array}$ & \\
\hline \multicolumn{3}{|c|}{ PRE } \\
\hline PreQ Link Email (11 - MANUAL) & PreQ Link Email (11 - MANUAL) & \\
\hline Complete PreQ Prompt (12) & Complete PreQ Prompt (12) -MANUAL & \\
\hline Thanks PreQ Prompt (13) & Thanks PreQ Prompt (13) MANUAL & \\
\hline \multicolumn{3}{|c|}{ INTERVENTION } \\
\hline Welcome Subjects & Welcome Control (Manual) & Welcome Patient (automated) \\
\hline Daily Reminder Prompt (18) & & Daily Reminder Prompt (18) (automated) \\
\hline Disuse Prompt 1 day (19) & & Disuse Prompt 1 day (19) (automated) \\
\hline Disuse Prompt 2 days (19) & & Disuse Prompt 2 days (19) (automated) \\
\hline Disuse Prompt 1 week (19) & & Disuse Prompt 1 week (19) (automated) \\
\hline Cores Complete (20) & & \\
\hline \multicolumn{3}{|c|}{ POST } \\
\hline PostQ Link Email (21- MANUAL) & PostQ Link Email (21 - MANUAL) & \\
\hline $\begin{array}{l}\text { Daily Reminder to Complete PostQ } \\
\text { (22) }\end{array}$ & $\begin{array}{l}\text { Daily Reminder to Complete PostQ (22) } \\
\text { MANUAL }\end{array}$ & \\
\hline PostQ Thanks Exp (23) & PostQ Thanks Control (23) (MANUAL) & \\
\hline \multicolumn{3}{|c|}{ POST1 } \\
\hline $\begin{array}{l}\text { PostQ 1-month Link Email ( } 24- \\
\text { MANUAL) }\end{array}$ & $\begin{array}{l}\text { PostQ 1-month Link Email ( } 24- \\
\text { MANUAL) }\end{array}$ & \\
\hline Daily Reminder Emails (25a) & $\begin{array}{l}\text { Daily Reminder Emails (25a) } \\
\text { (MANUAl) }\end{array}$ & \\
\hline Study Complete Thank You (26) & $\begin{array}{l}\text { Study Complete Thank You (26) } \\
\text { (MANUAL) }\end{array}$ & \\
\hline
\end{tabular}




\begin{tabular}{|c|c|c|}
\hline Email & Group & Timing \\
\hline \multicolumn{3}{|l|}{$\begin{array}{l}\text { Enrollment (automated, } \\
\text { except ineligible emails) }\end{array}$} \\
\hline Interest_form thank you & $\mathrm{E} \& \mathrm{C}$ & Interest_form thank_you (3) \\
\hline Not Eligible Thanks & $\mathrm{E} \& \mathrm{C}$ & $\begin{array}{l}\text { Email thanking IC for interest but informing them not eligible } \\
\text { (4b) (manual email) }\end{array}$ \\
\hline Send Contact Email & $\mathrm{E} \& \mathrm{C}$ & $\begin{array}{l}\text { Email confirming a how to and a good time to contact } \\
\text { participants }(4 \mathrm{c})\end{array}$ \\
\hline Generic IC link & $\mathrm{E} \& \mathrm{C}$ & $\begin{array}{l}\text { Email with generic link to consent form (for Ps who appear } \\
\text { eligible) sent with contact email ( } 4 \mathrm{c})\end{array}$ \\
\hline Signable IC link & $E \& C$ & Email with link to signable consent form (5) \\
\hline Signed Consent & $\mathrm{E} \& \mathrm{C}$ & Email with a copy of their signed consent form (9d) \\
\hline Ineligible Thanks & $\mathrm{E} \& \mathrm{C}$ & $\begin{array}{l}\text { Interest Form Thank You (Ps who are ineligible) }(\mathbf{4 b} \& 7 \text { - } \\
\text { manual email) }\end{array}$ \\
\hline \multicolumn{3}{|l|}{$\begin{array}{l}\text { Pre-Assessment (ALL } \\
\text { manual) }\end{array}$} \\
\hline PreQ Link Email & $\mathrm{E} \& \mathrm{C}$ & Link to PreQ surveys, separate from website (11) \\
\hline Complete PreQ Prompt & $\mathrm{E} \& \mathrm{C}$ & $\begin{array}{l}\text { If P does not complete the Questionnaire on Day 0, this email } \\
\text { is sent on Day } 1 \text { and again on Day } 2 \text { (unless the Pre- } \\
\text { Assessment Questionnaire is complete). Phone contacts and } \\
\text { further manual emails will then occur, and P will eventually } \\
\text { be manually dropped if the Questionnaire is not complete (see } \\
\text { operations manual). (12) }\end{array}$ \\
\hline Thanks PreQ Prompt & $\mathrm{E} \& \mathrm{C}$ & $\begin{array}{l}\text { Sent immediately after CCs complete PreQ alerting them that } \\
\text { they will receive further instruction about the study soon. (13) }\end{array}$ \\
\hline Welcome Control Ps Email & $\mathrm{C}$ & $\begin{array}{l}\text { Sent immediately after Ps complete PreQ, and are randomized } \\
\text { to the control group, alerting them that they will be contacted } \\
\text { again in } 21 \text { days to fill out PostQ. (16a) }\end{array}$ \\
\hline \multicolumn{3}{|l|}{ Intervention (automated) } \\
\hline Welcome_subject & E\&P & Provides user link, ID, and password (15) \\
\hline Diary Reminder Prompt & $\mathrm{E} \& \mathrm{P}$ & Daily automated email to remind P's to $\log$ in and journal (18) \\
\hline Day_0_Disuse_Prompt_1_day & $\mathrm{E} \& \mathrm{P}$ & Automated email sent if no login after 1 day (19) \\
\hline Day_0_Disuse_Prompt_2_days & $\mathrm{E} \& \mathrm{P}$ & Automated email sent if no login after 2 days (19) \\
\hline Disuse_Prompt_1_week & E\&P & Automated email sent if no login in 1 week (19) \\
\hline cores_complete & $\mathrm{E}$ & $\begin{array}{l}\text { Automated email sent on Day } 21 \text { informing Exp P's that the } \\
\text { intervention is compete and they no longer have access to the } \\
\text { journals. Also informs them that they will receive a link to the } \\
\text { PostQ shortly. (20) }\end{array}$ \\
\hline \multicolumn{3}{|l|}{$\begin{array}{l}\text { Post-Assessment (ALL } \\
\text { manual) }\end{array}$} \\
\hline PostQ Link Email & $\mathrm{E} \& \mathrm{C}$ & $\begin{array}{l}\text { Link to PostQ surveys, separate from website ( } 21 \text {-manual } \\
\text { email) }\end{array}$ \\
\hline $\begin{array}{l}\text { Daily Reminder to complete } \\
\text { PostQ }\end{array}$ & $\mathrm{E} \& \mathrm{C}$ & $\begin{array}{l}\text { Manual email sent on days 21-28 reminding P's to complete } \\
\text { post Q (22) }\end{array}$ \\
\hline PostQ Thanks Exp & $\mathrm{E}$ & $\begin{array}{l}\text { Manual email sent once PostQ is submitted, thanking Exp P's } \\
\text { and letting them know they have access to journals again if } \\
\text { they wish to use them. Also reminding them they will be } \\
\text { contacted again in } 30 \text { days to complete a final assessment. } \\
\text { (23) }\end{array}$ \\
\hline PostQ Thanks Control & $\mathrm{C}$ & Manual email sent once PostQ is submitted, thanking Control \\
\hline
\end{tabular}




\begin{tabular}{|l|l|l|}
\hline & & $\begin{array}{l}\text { P's, reminding them that they will be contacted again in 30 } \\
\text { days to complete the final assessment. After which they will } \\
\text { have access to the website(23) }\end{array}$ \\
\hline $\begin{array}{l}\text { Post-Assessment 1-Month } \\
\text { (ALL manual) }\end{array}$ & E \& C & Link to PostQ 1-month surveys, separate from website (25) \\
\hline PostQ 1-month Link Email & E \& C & $\begin{array}{l}\text { Sent manually on days 51-58 reminding P's to complete } \\
\text { PostQ 1-month assessment (25a) }\end{array}$ \\
\hline Daily Reminder Emails & E & $\begin{array}{l}\text { Sent once PostQ 1-month is completed thanking Ps for } \\
\text { participating, letting them know that they will be entered into } \\
\text { a drawing for an amazon gift certificate, and letting them } \\
\text { know that they have access to the online journals if they wish } \\
\text { to continue using them. (26) }\end{array}$ \\
\hline $\begin{array}{l}\text { Study Complete Thank You } \\
\text { Exp }\end{array}$ & C & $\begin{array}{l}\text { Sent once PostQ 1-month is completed thanking Ps for } \\
\text { participating, letting them know that they will be entered into } \\
\text { a drawing for an amazon gift certificate.(26) }\end{array}$ \\
\hline $\begin{array}{l}\text { Study Complete Thank You } \\
\text { Control }\end{array}$ & &
\end{tabular}




\section{The Psychological Well-being Scales - 42-ItemVersion}

Please indicate your degree of agreement (using a score ranging from 1-6) to the following sentences.

\begin{tabular}{|ll|}
\hline $1=$ Strongly Disagree & $4=$ Agree \\
$2=$ Moderately Disagree & $5=$ Moderately Agree \\
$3=$ Disagree & $6=$ Strongly Agree \\
\hline
\end{tabular}

\begin{tabular}{|c|c|c|c|c|c|c|}
\hline & $\begin{array}{l}\text { Strongly } \\
\text { Disagree } \\
(1)\end{array}$ & (2) & (3) & (4) & (5) & $\begin{array}{l}\text { Strongly } \\
\text { Agree } \\
(6)\end{array}$ \\
\hline \multicolumn{7}{|l|}{$\begin{array}{l}\text { 1. I am not afraid to voice my opinions, even when } \\
\text { they are in opposition to the opinions of most people. }\end{array}$} \\
\hline \multicolumn{7}{|l|}{$\begin{array}{l}\text { 2. In general, I feel I am in charge of the situation in } \\
\text { which I live. }\end{array}$} \\
\hline \multicolumn{7}{|l|}{$\begin{array}{l}\text { 3. I am not interested in activities that will expand } \\
\text { my horizons. }\end{array}$} \\
\hline \multicolumn{7}{|l|}{ 4. Most people see me as loving and affectionate. } \\
\hline \multicolumn{7}{|l|}{$\begin{array}{l}\text { 5. I live life one day at a time and don't really think } \\
\text { about the future. }\end{array}$} \\
\hline \multicolumn{7}{|l|}{$\begin{array}{l}\text { 6. When I look at the story of my life, I am pleased } \\
\text { with how things have turned out. }\end{array}$} \\
\hline \multicolumn{7}{|l|}{$\begin{array}{l}\text { 7. My decisions are not usually influenced by what } \\
\text { everyone else is doing. }\end{array}$} \\
\hline \multicolumn{7}{|l|}{ 8. The demands of everyday life often get me down. } \\
\hline \multicolumn{7}{|l|}{$\begin{array}{l}\text { 9. I think it is important to have new experiences that } \\
\text { challenge how you think about yourself and the } \\
\text { world. }\end{array}$} \\
\hline \multicolumn{7}{|l|}{$\begin{array}{l}\text { 10. Maintaining close relationships has been difficult } \\
\text { and frustrating for me. }\end{array}$} \\
\hline \multicolumn{7}{|l|}{ 11. I have a sense of direction and purpose in life. } \\
\hline \multicolumn{7}{|l|}{$\begin{array}{l}\text { 12. In general, I feel confident and positive about } \\
\text { myself. }\end{array}$} \\
\hline \multicolumn{7}{|l|}{$\begin{array}{l}\text { 13. I tend to worry about what other people think of } \\
\text { me. }\end{array}$} \\
\hline \multicolumn{7}{|l|}{$\begin{array}{l}\text { 14. I do not fit very well with the people and the } \\
\text { community around me. }\end{array}$} \\
\hline \multicolumn{7}{|l|}{$\begin{array}{l}\text { 15. When I think about it, I haven't really improved } \\
\text { much as a person over the years. }\end{array}$} \\
\hline \multicolumn{7}{|l|}{$\begin{array}{l}\text { 16. I often feel lonely because I have few close } \\
\text { friends with whom to share my concerns. }\end{array}$} \\
\hline \multicolumn{7}{|l|}{$\begin{array}{l}\text { 17. My daily activities often seem trivial and } \\
\text { unimportant to me. }\end{array}$} \\
\hline \multicolumn{7}{|l|}{$\begin{array}{l}\text { 18. I feel like many of the people I know have gotten } \\
\text { more out of life than I have. }\end{array}$} \\
\hline 19. I tend to be influenced by people with strong & & & & & & \\
\hline
\end{tabular}




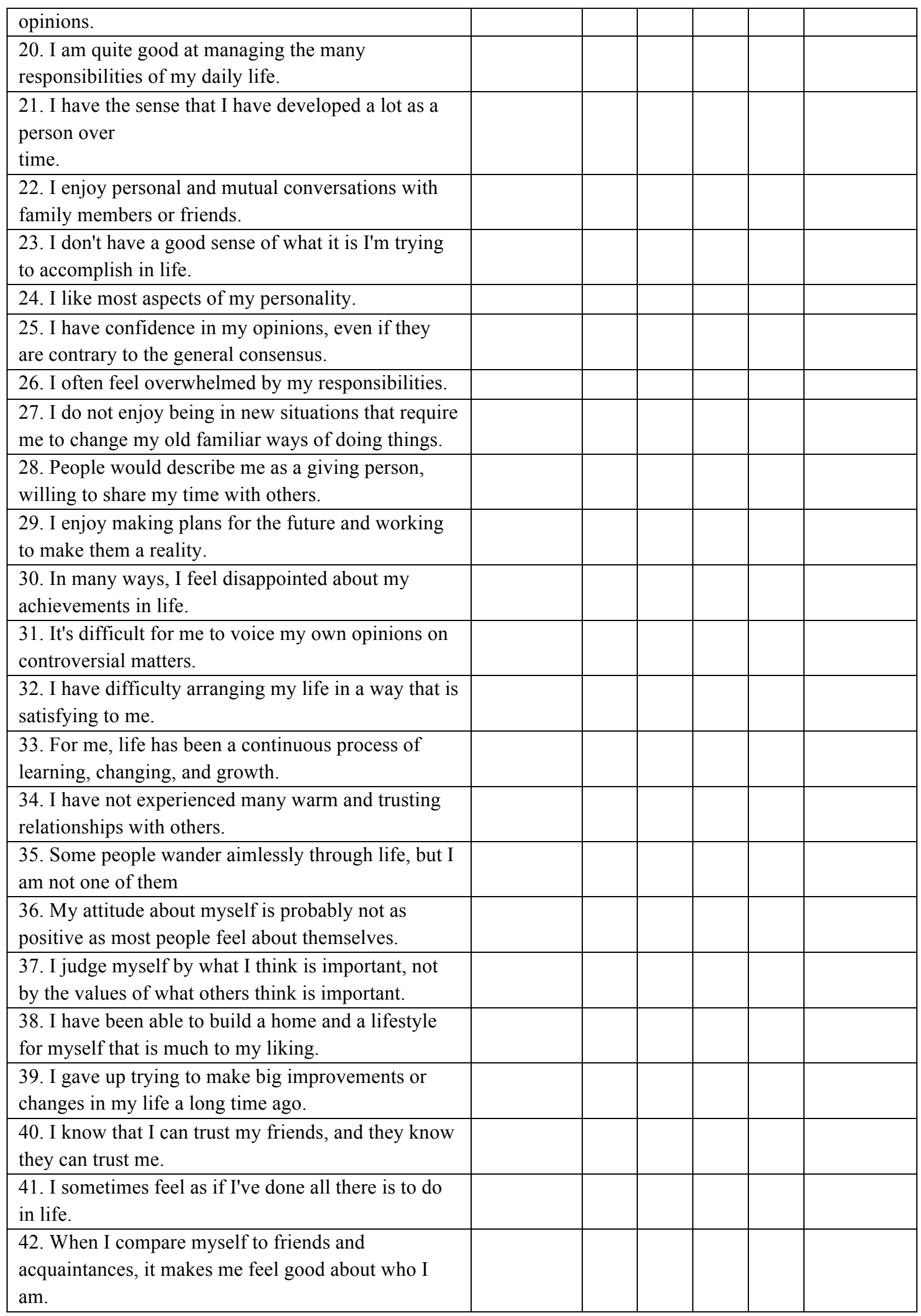




\section{The Gratitude Questionnaire - Six-Item Form}

Using the scale below as a guide, beside each statement, mark a number to indicate how much you agree with it.

\begin{tabular}{|ll|}
\hline $1=$ Strongly Disagree & $5=$ Slightly Agree \\
$2=$ Disagree & $6=$ Agree \\
$3=$ Slightly Disagree & $7=$ Strongly Agree \\
$4=$ Neutral & \\
\hline
\end{tabular}

\begin{tabular}{|c|c|c|c|c|c|c|c|}
\hline \multirow{2}{*}{ I have so much in life to be thankful for. } & 1 & 2 & 3 & 4 & 5 & 6 & 7 \\
\hline & & & & & & & \\
\hline $\begin{array}{l}\text { If I had to list everything that I felt grateful for } \\
\text { it would be a very long list. }\end{array}$ & & & & & & & \\
\hline $\begin{array}{l}\text { When I look at the world, I don't see much to } \\
\text { be grateful for. }\end{array}$ & & & & & & & \\
\hline I am grateful to a wide variety of people. & & & & & & & \\
\hline $\begin{array}{l}\text { As I get older I find myself more able to } \\
\text { appreciate the people, events, and situations } \\
\text { that have been part of my life history. }\end{array}$ & & & & & & & \\
\hline $\begin{array}{l}\text { Long amounts of time can go by before I feel } \\
\text { grateful to something or someone. }\end{array}$ & & & & & & & \\
\hline
\end{tabular}




\section{Positive and Negative Affect Schedule}

This scale consists of a number of words and phrases that describe different feelings and emotions. Read each item and then mark the appropriate answer on the scale next to the word. Indicate to what extent you have felt this way during the past week. Use the following scale to record your answers:

\begin{tabular}{ll}
$1=$ very slightly or not at all & $4=$ quite a bit \\
$2=$ a little & $5=$ extremely \\
$3=$ moderate & \\
\hline
\end{tabular}

\begin{tabular}{|c|c|c|c|c|c|}
\hline & 1 & 2 & 3 & 4 & 5 \\
\hline \multicolumn{6}{|c|}{ Interested } \\
\hline \multicolumn{6}{|c|}{ Disinterested } \\
\hline \multicolumn{6}{|c|}{ Excited } \\
\hline \multicolumn{6}{|l|}{ Upset } \\
\hline \multicolumn{6}{|l|}{ Strong } \\
\hline \multicolumn{6}{|l|}{ Guilty } \\
\hline \multicolumn{6}{|l|}{ Scared } \\
\hline \multicolumn{6}{|c|}{ Hostile } \\
\hline \multicolumn{6}{|c|}{ Enthusiastic } \\
\hline \multicolumn{6}{|l|}{ Proud } \\
\hline \multicolumn{6}{|c|}{ Irritable } \\
\hline \multicolumn{6}{|l|}{ Alert } \\
\hline \multicolumn{6}{|c|}{ Ashamed } \\
\hline \multicolumn{6}{|c|}{ Inspired } \\
\hline \multicolumn{6}{|c|}{ Nervous } \\
\hline \multicolumn{6}{|c|}{ Determined } \\
\hline \multicolumn{6}{|c|}{ Attentive } \\
\hline \multicolumn{6}{|l|}{ Jittery } \\
\hline \multicolumn{6}{|l|}{ Active } \\
\hline Afraid & & & & & \\
\hline
\end{tabular}




\section{Modified Differential Emotions Scale (mDES)}

Instructions: Please think back to how you felt during the past TWO WEEKS. Using the 0-4 scale below, indicate the greatest amount that you've experienced each of the following feelings.

\begin{tabular}{ll|}
$1=$ very slightly or not at all & $4=$ quite a bit \\
$2=$ a little bit & $5=$ extremely \\
$3=$ moderately & \\
\hline
\end{tabular}

\begin{tabular}{|c|c|c|c|c|c|}
\hline & 1 & 2 & 3 & 4 & 5 \\
\hline \multicolumn{6}{|l|}{ Amused, Fun-loving, Silly } \\
\hline \multicolumn{6}{|l|}{ Angry, Irritated, Annoyed } \\
\hline \multicolumn{6}{|l|}{ Ashamed, Humiliated, Disgraced } \\
\hline \multicolumn{6}{|l|}{ Awe, Wonder, Amazement } \\
\hline \multicolumn{6}{|l|}{ Contemptuous, Scornful, Disdainful } \\
\hline \multicolumn{6}{|l|}{ Disgust, Distaste, Revulsion } \\
\hline \multicolumn{6}{|c|}{ Embarrassed, Self-conscious, Blushing } \\
\hline \multicolumn{6}{|l|}{ Grateful, Appreciative, Thankful } \\
\hline \multicolumn{6}{|l|}{ Guilty, Repentant, Blameworthy } \\
\hline \multicolumn{6}{|l|}{ Hate, Distrust, Suspicion } \\
\hline \multicolumn{6}{|l|}{ Hopeful, Optimistic, Encouraged } \\
\hline \multicolumn{6}{|l|}{ Inspired, Uplifted, Elevated } \\
\hline \multicolumn{6}{|l|}{ Interested, Alert, Curious } \\
\hline \multicolumn{6}{|l|}{ Joyful, Glad, Happy } \\
\hline \multicolumn{6}{|l|}{ Love, Closeness, Trust } \\
\hline \multicolumn{6}{|l|}{ Proud, Confident, Self-assured } \\
\hline \multicolumn{6}{|l|}{ Sad, Downhearted, Unhappy } \\
\hline \multicolumn{6}{|l|}{ Scared, Fearful, Afraid } \\
\hline \multicolumn{6}{|l|}{ Serene, Content, Peaceful } \\
\hline Stressed, Nervous, Overwhelmed & & & & & \\
\hline
\end{tabular}




\section{Five-Facet Mindfulness Questionnaire \\ Observing Subscale}

Please rate each of the following statements using the scale provided. Write the number in the blank that best describes your own opinion of what is generally true for you.
$1=$ never or very rarely true
$4=$ often true
$2=$ rarely
$5=$ very often or always true
$3=$ sometimes true

\begin{tabular}{|l|l|l|l|l|l|}
\hline & & & & \\
\hline $\begin{array}{l}\text { When I am walking, I deliberately notice } \\
\text { the sensations of my body moving. }\end{array}$ & & & & & \\
\hline $\begin{array}{l}\text { When I take a shower or bath, I stay alert to } \\
\text { the sensations of water on my body. }\end{array}$ & & & & & \\
\hline $\begin{array}{l}\text { I notice how foods and drinks affect my } \\
\text { thoughts, bodily sensations, and emotions. }\end{array}$ & & & & & \\
\hline $\begin{array}{l}\text { I pay attention to sensations, such as the } \\
\text { wind in my hair and the sun on my face. }\end{array}$ & & & & & \\
\hline $\begin{array}{l}\text { I pay attention to sounds such as clocks } \\
\text { ticking, birds chirping, or cars passing. }\end{array}$ & & & & & \\
\hline I notice the smells and aromas of things. & & & & & \\
\hline $\begin{array}{l}\text { I notice visual elements in art or nature } \\
\text { such as colors, shapes, textures, or patterns } \\
\text { of light and shadows. }\end{array}$ & & & & & \\
\hline $\begin{array}{l}\text { I pay attention to how my emotions affect } \\
\text { my thoughts and behavior. }\end{array}$ & & & & & \\
\hline
\end{tabular}




\section{Demographic and Medical History Form}

Please indicate your answers to the following questions:

Current Age: Age at Diagnosis:

Gender: Male

Female

Race: White (non-hispanic)

Black/African American

Asian-American/Pacific Islander

Native American/American Indian

Hispanic

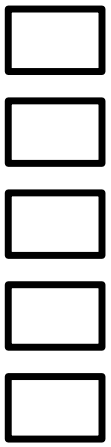

Marital

Status: Married

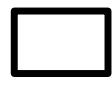

Single

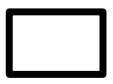

In an relationship

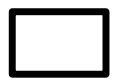

Divorced

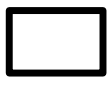

Other

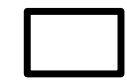

\section{Dependent}

Children:

Yes

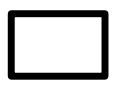

No

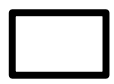

\section{Health}

Insurance:

Yes

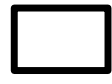

No

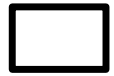


Income:

$<\$ 10,000$

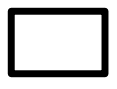

$\$ 11,000-20,999$

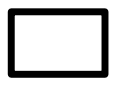

$\$ 21,000-30,999$

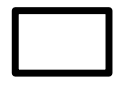

$\$ 31,000-50,999$

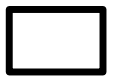

$\$ 51,000-99,999$

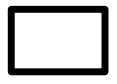

$\$ 100,00$ or more

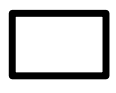

Don't know

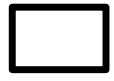

\section{Cancer}

Diagnosis:

Breast

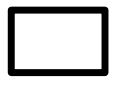

Brain tumor

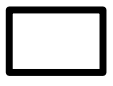

Leukemia

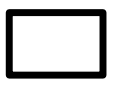

Lymphoma

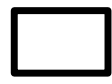

Colon

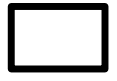

Soft Tissue

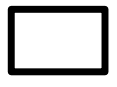

Other

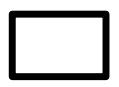

\section{Stage at}

Diagnosis:

I

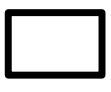

II

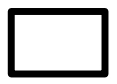

III

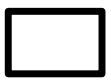

IV

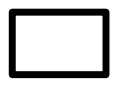

Unknown

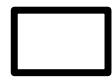


Relapsed

Disease:

Yes

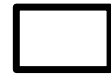

No

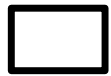

Metastatic

Disease:

Yes

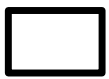

No

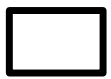

Currently Receiving Active Treatment:

Yes

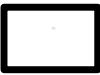

No

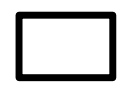

Currently on

Drug Trial:

Yes

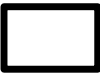

No

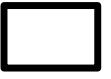

\section{Currently}

Receiving

Hospice/

Palliative

Care:

Yes

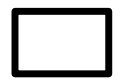

No

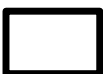




\section{Internet Evaluation and Utility Questionnaire}

These questions are about your use of the web program. Please read the items and tell us how you felt about using the web program. If the item does not apply, please choose "NA".

$\begin{array}{ll}0=\text { not at all } & 3=\text { mostly } \\ 1=\text { slightly } & 4=\text { very } \\ 2=\text { somewhat } & 5=\text { N/A }\end{array}$

\begin{tabular}{|c|c|c|c|c|c|c|}
\hline & 0 & 1 & 2 & 3 & 4 & $\mathrm{~N} / \mathrm{A}$ \\
\hline \multicolumn{7}{|l|}{ How easy was the web program to use? } \\
\hline \multicolumn{7}{|l|}{$\begin{array}{l}\text { How convenient was the web program to } \\
\text { use? }\end{array}$} \\
\hline \multicolumn{7}{|l|}{$\begin{array}{l}\text { How much did the web program keep } \\
\text { your interest and attention? }\end{array}$} \\
\hline \multicolumn{7}{|l|}{ How much did you like the web program? } \\
\hline \multicolumn{7}{|l|}{$\begin{array}{l}\text { How much did you like the way the web } \\
\text { program looked? }\end{array}$} \\
\hline \multicolumn{7}{|l|}{$\begin{array}{l}\text { How worried were you about your privacy } \\
\text { in using this web program? }\end{array}$} \\
\hline \multicolumn{7}{|l|}{$\begin{array}{l}\text { How satisfied were you with the web } \\
\text { program? }\end{array}$} \\
\hline \multicolumn{7}{|l|}{$\begin{array}{l}\text { How good of a fit was the web program } \\
\text { for you? }\end{array}$} \\
\hline \multicolumn{7}{|l|}{$\begin{array}{l}\text { How useful did you find the information } \\
\text { in the web program? }\end{array}$} \\
\hline \multicolumn{7}{|l|}{$\begin{array}{l}\text { How easy was the information to } \\
\text { understand? }\end{array}$} \\
\hline \multicolumn{7}{|l|}{$\begin{array}{l}\text { How much did you feel you could trust the } \\
\text { information? }\end{array}$} \\
\hline \multicolumn{7}{|l|}{$\begin{array}{l}\text { If difficulties continue or return, how } \\
\text { likely would you be to come back to } \\
\text { this web program? }\end{array}$} \\
\hline $\begin{array}{l}\text { How good of a method was the Internet } \\
\text { for delivering this intervention? }\end{array}$ & & & & & & \\
\hline
\end{tabular}

14. What was the most helpful part of the web program?

15. What was the least helpful part of the web program? 


\section{ECOG Performance Status}

These scales and criteria are used by doctors and researchers to assess how a patient's disease is progressing, assess how the disease affects the daily living abilities of the patient, and determine appropriate treatment and prognosis. They are included here for health care professionals to access.

0 Fully active, able to carry on all pre-disease performance without restriction

1 Restricted in physically strenuous activity but ambulatory and able to carry out work of a light or sedentary nature, e.g., light house work, office work

2 Ambulatory and capable of all self-care but unable to carry out any work activities. Up and about more than $50 \%$ of waking hours

3 Capable of only limited self-care, confined to bed or chair more than $50 \%$ of waking hours

4 Completely disabled. Cannot carry on any self-care. Totally confined to bed or chair

5 Dead 


\section{SBSQ-D Health Literacy Questionnaire}

Please indicate your level of agreement with each statement below.

1. How confident are you in filling out medical forms?

$1=$ extremely, $2=$ quite a bit, $3=$ somewhat, $4=$ a little, $5=$ not at all

2. How often do you have problems learning about your medical condition(s) because of difficulty understanding written information.

$1=$ never, $2=$ rarely, $3=$ sometimes, $4=$ often, $5=$ always

3. How often do you have someone help you read hospital materials?

$1=$ never, $2=$ rarely, $3=$ sometimes, $4=$ often, $5=$ always 
- Homepage Texts

$\circ \quad 1^{\text {st }}$ Login (Experimental and Patient Pathways)

- Intervention Login (Experimental and Patient Pathways)

- Day 22 (Experimental only)

- Homepage after completed Assessment (Experimental only)

- Alerts

- How to use

○ Welcome

○ Information Center

○ Journals

- Summary

$\circ$ Begin

- Website Content

- Homepage links texts

- Calendar Page

- Journal Entry Screen $1^{\text {st }}$ login (includes intervention instructions)

○ Journal Entry Screen Future login 


\section{HOME PAGE TEXT}

Top left corner shows the date.

\section{FIRST LOGIN (Experimental and Patient Pathway)}

Welcome to MyGratefulSelf!

Click the How To Use link at the bottom of the screen to learn how to use this program.

Once you have gone through the brief tutorial, you will be able to start using MyGratefulSelf!

\section{INTERVENTION LOGIN (Experimental and Patient Pathway)}

Welcome to MyGratefulSelf!

Click on the MY JOURNAL button on the left to access your online journal. Remember that MyGratefulSelf can only accept journal entries that are no more than one day old (for today and yesterday) so be sure come back every day and journal.

You've made it to Day XX of this study. Remember, this study is 21 days.

Thanks again for using MyGratefulSelf! You're the best!

\section{DAY 21 (Experimental only)}

Awesome! You've done great so far!

The next step is to complete another set of questionnaires. If you have not already, you will soon receive a link to the questionnaires by email.

You may notice that you do not have access to the JOURNAL button right now.

Don't worry!

As soon as you complete the questionnaires you can come back and keep journaling if you want.

Thank you so much for using MyGratefulSelf. We think you rock! 


\section{HOMEPAGE AFTER COMPLETED ASSESSMENT (Experimental only)}

Hey, you're back! Great!

If you want, you can access your online journal by clicking the JOURNAL button on the left of the screen and pick up right where you left off. This is not required for the study but feel free to use it for as long as you'd like (until the site goes down).

Remember that MyGratefulSelf can only accept journal entries that are one day old (for today and yesterday) some come back each day and journal! 


\section{ALERTS}

There are only 2 alert lines: Messages and Journals

\section{General Messages:}

Randomly show one of the following 4 messages:

Msg_1: Remember, you can only enter journals up to 1 day old, so come back regularly!

Msg_2: Click on the JOURNAL button on the left to continue!

Msg_3: Keep up the great work!

Msg_4: Seriously, you're awesome. We are grateful for you!

Journal Messages:

$\mathbf{1}^{\text {st }}$ journal_entry: Your first journal entry? Great! Just follow the writing prompt and come back tomorrow to write again!

Future_journal_entry: You have completed XX journal entries. Great job! 


\section{HOW TO USE}

\section{WELCOME}

Welcome! This tutorial will show you how to use MyGratefulSelf.

When you first log in to MyGratefulSelf, the main Home screen appears. There are three sections of the Home screen:

- The Home screen text is on the right side of the screen. This text provides important information about where you are in the program.

- Buttons along the bottom left of the screen provide links to this tutorial, contact information, and disclaimer information.

- The Information Center on the left of the screen provides access to the journal page and alerts. Each of these will be described next.

\section{INFORMATION CENTER}

Use the link in the Information Center to go to the journal screen:

- Click the Home link to return the program to the Home screen.

- Click on the MY JOURNAL link to bring up the journal section. From this screen, you can make new journal entries and review previous journal entries.

- Alerts appear on the bottom half of the Information Center. Alerts contain a quick message from the study team.

\section{JOURNALS}

In order to make the best use of MyGratefulSelf, you should make a journal entry every day.

First, click the "MY JOURNAL" link from the Home screen to:

(1) access the journal section

(2) learn more about making journal entries

(3) make a journal entry every day

After you begin making journal entries, you will be able to view previous entries but you will not be able to edit them.

\section{SUMMARY}


Here is a brief summary of how to use MyGratefulSelf.

1. Move around MyGratefulSelf by: (a) Clicking the Home button in the right hand corner to return to the Home page, and (b) Log off at any time by clicking the "Sign Out" button in the top right corner.

2. The Home screen contains three main areas: Home screen text, the Information Center, and the Bottom Button links.

3. The Information Center on the left of the screen provides access to the Journal screen and Alerts.

4. Use the MY JOURNAL to access the journal entry screen and login to make an entry daily and review your previous entries.

\section{BEGIN}

This ends the tutorial. You are now ready to begin using MyGratefulSelf!

Click the "Core Complete!" button to continue. Please be patient.

It may take a minute to load and return you to the Home screen. 


\section{WEBSITE CONTENT: HOME PAGE LINKS TEXT}

\section{Disclaimer}

The content of this website (MyGratefulSelf) should not be considered a medical intervention. It should never replace a visit, call or consultation with any medical or mental health care provider. Rather your medical and mental health care should be managed by your physician or other licensed care provider. We do not recommend selfmanagement of medical or mental health problems. Should you have any medical or mental health care-related questions, please call or see your physician promptly.

Copyright 2015 by the University of Virginia Behavioral Health \& Technology Lab, Department of Psychiatry and Neurobehavioral Sciences. All rights reserved. Copies, and/or reproduction of any kind, of the materials and/or information in this Website may not be made without the express permission of Behavioral Health \& Technology Lab in the Department of Psychiatry and Neurobehavioral Sciences at the University of Virginia School of Medicine

\section{Contacts}

Please email any general comments or questions to the Principle Investigator, Kate Adelstein, at MyGratefulSelf@virginia.edu.

Please include the word MyGratefulSelf in the subject line. 


\section{WEBSITE CONTENT: Calendar and Journal Screens}

\section{Calendar Screen:}

Find today's date, or the date of the journal you wish to enter. Click on that day to complete the journal entry. Click here to learn more about this calendar.

MyGratefulSelf can only accept journal entries that are no more than one day old (for today and yesterday). So be sure to come back every day and journal!

\section{More about this calendar: Mouse over text}

Two days are shaded in red to show you which days are available for MyGratefulSelf journals entries. It is very important that you keep up with your journal entries because you can only make an entry for today or yesterday. The shaded red days also have a small green circle in the upper left corner of that day. If the circle is filled, that indicates that you have made any entry for that day. If the circle is empty, you can make an entry for that day. Select the day you wish to enter by clicking on that date. This will bring up the MyGratefulSelf journal entry form.

\section{Journal Prompt:}

There are many things in our lives, both large and small, that we might be grateful for. Think back over the last 24 hours and write in the space provided below about at least one thing that you are grateful or thankful for and why.

Be aware of your feelings and how you "relish" or "savor" this gift in your imagination. Take the time to be especially aware of the depth of your gratitude.

If you are having trouble, try thinking of one moment in the last 24 hours that brought you pleasure, or made you feel happy. What was it about this moment that made you feel happy? How long did that happiness last? Can you re-experience that feeling of happiness as you write about it?

You can write as much or as little you want. When you are finished, click the SUBMIT button below. 


\section{Informed Consent Agreement}

\section{Please read this consent agreement carefully before you decide to participate in the study.}

Purpose of the research study: The purpose of the study is to develop and evaluate the feasibility and acceptability of an on-line writing intervention for young adults with cancer. Researchers aim to evaluate the feasibility (participant recruitment and retention) and acceptability of a daily, on-line writing intervention designed specifically for young adults with cancer. Additionally, researchers aim to evaluate the preliminary effect of participating in an on-line writing intervention on feelings of wellbeing and psychological functioning in young adults with cancer.

What you will do in the study: You will be asked to complete 6 brief questionnaires online that will take approximately 40 minutes of your time. After you complete the questionnaires you will be assigned to the writing group or the control group.

If you are assigned to the writing group you will receive a username and password. You will be asked to $\log$ on to the study website daily for 21 days and complete the specified writing prompt. After 21 days, you will be asked to complete the questionnaires again. You will also be asked to complete the same questionnaires 1 month after completion of the study-related writing assignment.

If you are assigned to the control group, you will be asked to complete the study questionnaires after 21 days and again one month later. After completion of the 1-month follow-up questionnaires, you will be given access to the study website and you will be able to complete the writing prompts if you'd like.

You have the right to withdraw from the study at any time. You also have the right not to answer any questions that make you uncomfortable.

Time required: You will complete a set of questionnaires three (3) times that will take approximately 40 minutes per session. During the study, if you are assigned to the writing group, study activities will require approximately 15 minutes daily. Overall, the study will require approximately 5.5 hours of your time over the course of two (2) months.

Risks: Potential risks of this study are minimal. They are related largely to possible psychological discomfort. In the event that you experience significant distress related to the study, you may contact the researcher and you will be directed to a licensed mental health provider who can talk with you over the phone and refer you to appropriate care in your area including outpatient counseling and Emergency Department evaluation.

Benefits: There are no direct benefits to you for participating in this research study. The study may help us understand a cost-effective and simple method to promote a sense of well-being in young adults with cancer. Additionally, this study will help us better understand recruitment methods that will improve participation of young adults with cancer in research studies in the future. 
Confidentiality: The information that you give in the study will be handled confidentially. Your information will be assigned a code number. The list connecting your name to this code will be kept in a UVA HIPAA protected network folder. Only the researchers will have access to this folder. When the study is completed and the data have been analyzed, this list will be destroyed. Your name will not be used in any report.

Voluntary participation: Your participation in the study is completely voluntary.

Right to withdraw from the study: You have the right to withdraw from the study at any time without penalty.

How to withdraw from the study: If you want to withdraw from the study, you may contact the principal investigator, Kate Adelstein, at any time via email, phone, or Internet call. There is no penalty for withdrawing. If you would like to withdraw after your materials have been submitted, please contact the principle investigator, Kate Adelstein, via email, phone, or Internet call. Should you choose to withdraw from the study for any reason at any time, your data will be destroyed.

Payment: You will be entered into a lottery to win one of $6 \$ 50$ Amazon.com gift cards. You have an $11.5 \%$ chance of winning a gift card.

If you have questions about the study, contact:

Kate Adelstein, RN, MSN, ANP-BC, PhD Candidate

School of Nursing

225 Jeanette Lancaster Way

University of Virginia, Charlottesville, VA 22903.

Telephone: (617)223-1189

kea5ft@,virginia.edu

Susan Bauer-Wu PhD, RN, FAAN

School of Nursing

225 Jeanette Lancaster Way

University of Virginia, Charlottesville, VA 22903.

Telephone: (434) 982-0645

sb6vk@virginia.edu

If you have questions about your rights in the study, contact:

Tonya R. Moon, Ph.D.

Chair, Institutional Review Board for the Social and Behavioral Sciences

One Morton Dr Suite 500

University of Virginia, P.O. Box 800392

Charlottesville, VA 22908-0392

Telephone: (434) 924-5999

Email: irbsbshelp@,virginia.edu

Website: www.virginia.edu/vpr/irb/sbs 


\section{Agreement:}

I agree to participate in the research study described above.

Signature:

Date:

You will receive a copy of this form for your records. 


\section{MyGratefulSelf Interest Site}

Primary links:

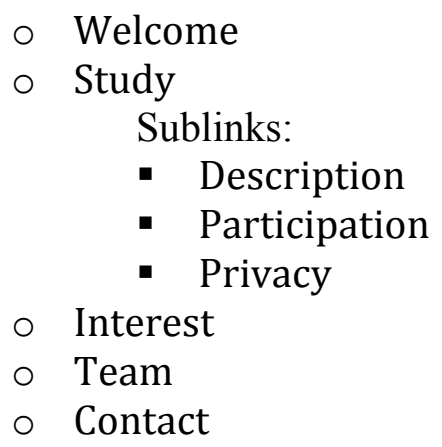

Study Login will be in the upper right corner of the screen.

\section{Copyright}

On the Login screen, we put our caveat/disclaimer/copyright information. Just one sentence stating "Copyright 2015 University of Virginia Behavioral Health \& Technology. All rights reserved."

A brief website with 5 sections: Welcome, Study (with sublinks), Interest, Team, and Contact. There is a form to be completed that can be accessed from the interest page. 


\section{Welcome}

\section{WELCOME!}

Thank you for your interest in MyGratefulSelf, a study to promote well-being in young adults with advanced cancer through writing.

At this site, you will find the following:

- STUDY: Description of the MyGratefulSelf study

- INTEREST: A consent form to sign and then a short form to fill out if you want to be considered for participation in the study.

- TEAM: Information about who created MyGratefulSelf

- CONTACT: Information about how to contact us.

If you have any questions, please do not hesitate to email us at MyGratefulSelf@virginia.edu. Please put the word MyGratefulSelf in the subject line.

If you're ready to fill out the Interest Form, click the button below:

$<$ Complete Interest Form $>$

In order to use MyGratefulSelf, a login and password must be provided to you. Currently, only participants in the research study are able to use this program at this time. If you would like to learn more about this study (and possibly become a participant), review the information on this site and sign the screening consent form and complete the online interest form. 


\section{Main Tab: Study}

Study Description

MyGratefulSelf is an on-line program designed to enhance and promote well-being for young adults between the ages of 20-39 with advanced cancer through short, daily writing exercises. It was developed at the University of Virginia School of Nursing with funding from the American Cancer Society. The purpose of this study is to find out if daily focused writing exercises can promote well-being in young adults with advanced cancer.

\section{Participation}

Interested individuals are needed to help evaluate MyGratefulSelf. Participation in this study will involve the following steps.

1. Give your consent to provide information over the Internet and electronically sign the screening consent form, then complete the interest form on this website.

2. Research staff will determine if you meet initial eligibility criteria.

3. If you meet initial eligibility criteria, we will contact you by email and schedule a phone or skype interview.

4. During the phone/skype interview, we will explain the study and discuss the criteria for enrollment. We will have time to answer any questions or concerns you may have during the phone call. We will also ask a few questions about how you have been feeling physically in the past few days and weeks. If you choose to participate, you will electronically sign a study consent form.

5. Next, you will receive a link via email to se set of questionnaires that will take approximately 40 minutes to complete.

6. Once you complete the questionnaires, you will be assigned to the writing group or the control group.

7. If you are assigned to the control group, we won't ask anything of you until it is time to complete the questionnaires again in 21 days.

8. If you are assigned to the writing group, you will receive a login and password to the MyGratefulSelf program.

9. Once you log on to the website, you will instructions on how to continue and get started writing.

10. After 21 days you will receive a link to the same set of questionnaires that will take about 45 minutes to complete.

11. Again, 30 days later, you will receive the same questionnaires for a final time.

12. If you were in the control group and would like to try the writing exercises, you will receive a login and password after you complete the third set of questionnaires.

13. All participants will be entered into a lottery to win one of six $\$ 50$ Amazon.com gift certificates.

More details can be found in the Study Consent Form.

Privacy 
We are committed to protecting your privacy. Here is how we will ensure that your privacy is protected:

1. The information you submit is stored on a secured server. Our servers meet HIPAA Privacy Rule protections (Health Insurance Portability and Accountability Act).

2. Our servers are maintained by the Information and Technology Communication staff at the University of Virginia, who continually assess our network structure to make sure we are using the latest software in security technology.

3. Only a few authorized research staff members have access to these servers. We strictly limit who can access the data and only those researchers intimately involved with our programs are included. All research staff have completed our Institutional Review Board (IRB) trainings including training on protecting your rights.

4. All studies in which our Internet interventions are involved have been reviewed and approved by the University of Virginia IRB as required by federal regulations regarding human research studies. The primary role of the IRB is to protect the safety and welfare of human participants.

5. We have a Certificate of Confidentiality from the federal government that provides additional protections for you. The Certificate helps us to refuse to share your study records without your consent.

You will find more information about privacy protections in the Study Consent Form. 


\section{Main Tab: INTEREST \\ INTEREST FORM}

Thank you for your interest in MyGratefulSelf. Please click on the button below to complete the Interest Form.

$<$ Complete Interest Form $>$

Interest Form - Consent

Thank you for your interest in the MyGratefulSef Study. Please review this brief Screening Consent form which has important information about the study. By electronically signing the box at the bottom of this page, you are giving us permission to ask you questions about yourself to determine whether you might be eligible to be included in this study. If you meet eligibility requirements, we will contact you to discuss the next steps for being in the MyGratefulSelf Study.

\section{Consent to Provide Personal Information Over the Internet}

In this form "you" means a person 18 years of age or older who is being asked to voluntarily provide personal information to be considered to participate in this study.

\section{Enter your name}

\section{here:}

Study records that identify you will be kept confidential as required by federal privacy regulations. By signing this form you agree to allow Kate Adelstein, RN, MSN and the study team to use health information about you to conduct this study. A description of this study is presented under the "Study" tab.

The University of Virginia Research Compliance staff and Institutional Review Board (IRB) members or designates may have access to the information you provide to the study team. The IRB is a special committee at the University of Virginia that reviews all medical research studies involving human participants.

If you sign this form, you have given us permission to release information to these other people. There is no expiration date to this permission. If you decide to withdraw your permission and end this agreement to release the information collected about you, please contact the principal investigator of the study, Kate Adelstein, RN, MSN (Email: kea5ft@virginia.edu). She will help you document in writing your decision to withdraw this permission. Please note that any information already obtained will continue to be used.

Because of the need to release information to these parties, absolute confidentiality cannot be guaranteed. There is the potential that information released to the groups and individuals listed above may be released again and would no longer be protected by privacy laws. 
Your participation in this research study is voluntary. However, you will not be allowed to participate in this research if you do not sign this Authorization. Refusing to sign will not affect the present or future care you receive from your oncology care team.

\section{Consent}

By checking this box and signing below, I have read the form above and I give you permission to ask me questions about my cancer diagnosis. To be completed by participant if 18 years of age or older.

Brief Consent Signature Box

$<$ Submit Button $>$

Thank you for your interest in MyGratefulSelf and for signing and submitting the Screening Consent Form. Please fill in the answers to the questions in the form below. You may print it out for your records. Then click SUBMIT. If you meet initial eligibility requirements, we will contact you to discuss possible next steps for being in the MyGratefulSelf study. We look forward to talking to you soon! All information given will be treated with strict standards of confidentiality.

Insert MyGratefulSelf Interest Form:

1. Name
a. First TEXT FIELD
b. Middle TEXT FIELD
c. Last TEXT FIELD

2. Address
a. Street TEXT BOX
b. City (TEXT), State (DROP DOWN), Zip (TEXT)

3. What is your date of birth? (mm/dd/yyyy) (DROP DOWN FOR MONTH/DAY/YEAR)

4. Gender? DROP DOWN FEMALE/MALE

5. Race (Please complete each of the two sections):

a. Hispanic or Latino / Not Hispanic or Latino RADIO BUTTONS

b. MULTI-SELECT BOXES

American Indian

Alaska Native

Asian

Native Hawaiian or Other Pacific Islander

Black or African American

White or Caucasian 
More than one race (select all that apply)

Other: TEXT BOX

\section{Contact information}
a. Home phone number TEXT BOX
b. Work phone number TEXT BOX
c. Cell phone number TEXT BOX
d. Best number to reach (DROP DOWN: HOME/WORK/CELL)
e. Best times to reach (TEXTBOX; TIMEZONE DROPDOWN)
f. Ok to leave a phone message? YES/NO RADIO BUTTON
g. Ok to email? YES/NO RADIO BUTTON
h. You will receive reminder emails during the study so please provide the best email address for PERSONAL, private communication. We recommend that this email is yours alone, rather than one you share with someone.
Email address (TEXT BOX)

7. How did you hear about the study? DROP DOWN: TWITTER, FACEBOOK, INSTAGRAM, PHYSICIAN/NURSE, MENTAL HEALTH PROFESSIONAL, FRIEND/FAMILY MEMBER, ANOTHER MYGRATEFULSELF USER, FLYER, OTHER

a. If other please specify? TEXT BOX

8. What is your cancer diagnosis: DROP DOWN: BREAST, BRAIN TUMOR, LEUKEMIA, LYMPHOMA, COLON, SOFT TISSUE, OTHER

a. IF OTHER PLEASE SPECIFY? TEXT BOX

9. What stage was your cancer at diagnosis? DROP DOWN: I, II, III, IV, DON'T KNOW

10. Have you experienced a relapse of your disease? DROP DOWN: YES, NO, DON'T KNOW

11. Is your cancer currently metastatic? DROP DOWN: YES, NO, DON'T KNOW

\section{$<$ Submit Button>}

This will appear once form is submitted: We have received your Screening Consent and Interest Form for the MyGratefulSelf Study. We will contact you in the next several days about your eligibility and how to proceed. Thank you again for completing the form and your interest in being a part of MyGratefulSelf. 


\section{Main Tab: TEAM}

MyGratefulSelf was developed at the University of Virginia School of Nursing in collaboration with the UVA Behavioral Health and Technology Laboratory. The research team is composed of a diverse set of individuals including, three oncology nurses with expertise in the experiences of young adults with cancer, one critical care pediatrician and one psychologist who has expertise in developing Internet interventions to promote mental health and well-being. Team members include:

\section{Creators:}

- Kate Adelstein RN, MSN, ANP-BC, Principal Investigator, Oncology Nurse Practitioner

- Susan Bauer-Wu RN, Ph.D., FAAN, Co-Investigator, Oncology Nurse

- Lee Ritterband, Ph.D., Co-Investigator, Clinical Psychologist

- Jessica Keim-Malpass, RN, Ph.D., Consultant, Oncology Nurse

- Jeanne Erickson, RN, Ph.D., Consultant, Oncology Nurse

- Julie Haizlip, M.D. M.A., Consultant, Pediatrician

Program Developers

- Steve Johnson

- Gabe Heath

The development and testing of this program was supported by a Doctoral Nursing Scholarship from the American Cancer Society. The content is solely the responsibility of the authors and does not necessarily represent the official views of the University of Virginia or the American Cancer Society. 


\section{Main Tab: Contact}

Please email any general comments or questions to MyGratefulSelf@virginia.edu

To send snail mail, use the following address:

Kate Adelstein

University of Virginia School of Nursing

225 Jeanette Lancaster Way

PO Box 800826

Charlottesville, VA 22903

\section{Contact Information for Media}

[OVERLAY] If you would like to contact someone regarding a media request or have questions about MyGratefulSelf, please email MyGratefulSelf@virginia.edu 


\begin{tabular}{|c|c|c|}
\hline Email & Group & Timing \\
\hline \multicolumn{3}{|l|}{$\begin{array}{l}\text { Enrollment (automated, except } \\
\text { ineligible emails) }\end{array}$} \\
\hline Interest form thank you & $\mathrm{E} \& \mathrm{C}$ & Interest form thank you (3) \\
\hline Not Eligible Thanks & $\mathrm{E} \& \mathrm{C}$ & $\begin{array}{l}\text { Email thanking IC for interest but informing them not eligible (4b) (manual } \\
\text { email) }\end{array}$ \\
\hline Send Contact Email & $\mathrm{E} \& \mathrm{C}$ & Email confirming a how to and a good time to contact participants (4c) \\
\hline Generic IC link & $\mathrm{E} \& \mathrm{C}$ & $\begin{array}{l}\text { Email with generic link to consent form (for Ps who appear eligible) sent with } \\
\text { contact email ( } 4 \mathrm{c})\end{array}$ \\
\hline Signable IC link & $\mathrm{E} \& \mathrm{C}$ & Email with link to signable consent form (5) \\
\hline Signed Consent & $\mathrm{E} \& \mathrm{C}$ & Email with a copy of their signed consent form (9d) \\
\hline Ineligible Thanks & $\mathrm{E} \& \mathrm{C}$ & Interest Form Thank You (Ps who are ineligible) $(4 \boldsymbol{b} \& \mathbf{\&}-$ manual email) \\
\hline \multicolumn{3}{|l|}{ Pre-Assessment (ALL manual) } \\
\hline PreQ Link Email & $\mathrm{E} \& \mathrm{C}$ & Link to PreQ surveys, separate from website (11-manual email) \\
\hline Complete PreQ Prompt & $\mathrm{E} \& \mathrm{C}$ & $\begin{array}{l}\text { If P does not complete the Questionnaire on Day 0, this email is sent on Day } 1 \text { and } \\
\text { again on Day } 2 \text { (unless the Pre-Assessment Questionnaire is complete). Phone } \\
\text { contacts and further manual emails will then occur, and P will eventually be } \\
\text { manually dropped if the Questionnaire is not complete (see operations manual). } \\
\text { (12) }\end{array}$ \\
\hline Thanks PreQ Prompt & $\mathrm{E} \& \mathrm{C}$ & $\begin{array}{l}\text { Sent immediately after CCs complete PreQ alerting them that they will receive } \\
\text { further instruction about the study soon. (13) }\end{array}$ \\
\hline Welcome Control Ps Email & $\mathrm{C}$ & $\begin{array}{l}\text { Sent immediately after Ps complete PreQ, and are randomized to the control } \\
\text { group, alerting them that they will be contacted again in } 21 \text { days to fill out PostQ. } \\
\text { (16a) }\end{array}$ \\
\hline \multicolumn{3}{|l|}{ Intervention (automated) } \\
\hline Welcome_subject & E\&P & Provides user link, ID, and password, reviews study procedures (15) \\
\hline Diary Reminder Prompt & E\&P & Daily automated email to remind P's to log in and journal (18) \\
\hline Day_0_Disuse_Prompt_1_day & $\mathrm{E} \& \mathrm{P}$ & Automated email sent if no login after 1 day \\
\hline Day_0_Disuse_Prompt_2_days & $\mathrm{E} \& \mathrm{P}$ & Automated email sent if no login after 2 days \\
\hline Disuse_Prompt_1_week & E\&P & Automated email sent if no login in 1 week \\
\hline cores_complete & $\mathrm{E}$ & $\begin{array}{l}\text { Automated email sent on Day } 21 \text { informing Exp P's that the intervention is } \\
\text { compete and they no longer have access to the journals. Also informs them that } \\
\text { they will receive a link to the PostQ shortly. (20) }\end{array}$ \\
\hline \multicolumn{3}{|l|}{ Post-Assessment (ALL manual) } \\
\hline PostQ Link Email & $\mathrm{E} \& \mathrm{C}$ & Link to PostQ surveys, separate from website (22-manual email) \\
\hline Daily Reminder to complete PostQ & $\mathrm{E} \& \mathrm{C}$ & Manual email sent on days 21-28 reminding P's to complete post Q (23) \\
\hline PostQ Thanks Exp & $\mathrm{E}$ & $\begin{array}{l}\text { Manual email sent once PostQ is submitted, thanking Exp P's and letting them } \\
\text { know they have access to journals again if they wish to use them. Also reminding } \\
\text { them they will be contacted again in } 30 \text { days to complete a final assessment. (24) }\end{array}$ \\
\hline PostQ Thanks Control & $\mathrm{C}$ & $\begin{array}{l}\text { Manual email sent once PostQ is submitted, thanking Control P's, reminding them } \\
\text { that they will be contacted again in } 30 \text { days to complete the final assessment. After } \\
\text { which they will have access to the website( } 24)\end{array}$ \\
\hline \multicolumn{3}{|l|}{$\begin{array}{l}\text { Post-Assessment 1-Month (ALL } \\
\text { manual) }\end{array}$} \\
\hline PostQ 1-month Link Email & $\mathrm{E} \& \mathrm{C}$ & Link to PostQ 1-month surveys, separate from website (26) \\
\hline Daily Reminder Emails & $\mathrm{E} \& \mathrm{C}$ & $\begin{array}{l}\text { Sent manually on days 51-58 reminding P's to complete PostQ 1-month } \\
\text { assessment (26a) }\end{array}$ \\
\hline Study Complete Thank You Exp & $\mathrm{E}$ & $\begin{array}{l}\text { Sent once PostQ 1-month is completed thanking Ps for participating, letting them } \\
\text { know that they will be entered into a drawing for an amazon gift certificate, and } \\
\text { letting them know that they have access to the online journals if they wish to } \\
\text { continue using them. (27) }\end{array}$ \\
\hline Study Complete Thank You Control & $\mathrm{C}$ & $\begin{array}{l}\text { Sent once PostQ 1-month is completed thanking Ps for participating, letting them } \\
\text { know that they will be entered into a drawing for an amazon gift certificate.(27) }\end{array}$ \\
\hline
\end{tabular}




\section{TEXT FOR EMAILS (AUTOMATED AND MANUAL)}

From:MyGratefulSelf@virginia.edu

These emails correspond with the table above:

\section{Enrollment}

Email Title: Interest Form Thank You Email

Recipient: Everyone who completes an interest form

Subject Heading: MyGratefulSelf Study: Interest Form Received

Hello from MyGratefulSelf:

Thank you for your interest in the MyGratefulSelf study! We received your interest form. Someone will be reviewing your interest form shorty. We will contact you soon by email to let you know if you may be eligible to participate. If so, we will need to set up a good time to call/skype/FaceTime you to ask you some additional questions.

If you have any questions, please don't hesitate to contact us at:

MyGratefulSelf@virginia.edu

Sincerely,

The MyGratefulSelf Team 
Email Title: Send Contact Email and Generic IC link Email: Email to schedule screening and consent call.

Recipient: Interested Candidates that appear eligible based on their Interest Form.

Subject Heading: MyGratefulSelf Study: Interest Form Reviewed

Hello from MyGratefulSelf:

We have reviewed your interest form for the MyGratefulSelf study! Congratulations - it sounds like this study might be a good fit for you. Next we need to set up a good time to call, Skype, or FaceTime you to try to enroll you in the study. The phone call lasts about 30 minutes. During the call, we will ask you some questions about your diagnosis and how you have been feeling lately. Once we establish that you are definitely eligible for the study, we will review and sign the study consent form. You will need email access on a desktop or laptop during our call to submit the consent form online.

In the meantime, please use this link to read the consent form and learn more about the study before our call: MyGratefulSelf Consent Form.

We are very flexible regarding times for this screening call so please email us some days/times over the next 7 days that work best for you for the call. We will respond to confirm a specific appointment time based on times you send and our matching availability.

If you have any questions, please don't hesitate to contact us at:

MyGratefulSelf@virginia.edu

Thank you and we look forward to talking with you soon!

Sincerely,

The MyGratefulSelf Team 
Email Title: Signable IC link Email: Email sent during consenting process

Recipient: Interested Candidates, who are eligible during phone interview.

Subject Heading: Link to your MyGratefulSelf Consent Form

Hello from MyGratefulSelf:

Here is the link to your MyGratefulSelf consent form:

\section{LINK}

If clicking the link above does not automatically open the Consent Form in your browser, please copy and paste the URL into your browser.

Please let me know right away if you have trouble accessing your form.

Sincerely,

The MyGratefulSelf Team 
Email Title: Signed Consent Email: Email to send signed consent for participants' records.

Recipient: Consented participants

Subject Heading: MyGratefulSelf Study: Consent Form Received

Hello from MyGratefulSelf:

We received your consent form for the MyGratefulSelf Study. Thank you!

Attached to this email is a copy of your consent form, signed by the principle investigator, to view and print for your records. Let us know if you have any trouble with the file and we'll be happy to help.

Be on the lookout for an email with the link to the pre-intervention questionnaires!

We can be reached at MyGratefulSelf@,virginia.edu

Sincerely,

The MyGratefulSelf Team 
Email Title: Ineligible Thanks link Email: Email sent upon learning interested candidate is ineligible

Recipient: Interested Candidates, who are ineligible prior to or after phone interview.

Subject Heading: Thanks for your interest in MyGratefulSelf

Dear XXXX,

Thank you for your interest in the MyGratefulSelf study. Unfortunately, you are not eligible for our current research trial. However, we understand you may still be interested in additional online information about improving well-being while living with cancer.

Here are some helpful resources.

Websites:

THE LIVESTRONG FOUNDATION YOUNG ADULT PROGRAM

http://www.livestrong.org/we-can-help/young-adults/

STUPID CANCER

http://www.stupidcancer.org

THE ULMAN CANCER FUND FOR YOUND ADULTS

http://www.ulmanfund.org

YOUNG ADULT CANCER CANADA

http://www.youngadultcancer.ca

THE SAMFUND FOR YOUNG ADULT SURVIVORS OF CANCER

http://www.thesamfund.org

CRITICAL MASS: THE YOUNG ADULT CANCER ALLIANCE

http://www.criticalmass.org

Please let me know if you have any questions or concerns.

Sincerely,

Kate Adelstein, RN, MSN

Principle Investigator

University of Virginia

School of Nursing

225 Jeanette Lancaster Way

Charlottesville, VA 22903

Office:

Email: kea5ft@virginia.edu 


\section{Pre-Assessment: ALL MANUAL EMAILS}

PreQ Link Email on Day 0: Email welcoming all participants to MyGratefulSelf with a link to the pre-intervention questionnaires.

Subject Heading: Welcome to the MyGratefulSelf Study!

Hello from MyGratefulSelf!

We are so pleased you have decided to take part in this important study.

The next step is to complete a set of questionnaires. Your answers to these questions are completely confidential and will not be associated with you name. Please keep in mind that it takes most people about 30-45 minutes to finish all the online questions. You can always use the Save and Quit button to save your progress so you can start now, and complete the questionnaires at a later time. Please try to complete the entire set of questionnaires in the next three days.

To access the questionnaires simply click on the link below:

\section{LINK}

If you have any questions, please don't hesitate to contact us at MyGratefulSelf@,virginia.edu

Sincerely,

The MyGratefulSelf Team 
Complete Pre-Q Prompt: If P does not complete the Questionnaire on Day 0, this email is sent on Day 1 and again on Day 2 (unless the Pre-Assessment Questionnaire is complete).

Subject Heading: MyGratefulSelf Study: Please Complete the Questionnaires

Hello from MyGratefulSelf:

Please complete your Questionnaire as soon as possible so you can get started with the MyGratefulSelf study!

To access the questionnaires, go to: LINK

We appreciate you being a part of this study!

If you have any questions at all, please don't hesitate to contact us at MyGratefulSelf@,virginia.edu

Sincerely,

The MyGratefulSelf Team 
Thanks Pre-Q Prompt: Sent immediately after CCs complete PreQ alerting them that they will receive further instruction about the study soon. (13)

Subject Heading: MyGratefulSelf Study: Questionnaire Received

Hello from MyGratefulSelf:

We have received your questionnaire! Thank you very much! You will be hearing from us soon regarding the next steps.

We appreciate you being a part of this study!

If you have any questions at all, please don't hesitate to contact us at MyGratefulSelf@,virginia.edu

Sincerely,

The MyGratefulSelf Team 
Welcome Control P's Email: Sent after Ps complete PreQ, and are randomized to the control group, alerting them that they will be contacted again in 21 days to fill out PostQ. (16a)

Subject Heading: MyGratefulSelf Study

Hello from MyGratefulSelf:

Great job on completing the questionnaire! For now, all we need you to do is sit tight.

In 21 days you will receive a link to another set of questionnaires.

If you have any questions at all, please don't hesitate to contact us at MyGratefulSelf@,virginia.edu

Sincerely,

The MyGratefulSelf Team 
Welcome_subjects_Email: Provides user link, ID, and password, reviews study procedures, sent when experimental subjects are moved to the experimental folder (15)

Subject Heading: MyGratefulSelf Study: Moving on!

Hello from MyGratefulSelf!

It's time to get started using the MyGratefulSelf program! Yay!

To log in to the program, use this link:

http://www.mygratefulself.org

Then enter your information in the upper right corner of the screen:

Your Username is: $\mathrm{XXXX}$

Your Password is: $\mathrm{XXXX}$

You will see instructions for how to use the site and how to access the journal function. Remember to log in and journal daily!

If you have any questions, please don't hesitate to contact us at MyGratefulSelf@,virginia.edu

Sincerely,

The MyGratefulSelf Team 


\section{Intervention (all automated emails)}

Diary Reminder Prompt: Daily automated email to remind P's to log in and journal (18)

Subject Heading: MyGratefulSelf: Journal Reminder

Hello from MyGratefulSelf:

This is a friendly reminder to complete your MyGratefulSelf journal entry for today. To log in to the program, go to:

http://www.MyGratefulSelf.org.

Remember that MyGratefulSelf can only accept journal entries that are one day old (from today and yesterday) so remember to log on and journal daily!

Let us know if you have any questions. We can be reached at MyGratefulSelf@virginia.edu

In Gratitude,

The MyGratefulSelf Team

"Gratitude is happiness doubled by wonder." G. K. Chesterson 
Day_0_Disuse_Prompt_1_day: Automated email sent if no login at all after 1 day (19)

Subject Heading: MyGratefulSelf: Time to Log in!

Hello from MyGratefulSelf:

We noticed you haven't yet logged in to the website.

Please log in and get started with MyGratefulSelf as soon as you can.

As a reminder, to access the site, go to http://www.MyGratefulSelf.org

Your Username is: XXX

Your Password is: $\mathrm{XXX}$

When you log on, you will learn more about how to use MyGratefulSelf and how to access the journal function. Remember that MyGratefulSelf cannot accept diaries that are more than one day old (today and yesterday) so please do your best to $\log$ on each day.

If you have any questions, please don't hesitate to contact us at: MyGratefulSelf@virginia.edu

In Gratitude,

The MyGratefulSelf Team 
Day 0_Disuse_Prompt_2_day: Automated email sent if no login at all after 2 days (19)

Subject Heading: MyGratefulSelf: Time to Log in!

Hello from MyGratefulSelf:

We noticed you haven't yet logged in to the website.

Please $\log$ in and get started with MyGratefulSelf as soon as you can.

As a reminder, to access the site, go to http://www.MyGratefulSelf.org

Your Username is: $\mathrm{XXX}$

Your Password is: $\mathrm{XXX}$

When you log on, you will learn more about how to use MyGratefulSelf and how to access the journal function. Remember that MyGratefulSelf cannot accept diaries that are more than one day old (today and yesterday) so please do your best to $\log$ on each day.

If you have any questions, please don't hesitate to contact us at: MyGratefulSelf@virginia.edu

In Gratitude,

The MyGratefulSelf Team 
Disuse_Prompt_1_week: Automated email sent if no login for 1 week (19)

Subject Heading: Remember to use MyGratefulSelf

\section{Hello from MyGratefulSelf:}

We noticed you haven't logged into MyGratefulSelf for a while. We hope you are getting something out of the daily journaling and it is most helpful if you make an entry every day.

To log in to the program, use this link: www.mygratefulself.org

If you have any questions, please don't hesitate to contact us at mygratefulself@virginia.edu.

In Gratitude,

The MyGratefulSelf Team 
cores_complete Email: Automated email sent on Day 21 informing Exp P's that the intervention is compete and they no longer have access to the journals. Also informs them that they will receive a link to the PostQ shortly. (20)

Subject Heading: MyGratefulSelf: Time for more Questionnaires!

Hello from MyGratefulSelf:

Great job on completing your journals over the past 21 days! It's time for you to fill out the second set of questionnaires. You will be receiving an email with a link to those questionnaires shortly, so be on the lookout and complete them as soon as you can.

You may have noticed that you can't see the JOURNAL link on the MyGratefulSelf homepage right now. Don't worry! Once you have completed the questionnaires you will have access to your online journal again, so you can keep going!

If you have any questions, please don't hesitate to contact us at: MyGratefulSelf@virginia.edu

In Gratitude,

The MyGratefulSelf Team 


\section{Post Intervention (ALL MANUAL)}

PostQ Link Email on Day 22: Link to PostQ surveys, separate from website (22 -manual email)

\section{Subject Heading: MyGratefulSelf Follow-up Questionnaire}

Hello from MyGratefulSelf!

You have made it to day 22.

The next step is to complete another set of questionnaires (they are very similar to the ones you completed 21 days ago). Your answers to these questions are completely confidential and will not be associated with you name. Please keep in mind that it takes most people about 30-45 minutes to finish all the online questions. You can always use the Save and Quit button to save your progress so you can start now, and complete the questionnaires at a later time. Please try to complete the entire set of questionnaires in the next three days.

To access the questionnaires simply click on the link below:

\section{LINK}

If you have any questions, please don't hesitate to contact us at MyGratefulSelf@,virginia.edu

Sincerely,

The MyGratefulSelf Team 
Daily Reminder to Complete PostQ: Emails sent on days 21-28 reminding P's to complete post Q (23)

Subject Heading: MyGratefulSelf Study: Please Complete the Questionnaires

\section{Hello from MyGratefulSelf:}

Please complete your Questionnaire as soon as possible.

To access the questionnaires, go to: LINK

We appreciate you being a part of this study!

If you have any questions at all, please don't hesitate to contact us at MyGratefulSelf@virginia.edu

Sincerely,

The MyGratefulSelf Team 
PostQ_Thanks_Exp: Automated email sent once PostQ is submitted, thanking Exp P's and letting them know they have access to journals again if they wish to use them. Also reminding them they will be contacted again in 30 days to complete a final assessment. (24)

Subject Heading: MyGratefulSelf : Thank You!

Hello from MyGratefulSelf!

We have received your questionnaires.

Thanks!

If you want to keep journaling, you cal head back to MyGratefulSelf.org and you will see the JOURNAL link again. You can pick up, right where you left off!

You will hear from us again in 30 days with a link to complete one final set of questionnaires and then you will eligible to win one of six \$50 Amazon gift certificates! Woohoo!

If you have any questions, please don't hesitate to contact us at MyGratefulSelf@,virginia.edu

In Gratitude,

The MyGratefulSelf Team 
PostQ_Thanks_Control: Automated email sent once PostQ is submitted, thanking Control P's reminding them that they will be contacted again in 30 days to complete the final assessment, after which they will have access to the website. (24)

Subject Heading: MyGratefulSelf : Thank You!

Hello from MyGratefulSelf!

We have received your questionnaires.

Thanks!

You will hear from us again in 30 days with a link to complete one final set of questionnaires and then you will eligible to win one of six \$50 Amazon gift certificates! Woohoo!

Once you complete the third set of questionnaires, you will also receive a username and password to access the journal function on the MyGratefulSelf website. You can begin journaling if you want to, but you don't have to. If you do choose to journal, we will not be tracking your entries.

If you have any questions, please don't hesitate to contact us at MyGratefulSelf@,virginia.edu

In Gratitude,

The MyGratefulSelf Team 


\section{1-month Post Intervention (ALL MANUAL)}

PostQ 1-month Link Email on Day 52: Link to PostQ surveys, separate from website (22 -manual email)

\section{Subject Heading: MyGratefulSelf Follow-up Questionnaire}

Hello from MyGratefulSelf!

Remember us?!

It's time to complete the final set of questionnaires (they are very similar to the ones you completed 30 days ago and at the beginning of the study). Your answers to these questions are completely confidential and will not be associated with you name. Please keep in mind that it takes most people about 30-45 minutes to finish all the online questions. You can always use the Save and Quit button to save your progress so you can start now, and complete the questionnaires at a later time. Please try to complete the entire set of questionnaires in the next three days.

To access the questionnaires simply click on the link below:

\section{LINK}

Once you have completed these questionnaires you will be entered in a lottery to win one of six $\$ 50$ gift certificates to Amazon.com.

If you have any questions, please don't hesitate to contact us at MyGratefulSelf@,virginia.edu

Sincerely, The MyGratefulSelf Team 
Daily Reminder to Complete PostQ 1 month: Automated emails sent on days 5188 reminding P's to complete post Q (23)

Subject Heading: MyGratefulSelf Study: Please Complete the Questionnaires

Hello from MyGratefulSelf:

Please complete your Questionnaire as soon as possible.

To access the questionnaires, go to: LINK

We appreciate you being a part of this study!

If you have any questions at all, please don't hesitate to contact us at MyGratefulSelf@,virginia.edu

Sincerely

The MyGratefulSelf Team 
Study Complete Thanks_Exp: Automated email sent once Post 1 month Q is submitted, thanking Exp P's and letting them know they have access to journals again if they wish to use them. Also reminding them they have been entered into the lottery. (24)

\section{Subject Heading: MyGratefulSelf : Thank You!}

Hello from MyGratefulSelf!

We have received your questionnaires.

Thanks!

Your username and password are still functional and, if you want, you can return to the MyGratefulSelf website and keep journaling for as long as you like.

You are now eligible to win one of six \$50 Amazon gift certificates! Woohoo! We'll contact you by email if your name is drawn!

If you have any questions, please don't hesitate to contact us at MyGratefulSelf@,virginia.edu

In Gratitude,

The MyGratefulSelf Team 
Study Complete Thank you Control: Automated email sent once Post 1 month Q is submitted, thanking Control thanking Ps for participating, letting them know that they will be entered into a drawing for an amazon gift certificate, and letting them know that they have access (including username and password) to the online journals if they wish to start using them. (27)

Subject Heading: MyGratefulSelf : Thank You!

Hello from MyGratefulSelf!

We have received your questionnaires.

Thanks!

You are now eligible to win one of six \$50 Amazon gift certificates! Woohoo! We will contact you by name if your name is drawn.

Now that you have completed all three sets of questionnaires, you will have access to the journal function on the MyGratefulSelf website. You can log in and start journaling if you want to. Your login is as follows:

Username: XXXX

Password: XXXX

If you have any questions, please don't hesitate to contact us at MyGratefulSelf@,virginia.edu

In Gratitude,

The MyGratefulSelf Team 


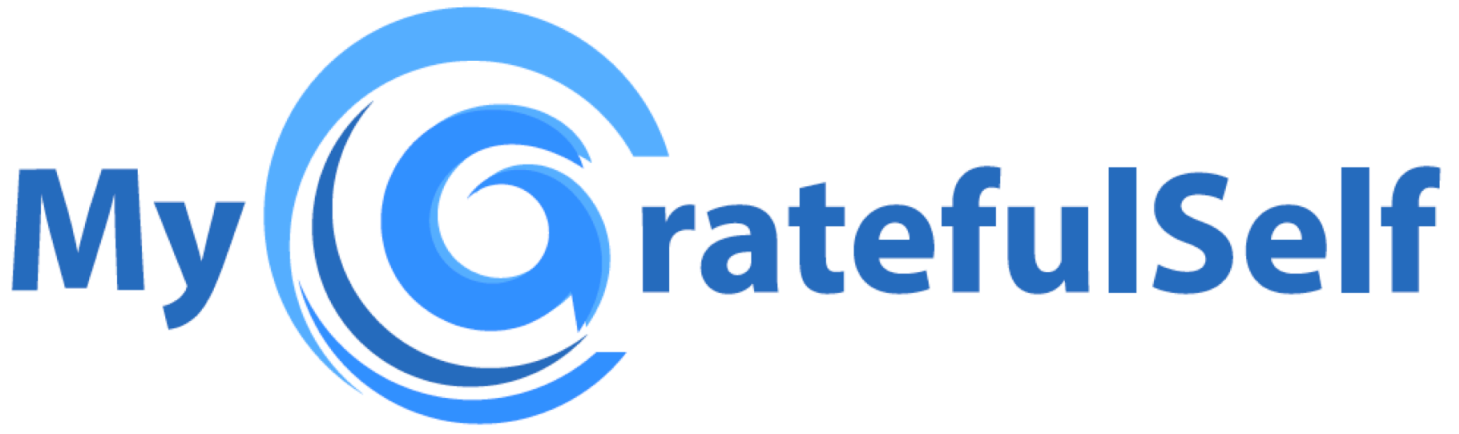

Now seeking young adults with cancer to participate in an internetbased research study to promote well-being!

\section{Are you?}

$\checkmark$ Between the ages of 20-39

$\checkmark$ Currently diagnosed with stage III or IV cancer

$\checkmark$ Interested in writing

$>$ No travel is required

$>$ Participants will be entered in a lottery to win a $\$ 50$ gift card to Amazon.com

For more information visit WWW.mygratefulself.org.

UNIVERSITY 